\title{
Corps et métissages dans l'anthropo-sociologie générative critique de Georges Balandier
}

Yves Le Pogam

\section{(2) OpenEdition}

1 Journals

\section{Édition électronique}

URL : http://journals.openedition.org/corpsetculture/887

DOI : 10.4000/corpsetculture.887

ISSN : $1777-5337$

Éditeur

Association Corps et Culture

Édition imprimée

Date de publication : 1 janvier 2004

ISSN : 1268-5631

Référence électronique

Yves Le Pogam, «Corps et métissages dans l'anthropo-sociologie générative critique de Georges Balandier », Corps et culture [En ligne], Numéro 6/7 | 2004, mis en ligne le 12 octobre 2007, consulté le 08 septembre 2020. URL : http://journals.openedition.org/corpsetculture/887 ; DOI : https://doi.org/ $10.4000 /$ corpsetculture.887

Ce document a été généré automatiquement le 8 septembre 2020

(c) tous droits réservés 


\title{
Corps et métissages dans l'anthropo-sociologie générative critique de Georges Balandier
}

\author{
Yves Le Pogam
}

«Penser une société, une culture, c'est nécessairement traiter de l'homme en fonction de sa condition, de sa personnalité, mais aussi et peut-être surtout de son corps ; (...) le corps est la première référence pour l'individu. On existe par lui, on accède par lui aux mondes extérieurs, ceux de la nature, des choses et des autres hommes. On peut dire que, d'une certaine façon, l'histoire des cultures est - en tant qu'anthropologue je prends le risque de cette affirmation - pour une part,

l'histoire des corps, une histoire du corps. »

(Balandier G., 1991b : 7)

« Le monde surmoderne (...) fait du corps, bien plus fortement que dans les périodes antérieures, son révélateur. Les techniques du corps disposent

de moyens accrus, non seulement celles qui relèvent des sauvegardes de la santé, des combats contre la maladie et la précarité, mais aussi celles qui contribuent au façonnage du corps, à l'accroissement des ressources et des adaptations corporelles. Le corps peut maintenant, avec le concours des industries qui le traitent comme une matière travaillable, avec l'usage de machines spécialisées et de procédés mécaniques encore naturels, être fabriqué “à façon”. "

(Balandier G., 2001 : 102-103) 
«Sur la culture de la surmodernité on a beaucoup dit, au négatif (...). On a été, en revanche, peu attentif à l'un de ses traits dominants : c'est une culture du mélange, syncrétique, capable

d'emprunter, de diffuser, d'allier des composantes disparates, d'effectuer un incessant travail de brassage. C'est moins une culture du cosmopolitisme populaire qu'une culture de la circulation et de la recomposition permanente, une culture génératrice de configurations fragiles, vulnérables au brouillage des messages et exposées aux effets de puissance et de concurrence des grandes industries culturelles. »

(Balandier G., 1994 : 133)

" Je ne dis pas que les identités, toutes issues de métissages, mélanges et acculturations sont nécessairement paisibles. Elles comportent aussi des affirmations conflictuelles. »

(Balandier G., 2003a : 113) " Aujourd'hui, chacun gère son plan de carrière et se préoccupe de la rentabilité de ses travaux. La vie intellectuelle accorde trop de place aux "comptables". Et si la véritable existence, c'était au contraire de se dépenser sans compter, de mettre du gratuit dans sa vie?»

(Balandier G., 2003b)

1 La communauté scientifique s'accorde à ranger les recherches anthropo-sociologiques publiées par Georges Balandier depuis les années 50 dans les approches dynamiques des sciences sociales. La désignation d'une orientation théorique dans un champ scientifique est certes une facilité de classement - elle fixe une pensée dans un courant qui le distingue d'approches fondées sur des paradigmes différents - mais elle laisse dans l'ombre la spécificité, la singularité de la genèse et des champs d'exploration qui font l'originalité de la pensée d'un auteur. Cette catégorisation d'une approche n'empêche nullement qu'au plan épistémologique soit montré comment les connaissances produites par l'auteur s'enrichissent à l'épreuve des terrains rencontrés, se précisent au contact des mouvances sociales traversées pendant plus d'un demisiècle et participent des turbulences théoriques nées des conflits d'interprétation structurant la dynamique des connaissances en sciences sociales propres à cette période. D'un point de vue général, l'inscription d'une analyse du social dans les théories dynamiques suppose certes que s'y lisent les principes qui la constituent et l'identifient comme telle, mais d'un point de vue particulier, elle oblige aussi à dévoiler ce qui en fait une œuvre irréductible à toute autre, parce qu'elle s'inscrit dans des contextes historiques et intellectuels jamais détachés des engagements personnels et des affects d'un chercheur qu'il s'agit aussi de faire resurgir parce qu'ils donnent tout son sens à son entreprise de recherche.

Des principes de l'approche "dynamique » traversent ainsi les recherches de Georges Balandier dont la singularité est d'analyser le social dans sa créativité, dans ses 
capacités de production, dans ses turbulences en donnant toute son importance à des notions comme l'inédit, l'imprévu ou au rôle des événements dans le changement ou les mutations sociales. Ce rattachement à une approche dynamique s'enracine dans une démarche ethnologique à la fin des années 40 - l'analyse d'un peuple de tradition, les pêcheurs Lébou installés au long de la presqu'île de Cap Vert, avant-poste du Sénégal et se rapporte actuellement à une anthropo-sociologie de la surmodernité mondialisante. En ce sens, l'intérêt constant porté à ce qui est nouveau, à ce qu'il nomme les "nouveaux commencements", ou les « Nouveaux Mondes» ou encore les «nouveaux Nouveaux Mondes » et ceci malgré le temps qui sépare les recherches (les années 40 pour l'Afrique et les années 1990 pour la surmodernité) et le changement dans l'ampleur de la réflexion (le passage d'une analyse du local à celle de la mondialisation), alerte sur une approche moins repérée par la communauté scientifique associée par Georges Balandier à celle de «dynamique » et qui guide aussi l'ensemble de son travail, qui est celle d'une sociologie "générative». La sociologie dynamique permet de révéler le caractère " génératif » de toute société.

Si le terme de « dynamique » est attribué par Paul Mercier dès les années 65 et par Jean Poirier en 1968 pour qualifier les recherches de Georges Balandier, la notion de sociologie "générative " n'apparaît dans les publications de l'auteur qu'en 1971, enfermée dans des guillemets signifiant la création d'un " concept nomade » (Stengers I., 1987) qui, pour devenir opératoire dans le champ des sciences sociales, doit être soumise à l'épreuve du terrain pour évaluer sa fonction heuristique ${ }^{1}$. Ce qualificatif émerge à la fin de la préface de Sens et Puissance, comme un concept synthétique condensant un ensemble de données permettant de comprendre le sens et l'orientation de l'ouvrage composé de textes inédits ou déjà publiés, dont l'objectif vise, à travers l'unité qui les assemble, à illustrer « une conception nouvelle » des rapports sociaux et de l'entreprise sociologique (Balandier G., 1971, 1986: 5). Ce nouveau regard sur le social se caractérise par des points forts qui permettent de rompre avec les théories du moment souvent doctrinales, en voulant donner à l'histoire toute son importance contre les permanences ou les systèmes intemporels, en privilégiant les événements et les processus de transformation plutôt que les structures et les organisations placées sous le signe du non-événement, en analysant le rôle des contraintes environnantes, les effets de domination ou d'importation sur les sociétés en développement et convenir qu'elles portent plusieurs avenirs possibles, bref, en reconnaissant la société comme un «ordre approximatif et toujours mouvant » (Balandier G., 1971, 1986: 8). C'est dans cette idée d'actions-réactions, de mouvance des configurations sociales « constamment en train de se faire et de déterminer leur sens ", que s'ancre la sociologie dynamique " générative ». Cette idée de mouvance et d'approximation d'un ordre est reprise dans Anthropo-logiques pour remettre en question le terme trompeur de reproduction, car la réalité sociale résulte d'une production continue et jamais achevée (Balandier G., 1974, 1985: 8). Ici encore se dit l'illusion de l'unité de la cohérence de la société et se défend le principe «d'une science sociale générative » dévoilant une société dans son inachèvement, en quête permanente de la recherche de sens, vulnérable car soumise à des menaces d'effondrement. Claude Rivière reconnaît bien la démarche "générative " de Georges Balandier au sens où les questions qu'il se pose visent à comprendre comment les acteurs contribuent à "faire " la société et à lui donner son sens, en montrant les confrontations entre les structures officielles et les structures sociales ainsi que la vulnérabilité de tout système relationnel soumis à de constants réajustements et à l'incertitude (Rivière C., $1985: 24$ ). En voulant montrer comment les 
sociétés « ne sont jamais ce qu'elles paraissent être ou ce qu'elles prétendent être » en ce qu'elles s'expriment par ces deux niveaux, l'un superficiel, celui des structures officielles, l'autre, profond «qui assure l'accès aux rapports réels les plus fondamentaux et aux pratiques révélatrices de la dynamique du système social», Georges Balandier estime que dès que les sciences sociales appréhendent ces deux niveaux et en déterminent leurs rapports, « elles deviennent éminemment critiques » (Balandier G., 1971, $\underline{1986}$ : 7).

4 Il est possible de faire l'hypothèse que cette notion émergente dans les années 70 , associée à l'approche dynamique, était en germe dans les travaux antérieurs relatifs aux sociétés africaines sous la domination coloniale et qu'elle sert de support, par approfondissements successifs, à l'analyse dynamique de toute société, c'est-à-dire à une " anthropologie généralisée " que Georges Balandier développe autour des années 70 et qu'il étend par la suite aux sociétés de la modernité. A l'image des méthodologies de l'auteur qui structurent son travail de recherche en accordant une importance au travail de l'histoire dans la compréhension des configurations sociales émergentes, il est nécessaire, afin de mieux comprendre son approche théorique "générative ", de voir comment elle se crée et se transforme dans le temps tout en gardant une unité repérable par des schèmes d'intelligibilité qui l'organisent. D'un point de vue épistémologique, il s'agit de dévoiler quelques éléments constitutifs de la genèse d'une connaissance scientifique originale qui s'enracine dans des dimensions subjectives tenant à la vie intellectuelle et affective de l'auteur, qui se lie aux résonances des événements historiques sur ses systèmes de pensée, qui s'enrichit des différences et des comparaisons entre les cultures observées et qui participe des conflits d'idées structurant le champ scientifique de cette période. Dans un premier temps, il faudra donc rendre compte de la singularité de la sociologie "générative" de Georges Balandier, sa genèse, sa sédimentation et son amplification, depuis ses premiers travaux qui apparaissent dans les années 50 jusqu'à ceux qui se poursuivent en ce début de $\mathrm{XXI}^{\mathrm{e}}$ siècle.

5 Ce parti pris diachronique pourrait être considéré comme une facilité de méthode, mais il permet aussi, par analogie avec l'approche dynamique du social de l'auteur approche qui ne peut faire abstraction de la mémoire -, de comprendre ses conceptions théoriques en incluant un passé qui les agence et qui permet de comprendre le présent $^{2}$. Ainsi pour Georges Balandier, diachronie et synchronie sont interdépendantes pour penser l'esprit du temps, principe aussi applicable pour rendre compte de la créativité scientifique dont il fait preuve pour construire une nouvelle théorie scientifique qu'il identifie comme "générative». Alors, pour illustrer de manière plus précise cette absence de coupure entre diachronie et synchronie, il est possible dans un second temps, de délinéariser l'histoire de la construction de sa pensée pour opérer des coupes synchroniques organisées autour de thèmes comme ceux de «corps » et de «métissages " qui traversent son oeuvre, en dégageant des catégories permettant de spécifier sa sociologie "générative». A priori le choix de ces deux thèmes "corps" et "métissages » quelque peu orienté par la thématique du numéro de Corps et Culture pourrait paraitre réducteur eu égard à l'immensité des terrains explorés par l'auteur et à la production d'une œuvre considérable. Mais une autre hypothèse peut être avancée selon laquelle il est possible d'y décrypter des éléments qui restituent sans trop de distorsions des principes originaux constitutifs de son approche. Les deux temps qui organisent cette note, genèse de ses conceptions et développement de quelques thèmes, sont complémentaires et devraient permettre à la 
fois de spécifier l'originalité d'une démarche théorique en montrant ses transformations dans le temps et d'éclairer les problématiques du corps et du métissage sous l'angle d'une sociologie générative en faisant surgir quelques catégories qui la singularisent.

Pour une clarté d'exposition, rendre compte de plus de cinquante ans d'écriture impose que les principaux travaux qui marquent cette longue durée soient présentés en périodes permettant de faire ressortir, de manière idéal-typique, les points centraux qui sont autant de jalons pour comprendre une théorie qui se travaille dans le temps. Ces scansions introduites dans une oeuvre cependant unitaire - qui commence par l'analyse d'une communauté de pêcheurs au Sénégal pour se terminer par une interrogation sur le sens de la techno-science et de l'économie libérale dans le temps présent - ont été déjà opérées par Pierre Ansart qui distingue deux grands moments dans le parcours intellectuel de Georges Balandier : une première période où il analyse les processus de mutation constitutifs de l'indépendance (1945-1965), puis une seconde où l'attention se porte sur les sociétés industrielles qui elles aussi sont soumises aux mêmes mouvements transformateurs et à l'inachèvement (depuis 1965), deux moments unis par une même opposition à une sociologie des permanences (Ansart P., 1990: 52). Georges Balandier lui-même reconnaît aussi deux fractions qui recoupent les précédentes : un moment de formation et de maturation marqué par son ancrage dans le terrain africain colonisé et connaissant l'indépendance qu'il appelle «la situation coloniale » (1945-1970), et le passage d'une anthropologie des « privilèges » (des autres) à une anthropologie " généralisée » (de nous-mêmes), celle de la modernité, liées entre elles par le même souci d'y décrypter les cultures de la différence ainsi que le mouvement permanent qui les traverse (Balandier G., 1997 : 27). Plus récemment, outre les deux temps déjà repérés, il y ajoute un troisième, celui d'une sociologie du temps présent en insistant de nouveau sur le caractère indissociable de cette partition, car ces trois repères ont en commun la même préoccupation constante de l'actuel et de l'histoire, en ce sens que ce qui l'intéresse, c'est la manière dont les "choses sociales " s'expriment dans le mouvement, dans l'événement et comment elles en sont venues à ce qu'elles sont, comment elles peuvent être à l'origine de «nouveaux commencements » (Balandier G., 2003 : 77-78). Sans rompre avec le principe de cette périodisation, il s'agit d'exhausser quelques principes fondateurs de la sociologie générative de Georges Balandier en les agençant ici en trois périodes: celle de l'émergence d'une théorie (1946-1967), celle de sa sédimentation consolidant le travail conceptuel (1967-1979), enfin celle de son amplification où sont explorés d'abord le contexte de la modernité (1980-1993) puis celui de la surmodernité (1994-2003).

Les prémisses d'une sociologie générative : l'Afrique et la situation coloniale

(1946-1967)

7 Henri Janne soulignait que la nature des sciences sociales fait qu'aucun chercheur ne peut prétendre à une "révolution scientifique" mais que plusieurs d'entre eux en anthropologie sociale, histoire ou sociologie, «inventent» des principes épistémologiques qui infléchissent la connaissance du social par des transferts théoriques et des interprétations, au rang desquels figure Georges Balandier. L'auteur ajoute que ce dernier appartient aux pionniers qui changent les perspectives et qu'il est impossible de comprendre son épistémologie sans se référer aux débuts de sa carrière (Janne H., 1988: 40). S'il est en effet une caractéristique du travail de Georges Balandier, c'est bien celle de n'avoir pas commencé son aventure de chercheur dans le confinement des bureaux-laboratoires, mais de s'être confronté dès 1946 aux terrains 
d'une «Afrique plurielle» où il reconnaît avoir rencontré là sa véritable Sorbonne (1997a : 32). C'est dans un article du début de sa carrière, La situation coloniale : approche théorique (1951), que s'élaborent les prémisses d'une sociologie générative construite sur deux ruptures par rapport aux pensées ethnologiques dominantes du moment, celle d'une ethnologie décontextualisée aveugle à l'histoire et aux dynamiques des relations extérieures et celle d'un "fonctionnalisme mécaniste simplificateur ", deux rejets qui ouvrent les voies à une sociologie générative reliant anthropologie et sociologie et attachée à « l'étude de la constante production du social et des jeux de domination qui s'y développent » (Balandier G., 2003 : 151-152).

8 Il est délicat de discriminer les processus qui conduisent à une conceptualisation nouvelle du social, car la créativité intellectuelle qu'elle implique de la part du chercheur relève de la rencontre de données subjectives et de dimensions objectives dont il est difficile de dire lesquelles sont les plus déterminantes dans l'acte de découverte. Georges Balandier insiste lui-même sur le caractère indissociable du double parcours où se lient, sans se confondre cependant, le tracé d'une vie et celui d'un savoir, en ce sens que le mouvement des événements et les engagements personnels participent de sa singularité et recoupent l'exploration du social (Balandier G., 2003a : 9). Comment alors l'auteur est-il parvenu, très tôt dans sa carrière de chercheur, à se fixer comme objectif de «mieux définir le mouvement des sociétés et des civilisations, de mieux déterminer comment les hommes les produisent sans que leur travail ne puisse jamais trouver le répit» (Balandier G., 1957, 1998: 382) ? S'il est vrai que l'itinéraire scientifique de l'auteur dépend de ses affects et de ses passions, au sens où les événements et les idées marquent une personnalité (Balandier G., 1992: 22), comprendre alors l'émergence d'une théorie scientifique nouvelle oblige à rechercher d'abord dans son histoire personnelle des événements qui justifient son engagement pour le terrain africain, à décrypter ensuite les influences théoriques qui orientent d'une manière originale ses observations, à dévoiler enfin les résultats des recherches de cette période sur l'Afrique pour dégager alors quelques principes fondateurs d'une théorie générative du social. Ce sont là trois temps présentés séparément pour des raisons de méthode mais qui sont en réalité profondément interpénétrés.

Le désir d'Afrique : l'événement comme production de l'inédit

9 Il faut comprendre l'importance accordée par Georges Balandier à l'événement dans la construction de sa personnalité, en lui accordant le sens donné par Roger Bastide, c'està-dire en le considérant moins dans son achèvement «que [dans] la prédiction de ce qui va se produire, afin de pouvoir agir sur le futur, l'orienter, ou le déterminer à être selon notre désir» (Bastide R., 1968: 159). C'est bien la résonance de l'événement en Georges Balandier comme producteur d'inédit, d'imaginaires, de nouveau ou d'action créatrice qu'il va transposer dans l'analyse anthropologique en donnant ainsi toute sa puissance au singulier, à l'imprévu et à l'aléatoire contre le normé, la loi ou le système.

10 Né en 1920, ce sont les événements historiques qu'il traverse dans les années 30-45 qui vont révéler ses capacités d'engagement et de résistance, autant d'éléments incorporés qui serviront de linéaments à la construction d'une théorie sociologique : «Si l'histoire ne s'arrête pas, si les sociétés se produisent constamment, chaque acteur individuel ou collectif est, dans une certain mesure, responsable de ce qu'il advient. Il n'est plus possible de s'en remettre à la commodité de l'accusation, d'invoquer la domination d'un système, de la société, de l'Etat, du Léviathan, bref toutes les métaphores du sujet opprimé. Mais ma conception n'est pas celle non plus d'un volontarisme triomphant ; je 
suis persuadé que ce que nous faisons est toujours entaché d'insuccès » (Balandier G., 1992: 22). C'est dans des événements familiaux puis historiques que vont être recherchés son désir d'Afrique et sa résistance à toute forme de domination qui entreront en convergence avec l'anti-colonialisme d'intellectuels ou d'hommes politiques noirs qu'il rencontrera sur le terrain africain.

Georges Balandier aime à rappeler ainsi comment son goût de l'ailleurs et son esprit libertaire lui viennent de l'héritage de deux figures familiales: l'une, un aventurier audacieux et énigmatique du côté maternel désigné sous le nom de " roi des Hoowa ", amant d'une reine de Madagascar qui s'était entourée d'étrangers pour développer le commerce, fit fortune et accumula un trésor, sorte de figure mystérieuse qui « fortifia son désir d'évasion » (Balandier G., 1997a : 105) ; l'autre est celle d'un aïeul, officier de Second Empire qui, en charge de la garde de prisonniers mexicains, rusa pour faciliter leur évasion ce qui entraîna sa dégradation de l'armée mais eut pour effet de radicaliser ses opinions et de refuser l'autorité des institutions comme l'Eglise et l'Etat (1997a : 110). Ces personnages dont il admira le courage de la dissidence, l'attention accordée à l'autre, la rupture avec les valeurs bourgeoises et la passion pour la liberté, ont irrigué en lui « les germes de cette maladie libertaire » et une préférence pour Proudhon plutôt que pour Marx. Dans ce microcosme familial où existaient aussi des défenseurs de l'ordre, Georges Balandier s'oriente vers les figures du mouvement, une vision du monde lui permettant d'interpréter les destinées que vont écrire les peuples africains en contact avec la modernité, dans une vision anthropologique attentive aux surgissements provoqués par la prise en compte de ces nouveaux contextes dans leur relations avec les traditions héritées.

A ces dispositions incorporées par les conditions d'existence familiales générant ce goût pour l'exotisme en même temps qu'une vision pour l'interroger, il faudrait ajouter le rôle joué par des événements historiques qui participent aussi au renforcement de cet imaginaire de l'Afrique et à la fabrication d'une pensée pour aborder le réel. Parmi ceux-ci, Georges Balandier admet connaître, avec un certain émerveillement, "ses premières impressions d'Afrique » lors de l'Exposition coloniale Internationale de 1931, véritable exaltation du temps des colonies où «la colonisation, tout en rose, déployait les grands moments de la séduction " (1997a : 130), tout en reconnaissant la présence de la différence, celle d'un autre lointain mais sans cependant prendre conscience de l'anticolonialisme et des désirs d'émancipation nationale africaine. C'est aussi par l'émotion et la sensualité des corps dans le jazz et les revues "nègres ", qu'une culture autre, estimée primitive, prend de la valeur et lui permet d'accéder à des choses nouvelles (1997a : 135).

D'autres événements, politiques cette fois, vont parfaire sa sensibilité à des idées d'une gauche non marxiste dont il ne se départira pas dans ses premières approches africaines en se montrant sensible aux luttes contre les dominations mais dans un engagement qu'il ne veut jamais borné : «Quand je parle d'engagement, je parle de la participation à l'endroit du monde où on se trouve, et aussi de l'ethnologie participante au sens le plus fort du terme. C'est très différent de l'engagement au sens de la philosophie sartrienne, du militantisme maoïste des années 60 . Ce que j'ai fui comme la peste, c'est l'engagement lié à une dogmatique: c'est un engagement de l'enfermement, d'auto-conditionnement; la véritable expérience ne peut pas être vécue dans un système dogmatique : elle y est cléricalisée » (Balandier G., 1992 : 22). 
14 Parmi ces événements, le suicide en 1936 du ministre de l'Intérieur Roger Salengro, suite à une campagne de diffamation, provoque sa révolte et lui révèle «la violence politique poussée jusqu'à l'exaspération sacrificielle» (1997a: 156), ou plus tard l'émergence du fascisme, le cheminement vers la guerre, la montée de l'antisémitisme de la politique de Vichy et les stigmatisations de l'autre lui font découvrir les dramaturgies politiques, les manifestations théâtralisées des pouvoirs, une théâtrocratie de masse au service des totalitarismes d'où naît son inquiétude. Cela génère en lui un certain nombre de dissidences allant de la ruse dans l'application des Instructions Officielles alors qu'il était instituteur sous Vichy en suivant parallèlement ses études à la Sorbonne, au port de l'insigne d'appartenance au mouvement intellectuel international portant "l'avènement du socialisme humaniste ayant une fonction d'émancipation généralisée » comme forme de rejet du fascisme (2003:19) et à son entrée dans la Résistance où il deviendra une figure symbolique locale grâce à sa participation active dans la lutte contre l'occupant, après avoir été réfractaire au Service du Travail Obligatoire.

15 C'est dans ce contexte que l'Afrique lui apparaît comme un territoire imaginaire, qu'une attention à l'autre dans ses différences se dessine et que s'expriment les premières formes de rébellion à l'égard des dominations symbolisant les désirs d'émancipation. Cette passion pour la liberté inscrite comme principe de vie personnelle est transposée comme principe méthodologique pour scruter l'histoire et le devenir des sociétés et c'est en cela que, refusant l'idée d'une vérité enfermée dans un système clos et des engagements dogmatiques, il s'accorde avec une épistémologie où le social ne peut pas être conceptualisé par les systèmes explicatifs établis mais par une voie nouvelle où seront privilégiés les approximations, les incertitudes et les imprévus qui l'éloignent de l'orthodoxie des schèmes d'intelligibilité du moment: «Elle [ma passion pour la liberté] m'a toujours été, et jusqu'à présent, salutaire ; elle m'a protégé des adhésions qui entravent par la discipline; elle m'a empêché d'être initiateur de systèmes intellectuels bouclés à mon propre profit, et davantage encore d'épouser la dogmatique des autres sous l'effet de l'engouement ou de l'opportunisme accordés aux modes. La posture intellectuelle commande de prendre parti, mais elle requiert tout autant de maintenir du jeu dans toutes les conceptions du terme, de la disponibilité propice à l'entreprise personnelle. C'est peut-être ce que Malraux suggérait en disant qu'il y a en l'homme un chercheur parce qu'il y a en lui un joueur » (Balandier G., 2003a : 27).

16 L'événement historique lui enseigne la fragilité des équilibres et son caractère perturbateur l'oblige à ne plus penser le monde social dans son enfermement ou son achèvement. Sa potentialité transformatrice le conduit à penser des nouveaux possibles et des imprévus et à concevoir une impossible fin de l'histoire (1997a : 293). Cet ancrage très personnel de valeurs tirées de l'expérience et érigées en vertus épistémologiques où la production du social compte plus que les permanences, va s'étoffer de rencontres intellectuelles, elles aussi ouvertes aux dynamiques sociales, aux turbulences et aux émergences qui les signifient.

Des influences théoriques déterminantes

17 Georges Balandier admet certes que son orientation vers la sociologie dynamique s'est faite par la conjonction de déterminations comme les débats intellectuels d'avantguerre et d'après-guerre ainsi que par des influences scientifiques, mais certainement faudrait-il, au préalable, mentionner aussi des influences littéraires dont il est possible 
de penser, qu'indirectement au moins, elles participent d'exigences qu'il reconvertira plus tard dans la construction de son analyse sociologique.

18 Ainsi, déclare-t-il avant vingt ans, avoir lu Gide qui lui fit naître son désir d'émancipation et d'indépendance ainsi que Nietzsche, Marx ou Fourier et reconnaît avoir éprouvé un goût certain pour la littérature, celle de Mauriac entre autres, en écartant Drieu la Rochelle et Céline. C'est au moment où il était collégien qu'il entre en "religion littéraire», ce qui n'ouvre certes pas aux sciences sociales de manière directe, mais qui peut, en créant une vision du monde et un imaginaire, le préparer à recevoir plus tard un discours qui prendra du sens grâce aux incorporations produites par cette littérature très sélective car parfois politique.

C'est ainsi que dès l'âge de 12 ou 13 ans, il apprend à l'école le goût du non-institué, grâce à des répétiteurs aux idées de gauche qui lui firent découvrir des «livres scandaleux » sur les excès coloniaux, blancs et noirs et qui forgèrent en lui une image politique et provoquèrent une déchirure dans son imagerie coloniale (Balandier G., 1997 : 138). Plus tard, avec des professeurs de Lettres passionnés il découvre les œuvres de Balzac, Stendhal et la poésie de Musset, d'Hugo, de Vigny, de Péguy et surtout de Baudelaire. Cette sacralisation de la littérature qui l'amène à considérer l'écrivain comme un être à part et à le placer très haut, lui permet d'établir de solides amitiés qui l'aideront dans ses publications littéraires, avec Paul Mercier, son " double », pour un ensemble de commentaires sur Mallarmé, Lautréamont, Rimbaud (Lettres sur la poésie, 1943), et avec Michel Leiris pour un roman (Tous comptes faits, 1947). Ce sont là deux figures de l'ethnologie qui outre leur profonde sensibilité littéraire, concouront de manière différente à la trajectoire scientifique de Georges Balandier : en participant à sa première recherche de terrain au Sénégal pour Paul Mercier et en étant son initiateur théorique et pratique de l'Afrique pour Michel Leiris.

Il faut alors rechercher dans l'ethnologie de l'époque des rencontres intellectuelles qui progressivement vont guider ses approches théoriques, au rang desquelles figurent entre autres Roger Bastide, dans sa manière de penser les changements dans la société et les conflits, Marcel Griaule et Maurice Leenhardt dont les enseignements reposaient sur une connaissance profonde des peuples étudiés - les Dogon du Mali pour le premier, les Canaques de Nouvelle Calédonie pour le second - ainsi que Michel Leiris à qui Georges Balandier reconnaît devoir beaucoup dans "ses apprentissages initiaux ». Il trouve auprès de lui une orientation pour l'africanisme alors qu'il était indécis, une défense du littéraire en précisant, «c'est à lui que je dois de ne pas avoir laissé mon métier d'ethnologue annuler mon besoin de littérature », et un désir d'ailleurs, une échappée à l'enfermement par les vertus d'un voyage décrites par l'auteur comme « une aventure poétique, une méthode de connaissance concrète, une épreuve... » dans Afrique fantôme qui avait échappé à la censure nazie (Balandier G., 1996, 2003 : 38).

C'est dans cet ouvrage qu'il découvre aussi un savoir-faire scientifique pour aborder les cultures de la différence avec une méthode nécessitant des techniques de recueil de données, comme la tenue scrupuleuse d'un carnet de route, une éthique comme l'énonciation de la vérité, ainsi que la pratique d'une ethnographie incisive, la critique de l'autre et de soi, la révélation des pièges de l'information et de l'observation des manières d'être ou des langages ainsi que l'exigence de la preuve afin d'accéder à un univers de significations des cultures africaines révélées par une indépassable liaison entre la subjectivité et l'objectivité (Balandier G., ibid., : 39). C'est ainsi que grâce à Michel Leiris, Georges Balandier après la Libération entre dans le mouvement 
intellectuel des Temps modernes avec Sartre, Simone de Beauvoir, Camus, Merleau-Ponty et de Critiques avec Georges Bataille.

Outre cet apport de l'ethnologie et d'idées critiques, Georges Balandier va trouver des éléments d'une construction théorique du social dans les débats intellectuels d'aprèsguerre qui «portaient à la fois sur le marxisme et le communisme comme pratique, et sur l'existentialisme dans son rapport à la phénoménologie et à la conception sartrienne de l'engagement » (Balandier G., 2003 : 152). Des lectures de Sartre, Critique de la raison dialectique et Questions de méthode, émergent des intuitions posant les bases d'une théorie dynamique construite sur la production sociale plutôt que la reproduction, notamment par « la considération du social à partir des situations dont il s'engendre; le primat de l'existence conduisant à voir le social et la culture sous l'impact de leur production continuelle et non par les seuls principes selon lesquels ils se définissent » (Balandier G., 2003 : 152-153). En voyant dans l'existentialisme l'éloge du mouvement, de l'inachèvement et d'une impossible fin de l'histoire, il trouve là des éléments fondateurs d'une anthropologie dynamique et critique singularisant une démarche interprétative qu'il va parfaire en commentant les textes de Sartre pendant deux ans lors de ses séminaires de recherche ou lors de ses enseignements.

C'est aussi dans la sociologie que Georges Balandier va s'enrichir d'assises théoriques sur lesquelles s'édifiera une singularité de pensée fondée non pas sur une opposition radicale entre tradition et modernité, mais plutôt sur leurs relations dialogiques. Il retient de la sociologie de Maurice Halbwachs l'idée d'une tradition non séparable du problème de la mémoire collective qu'il recherche alors dans des "lieux" où se stockent des symboles, des événements, des codes, c'est-à-dire des informations témoignant de l'activité générée par les hommes au cours du temps et qui font que le tradition n'est pas morte mais simplement mise en mémoire (Balandier G., $1992: 24$ ). De Georges Gurvitch, il saisit une double théorisation, celle du mouvement issue de l'héritage de Saint Simon et Proudhon et celle de la totalité, dans une filiation avec Marcel Mauss. Georges Balandier fut, selon Henri Janne, le confident et le collaborateur scientifique de Georges Gurvitch (Janne H., 1988), et il lui doit son orientation vers une théorie sociologique de la logique de production continue du social, amplifiée à partir des années 1950 par les controverses dans les sciences humaines et sociales avec le structuralisme naissant de Claude Levi-Strauss.

Ces débats d'idées visant l'imposition de deux paradigmes, dynamiste et structuraliste, sont simultanément des luttes pour les postes dans des lieux les plus prestigieux de la connaissance (Sorbonne, Ecole Pratique de Hautes Etudes, Collège de France, etc.) et des luttes pour le positionnement de la sociologie. Derrière les enjeux institutionnels se lisent des enjeux scientifiques (Ansart P., 1990 ; Farrugia F., 1997).

Georges Balandier présente Georges Gurvitch comme "un exclu de la horde", s'imposant en se situant à contre courant des modes et dont un des apports en sociologie fut de la considérer comme « un refus de la rigueur trompeuse acquise par négation du caractère mouvant et de $\mathrm{l}$ "effervescence" de la réalité sociale " (Balandier G., 1968a : VII). Il adhérait aux idées de Saint Simon tenu pour l'inventeur de la sociologie dynamique et il retient que la société se crée elle-même, que la réalité sociale est à la fois d'ordre matériel et spirituel et que la société est partagée entre des groupes antagonistes, bref une société de turbulences (Balandier G., 2003a : 328-330). Georges Gurvitch se passionnait pour les idées de Proudhon et de Marx en voyant en eux des analystes des contradictions sociales, mais plus encore selon Pierre Ansart il 
retient « le sens des dynamismes sociaux sous-jacents aux appareils, le souci d'analyser les résistances diffuses, susceptibles de mettre en cause les ordres établis. Sa recherche à travers les théoriciens de l'action, Saint Simon, Proudhon, Fichte, Hauriou, est une quête pour trouver de nouveaux éclairages sur cette dialectique du mouvant et de l'inerte, de l'“effervescence" contre les appareils, de la société contre l'Etat » (Ansart P., $1990: 11)$.

Georges Gurvitch érige la dialectique comme méthode, une manière de connaître adéquatement le mouvement des totalités sociales réelles et historiques et de penser la démolition des concepts acquis et cristallisés, c'est-à-dire leur "momification ", en évitant ainsi toute position scientifique préalable, et le mouvement réel c'est-à-dire « la voie prise par les totalités humaines, en premier lieu sociales et historiques, en train de se faire et de se défaire dans l'engendrement réciproque de leurs ensembles et de leurs parties, de leurs actes et de leurs œuvres, ainsi que dans la lutte que ces totalités mènent contre les obstacles internes et externes qu'elles rencontrent sur leur chemin " (Gurvitch G., 1962). Cette voie ouvre à la considération du changement social et à une proximité avec l'anthropologie de Marcel Mauss, notamment avec la notion de phénomène social total, développée dans son Essai sur le don (1923-1924) pour signifier l'imbrication de l'économique, du politique, du culturel, de l'idéologique.

Comme héritier de Georges Gurvitch, Georges Balandier partage avec lui une volonté de défendre une liberté créatrice peu encline à s'aliéner à une pensée dogmatique, attentive aux situations sociales et à ses aspects tensionnels, ouverte à une lecture du mouvement et du changement social généré par les conflits entre l'institué et les forces instituantes, sensible à la prise en compte de l'idée de totalité, bref, une théorisation du social en tous points opposée au structuralisme de Claude Levi-Strauss contre lequel ils lutteront à partir des années $50^{3}$. Georges Balandier formulera discrètement ses critiques à cause de l'amitié qui le liait à Claude Levi-Strauss, mais il ne pouvait adhérer à ses thèses en raison de leur enfermement dans les analogies linguistiques, des logiques et des combinatoires de relations trop formalisées et de leur éloignement des pratiques du social, tout en admettant leur efficacité rénovatrice en anthropologie (Balandier G., 1992 : 23). Il les réfute aussi à cause des méthodes dont les limites ne lui paraissent pas toujours bien tracées et qui définissent, selon leur logique propre, la réalité sociale à laquelle elles appartiennent (1967c, 2003a : 71-72).

C'est bien une double réduction qui s'énonce ici : théorique - car les sociétés et les cultures ne sont envisagées que comme des systèmes de communications dont les relations sont mathématisables dans leurs combinatoires en faisant abstraction alors des éléments concrets -, méthodologique, car la modélisation ne conduit qu'à des formes abstraites éloignées des réalités dont l'élucidation constitue pourtant l'objet d'analyse. La dynamique des structures sociales est préférée à la seule prise en compte du système formel des relations qu'elles impliquent (Balandier G., 1967c, 2003a : 72-73). C'est bien d'un équilibre précaire des structures (et non le principe de leur existence) qui est soulevé, des structures appelées à disparaître, à se transformer sous la force des événements, ce qui ne peut conduire à une vision figée d'un social soumis à un ordre permanent. Mais sans doute, faut-il s'accorder avec Pierre Ansart, qui note comment cette vision du social pouvait introduire deux soupçons, à l'égard de l'ethnologie traditionnelle envisageant les sociétés africaines comme des sociétés du manque ou des sociétés du «sans » (sans histoire, sans écriture) et à l'égard du structuralisme: un soupçon « que cette ethnologie traditionnelle, avide de découvrir des ordres constants 
et des structures permanentes, avait peut-être partie liée avec l'ancien ordre colonial porté à voir dans les sociétés colonisées des mondes immobiles qu'il importait, difficilement, d'ouvrir à la modernité(...). Dès lors, un autre soupçon est suggéré selon lequel le structuralisme, en polarisant l'étude sur les invariances et sur la répétition des ordonnancements sociaux, pourrait, dans une certaine mesure, prolonger les principes de l'ethnologie ancienne » (Ansart P., $1990:$ 49-50).

Les premières découvertes : les Afriques en mouvement

De 1946 à 1952, date de son entrée au C.N.R.S., Georges Balandier explore comme ethnologue les Afriques, le Sénégal en 1946, la Guinée, le Congo, le Gabon, la Mauritanie ou encore le Bénin (ex-Dahomey). Ce nomadisme le met en contact de peuples orientés vers les indépendances et, au-delà du politique, des pays animés par une modernité naissante. La question posée vise à savoir comment ces peuples de tradition vont vivre les turbulences économiques et politiques émergentes et quels effets sont générés par ces moments tensionnels annonciateurs de mutations possibles.

Les choix de terrain ne sont pas neutres et se lient à deux exigences entrevues: politique d'abord - sa propre passion pour la liberté et son engagement qui le sensibilisent aux pays en voie d'émancipation -, scientifique ensuite, par son ouverture au bougé des sociétés contre les formes stabilisées en choisissant alors d'analyser des populations proches des grandes villes (Dakar, Brazzaville) permettant de lire les effets de la domination coloniale et les métissages culturels. Ces deux regards unis ne se confondent pas, car Georges Balandier neutralise ses affects politiques en ne cédant jamais à la suffisance de la connaissance qui ferait de lui un conseiller et il préserve une distance de liberté qui marque une solidarité sans subordination afin d'avoir «la possibilité de contribuer au décryptage de ce qui est en voie de se faire » (Balandier G., 2003a : 27).

31 Ainsi, sa proximité d'Alioume Diop qui l'accueille au Sénégal, ou de Léopold Senghor qui en sera le Président, son rôle de rédacteur en chef de Présence africaine, sa séparation volontaire sur le terrain du monde blanc, sa participation à la Conférence anti-colonialiste de Bandung en 1955 où il propose la notion de Tiers Monde (le TiersEtat du monde), ne feront jamais de lui un chercheur assujetti à un quelconque régime ou celui qui écrit l'histoire qui doit se faire, mais l'observateur critique et lucide de l'histoire que ces peuples font: "Chaque peuple, dès lors qu'il dispose de liberté suffisante, accède à la responsabilité de sa propre histoire » (Balandier G., 1997a : 345).

Il montre ainsi que la raison politique guidant une recherche n'est pas un obstacle à la raison scientifique dès lors qu'une distance s'établit avec l'objet, que s'y applique une méthode rigoureuse et que l'enquête dévoile le caché des sociétés. Pierre Ansart montrait aussi à propos de Marx, Saint-Simon ou Proudhon que la pensée politique est une condition « de la clairvoyance et de la connaissance " (Ansart P., 1979: 41), ce qui s'applique aussi à Georges Balandier, car rien dans ses théories préalables ne permettait de prédire ce que le terrain allait dévoiler : la complexité du jeu dialectique entre les sociétés traditionnelles différenciées culturellement et historiquement et les forces de la colonisation et de la modernisation, la présence sous-jacente dans les mouvements transformateurs d'une réalité sociale masquée par la fascination des apparences. De ces premiers résultats de terrain, relatés ici sommairement à partir de quatre ouvrages et d'articles publiés dans cette période dans les Cahiers internationaux de Sociologie, vont émerger les éléments de la construction d'une anthropologie générative critique dans laquelle les structures sociales ne sont plus contenues dans 
leur gangue, mais se lient à des actions et des situations générées par des acteurs, à une dynamique en acte.

La « situation coloniale » comme totalité dynamique

33 Sa première recherche sur les pêcheurs Lébou avec Paul Mercier, relatée dans Particularisme et Evolution: les pêcheurs Lébou (1952a), constitue pour Georges Balandier une expérience initiatrice qui a laissé en lui des traces dans l'interprétation dynamique des sociétés et des cultures étudiées ultérieurement, dans le sens où tradition et modernité se peuvent être envisagées comme des termes antagonistes. Le but de la recherche est de dévoiler les persistances des univers traditionnels (ce qui relève du "particularisme", qui tient de l'héritage et qui est transmis) et ce qui relève du mouvement transformateur et du renouvellement (traduction de "l'évolution»). Ce que montre cette recherche, c'est que les Lébou ne sont pas des primitifs où rites et traditions se répètent - sujet de l'ethnologie classique du moment -, mais des « enfants de l'événement» (1997a: 236) qui vont donner à ces rites et traditions des significations dépendantes des situations nouvelles provoquées par la modernité.

Ils ajustent ainsi des traits anciens aux émergences nées de la proximité de l'urbanisme de Dakar: la permanence de rites comme le culte de la possession exprimé par des transes essentiellement féminines, sont «traduites » selon les nécessités de l'instant présent et sont ainsi des réponses aux angoisses et aux anxiétés produites par l'évolution brutale. Ces pratiques issues d'une antériorité ont une fonction de " conciliation" avec un univers social en mutation (Balandier G. 1997a: 27). Par la symbolique de la parole, du signe et du rite, la transe fait resurgir la dimension sacrée $\mathrm{du}$ religieux comme institution permanente mise au contact plus tard avec les religions importées (Balandier G., 1997a : 15). La Côte d'Ivoire apparaît comme un « creuset » où se prépare la modernité qui se combine aux traits d'une tradition qu'elle n'élimine pas et qui est réactivée comme réduction à l'angoisse générée par les transformations. Le temps actuel n'est pas unifié, il compose avec la durée et l'histoire, car le latent se conserve en mémoire et est toujours prêt à émerger.

Alors, les apparences provenant d'évolutions dépendantes des contextes extérieurs deviennent trompeuses. Le mouvement se lie à une autonomie du sacré et d'un imaginaire qui lui sont consubstantiels, des métissages et des synthèses sont générés par les confrontations/actions/réactions de deux cultures: "Ils [les Lébou] me montraient qu'aucun peuple ne peut se soustraire à l'emprise de l'histoire, que celle-ci travaille par métissages et conjugaisons d'influences. Elle mêle les personnages et les courants culturels, elle crée à partir de la diversité une unité inachevée et vulnérable, elle ne dresse aucune muraille à l'abri de laquelle les peuples pourraient maintenir une sorte de pureté mystique et fictive. Les Lébou me montraient aussi qu'aucune société n'échappe à la nécessité de se produire elle-même sans répit, sous la contrainte de sa propre imperfection et de l'événement. Et ce travail sans fin allie la continuité et les ruptures. Il n'autorise pas à opposer sommairement la tradition à la modernité : la première n'est pas un fardeau de formes mortes qui imposeraient son inertie à la seconde, elle est le fournisseur de mémoires où le présent recherche une part de ce qui est utile à son avènement » (Balandier G., 1997a : 238).

Les linéaments d'une théorie générative du social se complexifient dans ce qui est sa thèse principale de Doctorat publiée sous le titre Sociologie actuelle de l'Afrique noire (1955a) dans laquelle sont amplifiées des réflexions sur la " situation coloniale » (1951) et où sont restituées, dans une démarche historique comparative entre deux 
communautés traditionnelles, les Ba-Kongo du Congo Brazzaville et les Fang du Gabon, leurs réactions contrastées à la situation coloniale. Cette recherche montre deux types de «reprises d'initiative » des peuples colonisés à la modernisation naissante. Pour les Ba-Kongo, forts d'une longue tradition étatique, le retour à l'histoire religieuse et aux messianismes est un moyen de réagir à l'emprise coloniale sans se réapproprier l'histoire de leur royaume dont la colonisation a défait les formes politiques spécifiques. Ils tentent de conquérir une autonomie en innovant dans des formes religieuses (fondation d'églises autochtones) et en s'appuyant sur ces institutions lors des indépendances. Les Fang reconstituaient quant à eux une société fragmentaire par un mouvement de reconstruction des villages et de réorganisation de clans ou tribus société refaçonnée selon les langages anciens - tout en tenant compte des problèmes modernes liés au travail, à l'économie ou à l'échange et manifestaient ainsi une gestion autonome dans la modernité naissante en adhérant à certains des moyens introduits par la décolonisation (Balandier G., 1997a : 30-31 et 281 ; 1967a : 194-195).

Ces observations montrant la variété des formes de reprises d'initiatives des cultures de la tradition amènent Georges Balandier à une théorisation de la situation coloniale dans laquelle la filiation gurvichiennne-maussienne est présente : celle-ci est envisagée dans une "totalité dynamique» où le culturel n'est plus analysé indépendamment de l'économique et du politique, où toutes les composantes interagissent dans un "système » (1951). La société coloniale, assise de la domination, n'est pas séparable de la société colonisée, et dans ce contexte à évolution rapide, l'ensemble est saisi dans un état de continuel réajustement des relations selon les modes de domination et de dépendance. Cela requiert la sollicitation de toutes les sciences sociales, car l'objet construit n'est pas "pur", contrairement à l'ethnologie de l'époque attachée à comprendre les populations indigènes les plus éloignées des influences historiques propres à l'Afrique ou des rapports avec les systèmes coloniaux (Balandier G., 2003 : 45). Georges Balandier démontre ainsi que la situation coloniale ne se réduit pas à l'histoire coloniale ni à celle d'une histoire répétitive des peuples de la tradition mais elle se lie au mouvement produit par l'entrecroisement de ces deux histoires: "C'est une dynamique qui se révèle par les tensions que cette situation entretient, par les conflits et les crises qui les manifestent de façon permanente. Ceux-ci ne s'inscrivent pas simplement dans la bipolarité colonial/colonisé, dominant/dominé car les deux sociétés sont divisées : la coloniale par ses composantes - des acteurs aux intérêts, aux objectifs différents - que la situation de suprématie allie; la colonisée par la fragmentation en ensembles dits ethniques produits par les histoires particulières. Ce n'est plus une stratégie duelle qui en résulte, mais des stratégies à partenaires multiples, et changeants selon les conjonctures et l'opportunité » (Balandier G., 2003a : 156).

Cet intérêt pour la question anthropologique du fait colonial comme facteur de contacts et de conflits culturels se poursuit dans deux textes, Contribution à une sociologie de la dépendance (1952b) et Sociologie de la colonisation (1954) où Georges Balandier va continuer à penser relationnellement les société dominantes et les sociétés dominées en analysant les types de réactions à la domination subie par les "minorités sociologiques" (peuples colonisés mais aussi prolétariat ou classes démunies) en situation de dépendance, amenées à lutter pour leur reconnaissance à partir d'une prise de conscience. La question alors est de savoir comment s'effectue cette prise de conscience. Il la perçoit dans plusieurs indicateurs: dans les réactions confuses (ressentiment à l'égard du colonisateur dont l'aspect perturbateur se révèle lors des 
crises économiques ou lors des transformations sociales), dans l'altération et la destruction d'institutions fondamentales (dépossession religieuse par le christianisme avec une volonté pour les dominés de revenir aux valeurs et aux institutions antérieures, comme les Fang gabonais, ou aux systèmes d'autorité anciennes), dans l'état de soumission déterminée par les différences de cultures et de races (apartheid), dans des réactions directement politiques liées aux nouveaux rapports économiques et culturels (formation de mouvements nationaux par les minorités progressistes réfutant tant les autorités autochtones compromises que la puissance de la domination coloniale).

La prise de conscience du colonisé participe du mouvement réactionnel et se révèle à l'occasion de crises, soit économique, soit identitaire ou culturelle (dénaturation des institutions religieuses autochtones, différences culturelles placées dans un ordre hiérarchique), soit politiques (organisation de mouvements contre la situation coloniale). Ici se perçoit de nouveau la dynamique instaurée par cette situation dont Georges Balandier souligne l'ambiguïté : "Cette ambivalence - retour au passé et contre-acculturation, ou acculturation développée jusqu'à son extrême conséquence : l'assimilation des valeurs démocratiques dont se proclament parfois les nations dominantes - caractérise toutes les réactions actuelles aux situations coloniales ou para coloniales » (Balandier G., 1952b, 1971 : 160-161).

C'est bien à une complexification de la lecture de la situation de dépendance qu'il appelle, en objectivant les formes réactionnelles des dominés qui vont de l'acceptation passive (servant les buts des coloniaux), à l'acceptation active (loyalisme à l'égard du colonisateur), et de l'opposition passive (d'origine défensive, visible dans l'angoisse et le désajustement socio-psychologique de l'acculturation), à l'opposition active (attaque directe par les mouvements nationaux de la dépendance colonisée). C'est bien aussi cette tension qui est révélée, produite par des inégalités entre les sociétés les plus techniquement avancées et celles qui "sont moins développées", ce qui permet d'assurer la domination et de maintenir l'écart différentiel que les dominés veulent réduire. Et dans ce jeu de relations entre les deux types de sociétés globales, il s'agit de comprendre la dynamique née de cet antagonisme entre deux types de forces: celles qui tendent à l'unification et à l'homogénéisation (sociétés dominantes) et celles qui défendent la sécession et le pluralisme (sociétés dominées revendiquant l'émancipation sans renoncer à leurs spécificités culturelles (Balandier G., 1954, 1971 : 179-181). De là, peut se comprendre le souci de Georges Balandier de penser le Tiers Monde dans une approche qui ne peut être que relationnelle, dans la mesure où les inégalités sont générées par des processus venant de l'extérieur - notamment les incitations aux progrès techno-économiques qui imposent à ces sociétés des discontinuités brutales par rapport à leurs moyens traditionnels - et qui produisent des bouleversements culturels et sociaux créateurs de discordances, de ruptures d'où naissent de nouveaux engendrements (Balandier G., 1956 : 200).

Une Afrique se faisant : le mouvement transformateur

41 Fort de ses recherches anthropologiques attentives aux configuration culturelles depuis des sociétés de petites dimensions - mais qui ont montré d'un point de vue dynamique que toute la réalité sociale était concernée par le changement - Georges Balandier va plaider pour l'apport de l'anthropologie et son caractère synthétique à une théorisation du changement, car aucune science sociale ne permet l'élaboration d'une théorie générale du changement social à cause de leur cloisonnement et d'une 
absence de langage commun qu'il déplore et dont il souhaite la rencontre à propos d'un tel objet (Balandier G., 1959, 1971: 128-129). Comme il l'a montré, l'anthropologue permet de conjoindre des données économiques, techniques, psychologiques et sociologiques. Il introduit un point de vue relativiste qui met en garde les sciences sociales contre toute généralisation prématurée. Il permet de mieux différencier la dynamique relevant de facteurs endogènes de celle qui est particulière aux changements exogènes. Il tente d'apprécier comment les éléments constitutifs d'une société et d'une culture changent ou ne changent pas, avec des rythmes variés (ibid., : 145). C'est en ce sens que l'anthropologie peut apporter sa contribution à l'élaboration d'une théorie générale du changement social.

Dans sa deuxième thèse de Doctorat, Sociologie des Brazzavilles noires (1955b), Georges Balandier opère encore une rupture en consacrant une étude à une ville africaine, Brazzaville, où il est affecté à l'Institut d'Etudes Centrafricaines en 1948, ce qui ouvrira ultérieurement à une anthropologie urbaine féconde. Cet autre projet novateur considère la ville comme un "révélateur", comme un laboratoire de nouveaux rapports sociaux ou de relations inédites, comme un nouveau monde social en devenir où les problèmes sont exacerbés et où se retrouvent les conflits entre les cultures de la tradition et de la modernité. Il y découvre en fait une ville divisée en trois parties, une ville blanche et deux villes noires construites à chacune de ses extrémités. La ville blanche se peuple ainsi de Noirs, preuve de la situation et de la domination coloniales. Ces Brazzavilles noires sont à considérer comme un phénomène social total en voie de constitution.

43 Ici encore, il ne s'agit pas d'envisager la ville avec les yeux de l'Europe et de rechercher par analogie des éléments d'une modernité, ou à l'inverse, en y voyant une opposition à cause des présences africaines comme le suggère Jean Copans (1986). Le projet anthropologique vise au contraire à changer de position en interprétant la situation actuelle et en analysant la dynamique de ces trois fragments qui composent cette ville animée d'un mouvement transformateur engendrant des incertitudes. Cette recherche montre que chaque ville a une singularité culturelle, identitaire et politique qui l'oppose aux autres. Bacongo, au sud, dispose d'un ancrage historique et culturel homogène, tandis que Poto-Poto, au nord, est une ville nouvelle ouverte à la migration, multi-ethnique et pluriculturelle; dans la première, l'identité reste forte et le collectif est offensif, dans la seconde règne un cloisonnement identitaire peu propice aux luttes unitaires; Bacongo en alliant politique et religion entretient la vigueur des revendications nationales kongo, tandis que Poto-Poto, du fait d'un espace urbain favorisant les expériences individuelles est plus centrée sur la réussite personnelle. Chacune d'entre elles témoigne d'un itinéraire d'accès particulier au mode de vie urbain. La ville blanche se présente comme une zone neutre qui n'empêche nullement les affrontements entre les deux Brazzavilles (Balandier G., 1997a : 267-269).

Jean Copans (1986: 255-263) montre aussi comment Georges Balandier, pour rendre compte de cette accession à une Afrique en train de se faire et pour décrypter les processus de cette transformation, recueille au plan de la méthode un ensemble de données sur la distribution des métiers selon les races - les nouveaux métiers sont pour ceux qui arrivent de la brousse, les salaires sont inférieurs-, sur le recensement. Georges Balandier construit un questionnaire pour connaître les migrations de la ville, les loisirs, les associations communautaires (ces dernières dominent tout autre mode d'identification sociale, régissent les affinités culturelles et justifient les exclusions), la 
place des femmes, la vision raciste coloniale de l'évaluation des besoins économiques des Noirs, la permanence des liens familiaux et ethniques où se forment les solidarités (les vrais prolétaires isolés n'existent pas car la culture d'origine n'est pas abandonnée). Ce qui est décrit dans cette liaison avec la modernité, c'est cette ambiguïté née de la présence à la fois d'acquis occidentaux et de l'attachement aux ancêtres et à la tradition, la libération (les danses du samedi soir) et l'aliénation (crise de personnalité). Ici encore, Georges Balandier montre comment les différences culturelles et identitaires structurant la mémoire des communautés participent de manière différentielle à une modernité émergente qui n'homogénéise pas les manières de faire. L'actuel n'évacue pas l'histoire qui est retravaillée et réactivée dans ces nouveaux contextes de mutation générant de l'inédit, autant de situations conflictuelles et nouvelles qui font système et dont la complexité n'est saisissable que si l'objet est compris comme un phénomène social total.

Dans La vie quotidienne au royaume de Kongo du XVI au XVIII siècle (1967a), la nécessaire relation entre la sociologie et l'histoire est amplifiée, mais cette dernière est déjà théorisée : les parcours du peuple Kongo sont reconstitués malgré les ruptures et les grands bouleversements introduits par la colonisation, non pas à la lumière d'une causalité linéaire ou de déterminations simples et bien alignées, mais en prenant en compte les variations et les bifurcations (Balandier G., 1997b : 32). Ici, figure de nouveau un point d'épistémologie d'une construction générative du social : le social ne se donne à lire que dans la complexité parce que s'y affirme le jeu de la liberté humaine.

Dans cette recherche, Georges Balandier montre comment l'actuel - l'espoir de la décolonisation dans les années 65 , déjà brisé à la fin du XvIII siècle et définitivement à la fin du XIX siècle en séparant les deux Congo modernes de part et d'autre du fleuve est nourri par l'exaltation du passé des Kongo: "Une unité culturelle et politique affaiblie ne pouvait que subir cette mutilation, ce tronçonnement résultant de nouvelles frontières. Mais la nostalgie de l'unité et de la grandeur disparues se transformera en exigence de libération. Les Ba-Kongo prendront en 1920 l'initiative des luttes d'indépendance ; leurs guides politiques revendiqueront symboliquement le titre de roi afin d'affirmer une continuité;la résurrection d'un Kongo rajeuni et techniquement équipé paraîtra possible » (Balandier G., 1967a : 6).

Sur le plan de la méthode, afin de reconstituer l'image d'une société et d'une civilisation congolaises autrefois prestigieuses, leurs conditions de vie et leurs contacts avec les civilisations, Georges Balandier va déchiffrer un ensemble de données multiples nécessitant une traduction des informations, une distance par rapport aux sources souvent trompeuses (venant entre autres des missionnaires), la connaissance d'un vocabulaire masquant souvent la réalité. Le présent s'éclaire par la connaissance de cette historicité depuis le $\mathrm{XVI}^{\mathrm{e}}$ siècle (parenté, organisation de la vie matérielle, répartition du travail selon des règles qui demeurent malgré les siècles), notamment dans les projets politiques du moment remaniant les cartes tracées par les colonisations afin de reconstituer l'unité disparue. Ainsi, s'affirme encore le fait que non seulement ces sociétés ont une histoire, mais que la production des actions ou réactions des sujets dans un contexte de domination ne peut se comprendre qu'à partir d'elle. Elle détermine non seulement le présent mais elle donne également une forme aux projets politiques à venir: la mémoire et la tradition continuent de travailler dans la modernité. 

à Georges Balandier de mettre en place les éléments de construction d'une approche dynamique-générative des sociétés sous domination coloniale. Si cette épistémologie s'enracine au préalable dans des données personnelles, institutionnelles ou théoriques, le terrain pluriel de l'Afrique va s'affirmer comme un laboratoire de recherche fructueux permettant de rompre avec les approches ethnologiques dominantes du moment. D'abord en choisissant des objets «impurs ", c'est-à-dire des populations soumises aux mutations provoquées par la situation de dépendance en contact culturel avec la modernisation émergente, il montre toute la complexité des processus d'acculturation et de contre-acculturation entre le traditionnel et le moderne. Par une méthode comparative et historique, il révèle une générativité du social objectivée dans des versions différentielles compte tenu des histoires singulières de ces peuples et de leur désir d'émancipation. Il présente ainsi les bases d'une conception dynamique du social témoignant d'une puissance de la tradition, réactionnelle à l'emprise du pouvoir de la société dominante. Si les peuples de tradition maintiennent des rites, leur sens ne se reproduit pas inlassablement car leurs fonctions se lient aux contextes en évolution en permettant aux populations de préserver une parcelle d'autonomie et de réduire l'angoisse dans un temps d'incertitude produit par les transformations sociales.

Ensuite, Georges Balandier montre bien comment ces deux sociétés doivent être théorisées comme un «système ", c'est-à-dire pensées dans leurs relations, dans leurs combinaisons, dans leur dialectique ${ }^{4}$. De ces contacts culturels émergent des conflits et des tensions qui se perçoivent dans des actions/réactions dont toutes ne sont pas «actives» au sens politique du terme, c'est-à-dire capables d'être organisées pour conduire au renversement de l'ordre dominant. Par les mouvements créateurs, les grandes transformations favorisent la puissance de l'imaginaire social, notamment de nouvelles utopies. Enfin, Georges Balandier attire l'attention sur le rôle que l'anthropologie peut jouer dans la construction d'une théorie générale du changement social.

50 Il n'est pas étonnant alors de voir toute l'actualité des pages écrites par Georges Balandier dans les années 50 sur la situation coloniale qui peuvent aider à comprendre l'actuelle tension entre des pays dont les rapports sont toujours régis par les écarts différentiels (Saada E., Copans J., 2001). Même si la terminologie pour qualifier ces nations a changé, la question posée sur l'unification voulue par les pays développés face aux différentialismes économiques, culturels et politiques propres aux pays soumis à la dépendance de la mondialisation demeure constante. Mais l'anthropologie de Georges Balandier est éminemment critique: elle appelle à dépasser les apparences d'une unification imposée par l'ordre techno-économique dominant pour montrer les forces cachées de la dynamique instituante endogène mettant en place des ruses et des stratégies pour préserver les identités culturelles face aux forces exogènes. Dans les publications ultérieures l'approche générative va être désignée comme telle et faire l'objet d'une théorisation.

L'affirmation d'une anthropo-sociologie générative (1967-1979)

51 Les bornes segmentant le parcours intellectuel de Georges Balandier sont toujours trompeuses. L'année 1967 en effet se présente comme une transition exprimant à la fois ce qui serait la fin de l'émergence d'une démarche générative et le commencement de son affirmation. Cette année-là, la nécessité du recours à l'histoire pour comprendre les dynamismes africains du moment continue de s'affirmer dans la publication de La vie 
quotidienne au royaume de Kongo $d u X V I I^{e}$ au XVIII siècle, en même temps qu'apparaissent des éléments théoriques consolidant la démarche générative par une opposition au structuralisme dans son ouvrage Anthropologie politique et dans une communication faite à Bruxelles Tradition et continuité (publiée en 1968). Ce renforcement va s'amplifier dans deux autres ouvrages, Sens et Puissance, les dynamiques sociales (1971) et Anthropo-logiques (1974) où une "science sociale générative » est désignée comme telle et sa nécessité revendiquée.

C'est donc de manière idéal-typique que cette période 1967-1979 est constituée en postulant que s'y décrypte un approfondissement des réflexions antérieures intégrant de manière plus ouverte les sociétés de la modernité, elles-mêmes soumises à la " grande transformation » et à l'engendrement de mutations et de crises qualifiant ces bouleversements. Cette théorisation se construit sur la connaissance des cultures autres, sur les enseignements tirés des recherches sur les Afriques en mouvement, pour interroger nos cultures propres à partir de leurs différences. Le mouvement des peuples africains défriché par Georges Balandier pendant vingt années l'invite à scruter les sociétés de la modernité comme un nouveau champ exploratoire des turbulences qui les affectent. Les indicateurs de l'affirmation de ce qu'il va qualifier de "science sociale générative" vont être recherchés en deux temps: d'abord dans son positionnement contre-structuraliste (1967b, 1968b), ensuite dans sa théorisation des mutations sociales (1970), des dynamiques sociales (1971) et des logiques sous-jacentes en oeuvre dans la modernité $(1971,1974)$.

Les " générateurs de changement »: l'envers de la pensée structuraliste

Fort d'avoir montré la nécessité de prendre en considération l'ancrage historique des sociétés exotiques, les formes de pouvoir en relation avec le sacré qui s'y manifestent, les variations d'organisations qui les agencent selon les cultures et la place du symbolisme et des dramatisations dans le gouvernement des hommes qui les structurent, Georges Balandier dans son ouvrage Anthropologie politique (1967a) décrypte les formes du politique dans ces sociétés qui ne connaissent pas d'État au sens moderne du terme. C'est encore un objet novateur qu'explore ce travail, car il est peu habituel de repérer une politisation dans des sociétés exotiques, ce qui peut apparaître, a priori, comme la transposition d'une pensée moderne aux sociétés autres. Les polémiques qui suivirent la sortie du volume, qu'il relate dans la préface à la 2ème édition, concernent un objet qui paraitt surestimé (Louis Dumont), mais peut-être aussi l'épistémologie sous-jacente qui construit ce regard dynamique.

Pour théoriser la présence du politique dans ces sociétés, il recourt à une approche où l'histoire est privilégiée, où les déséquilibres de ces peuples et leur mobilité sont considérés, autant de directions opposées au seul pouvoir explicatif des structures aveugles à leurs dynamismes sous-jacents. Dès lors, cette anthropologie politique cristallisait l'opposition au structuralisme en œuvre déjà depuis les années 50 et déconstruisait l'idée de politique déterminée par l'État et les institutions formelles pour en donner une lecture extensive dans la recherche de structures appelées à se manifester dans des situations très précises, par des actions qui visent à la conservation ou à la modification de l'ordre établi. Cette nouvelle conception fait de l'instance politique "un lieu d'émergence de dynamismes sociaux confrontés et affrontés " à cause des déséquilibres et des contestations qui sont constitutifs de son essence (Balandier G., 1967b; 1995 : VII-IX). 
Chaque chapitre composant l'ouvrage est à considérer comme un système de preuves montrant la pertinence d'une approche dynamique dans la construction d'une anthropologie politique. C'est dans les publications orientées vers l'objet politique, qu'elles soient d'origine sociologique, philosophique ou ethnologique, qu'il construit son objet. Ainsi analyse-t-il les travaux d'Edward E. Evans-Pritchard sur les Nuer du Soudan qui reconnaît la présence d'une " anarchie ordonnée ", ceux de Max Gluckman sur l'ordre et le désordre en Afrique, ceux de Meyer Fortes qui avec Max Gluckman confère un statut scientifique à l'anthropologie politique grâce à leur travail de terrain en montrant l'instabilité des équilibres socio-politiques et le décalage entre le système de relations sociales et politiques, ou encore les recherches d'Edmund R. Leach sur les Kachin de Birmanie. Contrairement à la pensée structuraliste, ces recherches montrent que les relations sont pensées dans leur dynamique, dans leurs contradictions, leurs tensions. C'est la voie d'un "structuralisme dynamique» ouverte par l'école de Manchester impulsée par Max Gluckman, que Georges Balandier explore, mais en poussant au plus profond la capacité heuristique de leur épistémologie qui prend en compte la dynamique interne mais en réduisant sa portée modificatrice, dans la mesure où l'histoire n'est vue que comme répétitive. C'est là une dimension de stabilité que Georges Balandier ne peut partager. L'approche générative du social conçue à partir de l'objet politique va s'illustrer dans les relations qu'entretient le pouvoir avec la parenté, la stratification sociale ou la religion.

$56 \mathrm{Du}$ point de vue dynamique qui postule la précarité des équilibres sociaux, l'anthropologie politique envisage le pouvoir dans sa fonction de maintien de l'ordre, " comme résultant, pour toute société, de la nécessité de lutter contre l'entropie qui la menace du désordre » (ibid., : 43). Pour cela la coercition n'est pas le seul recours et les rituels qui peuvent être de rébellion, participent de cette « remise à neuf » de la société par la libération des tensions: "La ruse suprême du pouvoir est de se contester rituellement pour mieux se consolider effectivement " (ibid.,: 50). Dans certaines sociétés africaines le pouvoir peut être dédoublé : une des figures dominantes s'attache à l'unité de la communauté, l'autre est chargée de réguler les menaces venant de l'extérieur, et cette bipolarité les met en compétition pour résoudre la présence d'un désordre d'origine interne et externe. Le pouvoir se donne à lire non dans les structures mais dans les relations dont la finalité est le maintien de l'ordre face aux déséquilibres engendrés en permanence et aux régulations nécessaires. Il est le révélateur des mouvements sous-jacents qui animent toutes les sociétés.

En liant parenté et pouvoir, Georges Balandier entend bien montrer toute la complexité de leurs relations qui échappe au regard structuraliste. Encore une fois, les seules structures ne peuvent permettre de comprendre le champ politique pensé par des relations exprimant des oppositions. L'exemple des Nuer du Soudan est en ce sens éloquent. La réduction des relations inégalitaires ne les élimine pas. Les lignages aristocratiques confèrent plus de prestige à ceux qui en font partie et les rituels d'initiation jouent un rôle politique en socialisant les individus et en les répartissant selon des classes d'âges à statuts différenciés. E. Edward E. Evans-Pritchard montre que les hommes les plus influents se caractérisent par une position clanique (aristocratie) et lignagère (chef de famille étendue), par leur situation de classe (statut d'aîné), par leur richesse (en bétail) et leur forte personnalité (ibid. : 70). Cela démontre que sans pouvoir distinct, le pouvoir opère par ces critères mais il ne se définit pas par ces 
structures «mais bien plus par des relations inégales qui le fondent et la dynamique des oppositions et des conflits qui les manifestent » (ibid., : 70).

Pour théoriser les relations entre stratification sociale et pouvoir, Georges Balandier fait de nouveau appel à Georges Gurvitch car les sociétés exotiques comportent des rapports inégaux liés aux hiérarchies et la tâche de l'anthropologie politique est de montrer les formes particulières prises par le pouvoir et les inégalités sur lesquelles il s'appuie. Il montre entre autres, par une analyse comparée entre les Tanala de Madagascar et les Indiens Comanches, que ces peuples disposent d'une double hiérarchisation: les hommes et les femmes pour les premiers sont hiérarchisés selon l'âge et la proximité des ancêtres, pour les seconds, les hommes dans la plénitude de la virilité et les femmes dans la plénitude de la fécondité sont placés au sommet. Ce sont là autant d'inégalités qui déterminent privilèges et obligations. Dans d'autres peuples, les stratifications sociales s'ordonnent selon les clans ou les lignages, en plus des classes d'âge, générant des différences de statuts auxquels sont liées des charges politiques et juridiques. Tout cela l'amène, comme l'a fait Georges Gurvitch, à identifier toute structure «à un équilibre précaire, sans cesse à refaire par un effort renouvelé, entre une multiplicité de hiérarchies » (ibid. : 103).

De même, la relation religion-pouvoir est patente. Il existe en effet une sacralisation du pouvoir dans la mesure où la personne royale est investie d'une supériorité imposant aux sujets une distance maintenue par les rituels et les cérémonies, sujets unis au souverain par la vénération ou la soumission. Mais de nombreux exemples dans les sociétés de tradition, montrent que même si la sacralisation conférée au souverain est d'origine divine ou historique (les Mossi de Haute Volta par exemple), le pouvoir n'est pourtant jamais acquis de façon définitive et il constitue un enjeu de compétition politique qui peut conduire à sa renonciation. Mais cette période de vacance de pouvoir et de désordre doit être comblée rapidement pour que l'ordre règne de nouveau. Se trouve encore exprimé ici l'aspect génératif d'un social jamais stabilisé car toute société est vulnérable, en équilibre instable, menacée d'entropie et soumise à la lutte contre les facteurs de dissolution pour remédier au désordre.

Cette approche dynamique permet à Georges Balandier de mettre en question le concept d'État en montrant qu'au-delà des distinctions légitimes avec l'État moderne, l'État traditionnel comporte des caractéristiques sociologiques peu différentes. "C'est un organe différencié, spécialisé et permanent de l'action politique et administrative, il requiert un appareil de gouvernement capable s'assurer la sécurité au-dedans et sur les frontières (...). En conséquence, l'organisation étatique traditionnelle est un système essentiellement dynamique exigeant le recours permanent aux stratégies qui maintiennent sa suprématie et celle du groupe qui le contrôle » (ibid., : 175-176).

61 Enfin il restait un dernier domaine d'exploration cher à Georges Balandier, celui des relations entre la tradition et la modernité rapportées à la situation coloniale qui engendre une mutation des formes politiques repérable par plusieurs indicateurs : la dénaturation des unités politiques traditionnelles (cas du Kongo dont les frontières ne correspondent pas aux frontières politiques établies par l'histoire qui entretient la nostalgie d'un passé unitaire), la dégradation par dépolitisation (la vie politique sous domination demeure clandestine ou s'exprime dans la culture qui le sépare $d u$ colonisateur), la rupture des systèmes traditionnels de limite du pouvoir (affaiblissement du prestige des chefs traditionnels et le pouvoir devient arbitraire par rapport au pouvoir des administrateurs coloniaux), l'incompatibilité des deux systèmes de pouvoir et d'autorité 
(entre le traditionnel-sacralisé et le moderne-bureaucratisé instaurant des rapports plus personnels et le possible jeu entre les deux), la désacralisation partielle du pouvoir (rois et chefs se trouvent sous la domination du gouvernement colonial et non des ancêtres) (ibid., : 188-193). Georges Balandier multiplie les exemples de nouveaux engendrements provoqués par la colonisation et la déstructuration qu'elle opère sur les stratifications sociales affectant l'action politique. Ce qui est montré, c'est non seulement l'effet produit sur les pouvoirs traditionnels, mais leur difficulté à se remodeler lors de la décolonisation. C'est encore ces tensions entre une tradition de pouvoir non disparue et les difficultés de son refaçonnage dans une forme moderniste qui sont évoquées, signe du mouvement incessant qui produit les sociétés. La modernité ne parvient pas à triompher d'une tradition qui revêt plusieurs formes (traditionalisme fondamental, formel, de résistance ou pseudo-traditionalisme) et qui serait pensée comme une continuité. L'anthropologie politique saisie dans une démarche dynamiste, suppose une attention aux termes de stratégies, de ruse, de manipulation. Elle s'attache davantage aux processus qu'aux structures et rompt avec une vision intégrée des sociétés faites au contraire de contradictions, d'imprévus et de désordres (ibid., : 221).

Le terme " générateur » va prendre de l'importance à partir d'une communication faite en 1967 à Bruxelles où Georges Balandier approfondit les relations entre tradition et continuité (Balandier G., 1968b). Il y réfute l'opposition entre deux pensées sociologiques, l'une conservatrice centrée sur les facteurs de continuité et attachée à observer les sociétés dans leurs invariants, l'autre "radicale» attentive aux transformations et aux changements structurels, pour proposer un "dépassement dialectique » de ces deux épistémologies (Balandier G., 1968b, 1971: 99). C'est bien le débat entre une sociologie des structures et celle des processus qu'il poursuit en montrant le renouveau de cette dernière lié non seulement au développement des sciences du moment mais encore à des effets de conjoncture : "Toutes le sociétés et toutes les civilisations sont de quelque manière à l'épreuve, les unes par excès de modernité difficilement contrôlable, les autres par une revendication de modernité difficile à satisfaire " (ibid., : 100). Certes, les "générateurs de changement » selon sa formule, sont plus opérants et plus visibles dans les sociétés dites développées (nouvelles sources d'énergie, automatisation de la production, agents stimulant la consommation des biens ou des symboles culturels, les techniques de communication et l'informatique), et elles connaissent une dynamique interne qui en fait des " sociétés de la mobilité généralisée ", mais c'est dans les sociétés sous dépendance, en "procès de développement ", que se saisit le mieux la dialectique du traditionnel et du moderne.

Celle-ci se repère dans trois générateurs de transformations: d'abord l'accession aux techniques n'affecte pas toute une population et crée des "îlots de modernisme » et donc des inégalités, ensuite la nouvelle organisation politique des indépendances et le système bureaucratique et gestionnaire qui l'accompagne efface ou affaiblit les formes d'autorité traditionnelle, enfin les nouvelles conditions d'éducation, l'ensemble des nouvelles formes de savoir, la diffusion des mass media provoquent une réelle révolution par l'information (ibid., : 103). Il s'agit alors de repérer les dynamismes en acte et les survivances dans les sociétés traditionnelles contre la certitude des mutations des sociétés dominantes, elles-mêmes liées à une certaine continuité. Les nouvelles questions posées aux sociétés concernent les tensions entre les forces antagonistes de maintien et de changement qui assurent la continuité et les transformations et qui affectent de manière inégale les secteurs d'une société, quelle 
qu'elle soit (par leur fonction sécurisante, la religion ou les cultures changent moins rapidement que la sphère technoscientifique par exemple). Ainsi est-il nécessaire de repérer dans nos sociétés des formes de contre modernité dont la fonction critique recourt à des formes archaïques d'existence pour se signifier (bandes, communautés, sectes) ou à des expressions culturelles (orientales ou folkloriques). La tradition n'est plus en continuité, comme dans les sociétés en développement, mais elle est syncrétique et forte d'une critique. Ainsi s'affirme la volonté de Georges Balandier de ne plus penser dichotomiquement les approches sociologiques car il devient nécessaire de penser dialectiquement tradition-modernité pour appréhender un terrain en transformation où continuent à se lire des formes de tradition, venant soit de l'histoire singulière des peuples (comme en Afrique), soit de l'emprunt transformé de traits du passé (tradition bricolée de la contre modernité).

Dans ces deux textes, Anthropologie politique et Tradition et continuité, Georges Balandier entend déconstruire tant un structuralisme radical que des théories dynamiques ne voyant que le changement, car ces deux approches demeurent incapables de révéler la complexité sociale engendrée par la dialectique tradition-continuité dans les sociétés anthropologiques comme dans les sociétés industrielles. Cette nouvelle approche appelle à observer les dynamismes différentiels sous-jacents produits par les générateurs des mutations. Dès lors une sociologie des mutations doit se construire sur ces enseignements révélés par des sociétés contrastées, toutes soumises au mouvement des transformations, aux tensions sociales qui en résultent et aux formes latentes non exprimées qui ne demandent qu'à émerger.

Une nouvelle nécessité : l'anthropo-sociologie générative

Dans son article Sociologie des mutations (1970) publié après un colloque d'octobre 1968 (faisant suite aux événements de mai), Georges Balandier entend bien - contre les sociologies du consensus valorisant l'intégration et la stabilité- renforcer son positionnement théorique en privilégiant les théories du conflit, attentives aux dynamismes des structures, ouvertes à la précarité des équilibres sociaux et orientées vers une conception des dynamismes sociaux irréductibles aux seuls dysfonctionnements ou aux menaces de l'ordre établi. Le terme de mutation est un concept nomade dont la définition dans les sciences sociales désigne pour Georges Balandier, en référence à Roger Bastide, « le passage d'une structure sociale à une autre ou d'un système de structures à un autre " (Balandier G., 1970 : 16). En contradiction avec les thèses marcusiennes de l'unidimensionnalité ou celle d'un État totalitaire, travailler sur un objet comme les mutations sociales entraîne une évolution des théories du changement puisque ses travaux sur les sociétés sous dépendance ont montré la pluralité des voies d'accession à l'état de société moderne et une multiplicité d'avenirs possibles. Il n'existe pas une homogénéisation des sociétés sous l'effet des puissances techno-économiques, mais des différenciations liées au fait que les transformations n'affectent pas de manière identique tous les secteurs d'une société, ni au même moment. Il vaudrait mieux, alors, parler de "dynamiques différentielles", contrairement aux théories évolutionnistes (plaidant pour le développement des sociétés dans son entier) ou les approches systémiques (appréhendant le changement de structures sous l'aspect de transformations globales).

Identifier les mutations suppose que soit reconnue l'existence de configurations latentes refoulées par la société officielle avant qu'elles ne se manifestent, ce qui requiert une attitude critique « capable de détecter les courants de changement sous 
les eaux mortes de la continuité » (ibid., : 26). Cette identification est rendue difficile pour plusieurs raisons: d'abord parce que se conjuguent trois temps dans le même moment: le poids du passé (la continuité), les événements récents, et les éléments potentiels des formes sociales à venir. Ensuite, parce que les "générateurs " du changement (informatisation, médias, etc.) n'entraînent pas une mutation immédiate de la société comme le montre l'exemple des révolutions qui émergent sous l'effet d'une conjonction de facteurs et de leurs combinaisons autonomes et de conditions permettant leur accomplissement. Dans ce cas, les conjonctures comptent plus que les structures. Le programme de recherche consiste dans ce cas à repérer «le jeu de la différence et de la répétition" dans une double direction: celle de la recherche de " processus par lesquels une société devient créatrice de différenciation et non plus de répétition ", celle de la détermination "des limites et des variations à l'intérieur desquelles la société reste elle-même » (ibid., : 30).

Les théories développementalistes, selon lesquelles les dynamiques internes seraient les vrais générateurs de la mutation, ignorent ou minorent le rôle des dynamiques du dehors et ne permettent pas de montrer - s'agissant par exemple des sociétés en développement - comment leurs façons d'accéder à la modernité sont induites par les pays dont elles dépendent. C'est bien cette nécessité de tenir ensemble les dynamiques internes et externes qui prévaut en cherchant des indicateurs dans les désajustements, les inadaptations, les déviances ou les contestations par rapport aux règles établies par la société officielle, dans des agents créant des ruptures (communautés ou collectifs de dissidence), dans les signes et les langages (de rupture, révolutionnaire, technique, messianique) propices à la réalisation d'un imaginaire social favorisant la formation d'utopies, ou encore dans des lieux où la mutation entraîne la société dans son mouvement (ibid., : 37).

La prise en compte conjointe des dynamiques du dedans et des dynamiques du dehors va être théorisée dans le chapitre fondateur intitulé « Dynamiques sociales » dans Sens et Puissance, les dynamiques sociales (1971, 1986 : 13-74). Les générateurs contribuant à faire un social pluriel et en perpétuelle déstabilisation témoignent d'une production sociale et ceci va amener "naturellement » Georges Balandier à qualifier sa démarche de "science sociale générative " dans l'objectif de décrypter les tensions et les crises qui résultent des dynamiques dominantes du dehors. Ceci rend encore inadéquate la seule considération des structures a-historiques inattentives à la fois à ce que les sociétés font et défont et aux processus de transformations introduits par une extériorité qui impose d'autres manières de faire, déstabilisantes. La question posée revient à savoir comment s'opèrent la coexistence de formations sociales d'âges différents et le passage d'un système structurel à un autre. C'est là un objectif théorique en phase avec les mouvements que connaissent les sociétés : «Les recherches nouvelles conduisent à mieux mesurer l'espace de liberté et de spécificité présent en toute société. Elles révèlent, par une démarche que l'on peut qualifier de "générative", à quel degré les configurations sociales sont mouvantes : constamment en voie de se faire et de déterminer leur sens » (ibid., : 9).

Pour construire cette approche générative, Georges Balandier va reprendre en les étoffant, les analyses critiques qu'il a déjà formulées à propos des sociologies évolutionnistes ou développementalistes et s'intéresser aux sociologies du conflit qui dévoilent certes les processus de changements mais pas les dynamiques sociales. C'est l'anthropologie dynamiste d'Edmund R. Leach ou de Max Gluckman qui lui paraît la 
plus remarquable, en ce sens qu'ils s'efforcent « de saisir la dynamique des structures tout autant que le système formel de relations qui les constituent» (ibid.,: 34). De même sera-t-il sensible à l'analyse des systèmes et aux modèles cybernétiques d'Amitai Etzioni qui propose « une théorie de l'énergie sociale " pour déterminer les modes de transformations en s'opposant en cela aux théories fonctionnalistes recourant à l'intégration. De plus, sa théorisation des dynamismes du dehors comme agent de transformation des sociétés anthropologiques s'étoffe de références aux travaux d'Edmund R. Leach sur les Kachin de Birmanie et Max Gluckman sur les Zoulou de l'Afrique du Sud. Le premier a montré comment il était nécessaire de prendre en compte les relations entre les dynamismes internes et externes pour comprendre l'oscillation de ce peuple entre le pôle démocratique et le pôle aristocratique, leur instabilité ou leurs ajustements culturels, et le second a découvert que les dynamiques externes agissaient différentiellement en fonction des clivages de la population Zoulou. Georges Balandier avait lui aussi insisté sur le fait de penser les relations entre les sociétés dominées et dominantes et de les envisager dans une totalité pour comprendre la situation coloniale. Toutes ces recherches convergent vers la nécessité de concevoir une nouvelle sociologie attentive aux relations entre les secteurs qui composent une société plurielle n'échappant pas aux rapports d'extériorité (internationaux), et apte à relever le défi consistant à saisir la société « comme un système dynamique en oeuvre et situé dans la totalité de ses environnements » (ibid., : 41). Toutes les sociétés sont soumises à la précarité de l'ordre social qui oblige à dépasser la dualité statique/ dynamique pour comprendre comment cet ordre assure la continuité.

Cette notion de « système dynamique » mérite d'être clarifiée selon Georges Balandier. Penser la société comme un système (un grand système) ou résultant d'un accord entre plusieurs systèmes, suppose que la définition du terme système ne se circonscrive pas à une interdépendance liant les unités qui le constituent, mais implique des dynamismes en raison même des différences entre elles qui ne sont pas traitées de manière équivalente. Cela produit des tensions et une instabilité qui rendent vulnérables les éléments qui composent ledit système. Par exemple, des différences de nature comme l'âge, le sexe ou la parenté sont converties en différences sociales et font partie d'un système en même temps qu'elles génèrent des tensions qui le menacent et qui peuvent le remettre en cause (ibid., : 51). La question se complexifie quand il s'agit des relations hiérarchiques entre les sociétés (sociétés dominantes et dominées) desquelles naissent des tensions et une dynamique pour créer de nouvelles combinaisons: "L'analyse "systémique", quels que soient ses limitations et ses artifices, manifeste une liaison nécessaire du système et de la dynamique » (ibid., : 53).

71 Une autre interrogation concerne le rapport entre la dynamique sociale et les niveaux de la réalité sociale que Georges Balandier va théoriser à partir de la sociologie de Durkheim (les niveaux structurels), de l'histoire de Braudel (les niveaux de temporalités : la durée brève, la durée avec un rythme plus large et plus lent et la longue durée) et du néo-marxisme (le niveau économique). Les dynamismes sociaux sont engendrés par les crises ou les conflits issus des relations entre les niveaux composant une société. Ainsi à partir de deux niveaux structurels de la sociologie durkheimienne que sont les institutions et les représentations collectives, des conflits peuvent naître de leur interaction: les représentations collectives plus créatives n'entraînent pas immédiatement une transformation des règles et des normes institutionnelles. Cette discordance, ou « non-correspondance » entre les niveaux de la 
réalité sociale peut être cependant source de progrès car l'anomie engendre de nouveaux ajustements.

Il reste un autre domaine d'exploration des dynamismes sociaux tenant cette fois à la possibilité et à la créativité dynamique des individus, ce qui renvoie à leurs pratiques. Celles-ci vont de la conformité (la soumission à l'ordre établi), à la stratégie (l'utilisation de la règle dominante à ses avantages), à la manipulation (acquérir un avantage mais sans respecter les règles et les normes), à la contestation (remise en cause de l'ordre social et ébauche d'une contre-société dans la société officielle). De nombreux exemples tirés de l'anthropologie viennent illustrer les concepts de stratégie et de manipulation présents aussi en toute société et que les circonstances rendent apparentes, notamment quand existent une rareté ou des inégalités par exemple.

Une telle approche conduit à poser des principes directeurs d'une théorie générative pour penser le social : « Toute société est plurale et, par là même, constamment en voie de se faire et de se définir. Sa définition scientifique ne peut être que générative " (ibid., : 294-295). Il ne suffit pas alors de reconnaître l'hétérogénéité des formations sociales ou les différentes temporalités, mais il est nécessaire de considérer une réelle dynamique différentielle en œuvre au sein des sociétés, « rien n'est donné, rien n'est jamais acquis » (ibid., : 69). De plus, une telle sociologie doit considérer dialectiquement la continuité/discontinuité, les répétitions/différences, en recherchant ce qui est réellement nouveau dans les discontinuités et en repérant les liens entre les discontinuités et les continuités les plus profondes. Les sociétés sont ainsi saisies en création permanente, à la fois « donné et projet » (ibid., : 70). En outre, les pratiques sociales permettant de voir comment les sociétés s'expriment, se forment et se transforment doivent être considérées. Enfin, il est nécessaire de prendre, ensemble, les dynamiques du dehors et du dedans. Les dynamiques sociales ne se réduisent pas aux seuls changements dont certains participent de la reproduction. Dès lors, la présence dans une même société de configurations d'âges différents assurant à la fois conservation et transformation, entraîne une interrogation sur les mutations sociales qui, sous la forme de révolutions, " provoquent moins l'irruption de l'inattendu que l'accélération de processus depuis longtemps à l'œuvre, l'émergence de configurations potentielles (...). On comprend d'autant mieux ces modes d'interprétation que l'on admet la "définition" dynamiste (et générative) de la société » (ibid., : 298).

Ces deux textes, Sociologie des mutations et "Dynamiques sociales" peuvent être considérés comme deux temps d'un même processus consolidant une démarche anthropo-sociologique générative, une épistémologie en phase avec les grandes transformations que connaissent toutes les sociétés. Un troisième texte, Anthropologiques (1974) renforce cette conception d'une société en création collective et jamais achevée, toujours en voie de se construire et de se donner un sens, soumise à un ordre approximatif et à une vulnérabilité : "Ces constatations entraînent à l'élaboration d'une science sociale générative, retrouvant ainsi l'enseignement d'une épistémologie moderne qui oriente vers des interprétations définies en terme d'action et interactions complexes, et en termes d'engendrement " (Balandier G., 1974: 24-25). Cet ouvrage contribue à la solidification de la démarche générative et à sa légitimation dans le champ des sciences sociales en montrant son caractère heuristique par le dévoilement de logiques en œuvre dans toutes les sociétés ${ }^{5}$. Les logiques dévoilées par Georges Balandier sont celles qui concernent des «données premières" de l'ordre social associant des faits de nature et des faits de culture, comme les rapports entre le 
masculin et le féminin, entre les générations ou entre les stratifications sociales. Il s'agit de montrer les dynamiques générées par les systèmes d'inégalités et de domination relativement aux dimensions comme le sexuel, les âges et les hiérarchies sociales qui sont des anthropo-logiques.

Ancrée dans les mouvements de libération de la femme contre la domination masculine des années 70, la réflexion de Georges Balandier va porter sur une analyse des rapports entre les sexes, non pas d'un point de vue structurel, mais dans la manifestation des tensions entre eux. Cette relation homme-femme est un révélateur des inégalités, ce qui explique les contestations symboliques ou réelles pour les remettre en cause. Le détour par les sociétés anthropologiques permet de montrer que les racines de "la domination mâle se sont enfoncées et multipliées dans les couches les plus profondes des sociétés et des consciences. La subversion féministe tente maintenant de les arracher, de produire une révolution plus corrosive que celle visant la seule élimination des rapports de classe (...). Les revendications féministes radicalisées ne cherchent plus à assurer la différence et l'altérité. Elles les maintiennent au contraire et tentent de faire surgir la société cachée, celle que j'ai dite "société féminine" tout au long de l'analyse anthropologique. En voulant couper les racines du mâle, elles reposent en termes désirés révolutionnaires un vieux problème : celui de l'articulation des sociétés femme et masculine, de leur connaissance et reconnaissance mutuelle » (Balandier G., 1974 : 82-84).

De même Georges Balandier relève un autre lieu de tensions dans les conflits d'âge et dans les affrontements entre générations (père/fils, aînés/cadets). Cette relation tensionnelle entre les jeunes et le monde adulte se traduit par des réactions différenciées allant d'une intégration active à une revendication plus politique par la création d'une anti-société ou d'une contre culture dissociée de la société globale. Cette coupure entre les générations produit des dynamismes sociaux résultant de la précarité de l'équilibre entre coopération et opposition. Le retour à l'analyse des sociétés autres montre toute la complexité des fonctions sociales qui varient selon cultures, relativement à la répartition selon les tranches d'âge, aux divisions générationnelles ou aux sexes. Pour Georges Balandier, "L'âge et le sexe, matériaux premiers et toujours présents, donnent à toute société son infrastructure la plus profonde, plus enfouie et moins vulnérable que celle résultant de la production de la vie matérielle » (ibid., : 135). Dans les sociétés de la modernité, les crises apparaissent à travers les antagonismes de classes sexuelles ou de classes d'âge.

Enfin, il existe une dynamique tensionnelle produite par les différences relatives à la stratification sociale générant d'autres inégalités et d'autres systèmes de domination. Après une analyse critique de la notion de "classe" montrant comment les stratifications ont toujours stimulé la réflexion sociale et politique, Georges Balandier définit la stratification sociale comme "un arrangement ordonné incorporant les hommes, les richesses, les pouvoirs et les symboles. Elle requiert des différenciations, une organisation hiérarchique des éléments différenciés, un "ordre" liant les hiérarchies dans un système de large extension » (ibid., : 146). Cet « ordre » est porteur d'inégalités et de dominations. Ainsi se retrouvent les principes théoriques d'une lecture de la stratification sociale. Elle implique une totalité (modes de production, symboles, accès aux valeurs culturelles, etc.), se saisit comme un système complexe (rapports d'inégalités et hiérarchies interagissent), comme une hétérogénéisation des formations sociales (agencements d'âges différents), comme un système dynamique (corrélation 
entre les inégalités et l'intensité des dynamismes internes) et comme une tension entre forces de cohésion et de rupture, entre les modes d'accès à des cultures hiérarchisées dans la société.

78 Georges Balandier dresse bien ici, toujours depuis les apports des sociétés de tradition, une anthropologie critique de la modernité dans la mesure où les relations de domination se rapportant au sexe, aux âges et aux hiérarchies sociales produisent des tensions ouvrant aux mutations dans toutes les sociétés. Dès lors, les frontières entre la sociologie et l'anthropologie n'ont plus lieu de s'exercer pour être en harmonie avec une démarche générative de la modernité dont les champs concernent les rapports nature-culture, les essais de re-personnalisation du rapport social par la recherche de nouvelles formes d'identité, et les essais de restitution de sens par la création culturelle, par la perméabilité de la vie quotidienne à de nouvelles formes de sacré. Autant de crises consécutives à l'accélération des changements propres à toutes les sociétés. Se trouve là esquissé le passage à une « anthropologie généralisée ».

Cette période de renforcement théorique d'une démarche générative se caractérise par l'usage explicite des termes "générateurs » et de "science sociale générative » et par l'union nécessaire de deux disciplines que sont l'anthropologie et la sociologie dont les épistémologies doivent s'accorder pour penser les mutations sociales que connaissent toutes les sociétés. C'est bien dans ce moment que s'affirme la légitimité d'une démarche générative critique dans la mesure où elle a pour tâche de dévoiler les turbulences qui sourdent dans les sociétés, produites par des tensions entre des structures " anthropo-logiques » socialement inégalitaires ou par la dialectique entre les dynamiques du dehors et les dynamiques du dedans.

Cette perspective critique appelle ainsi à dévoiler les discordances de temporalités entre les transformations induites par la culture qui précèdent leur prise en compte par le normé et l'institué appelés aussi à se défaire. C'est bien cette instabilité née de contradictions fragilisant les équilibres sociaux qui est majorée. Cette affirmation de l'approche se réalise sous l'effet d'un double mouvement théorique ancré à la fois aux apports antérieurs et à l'état des sciences sociales du moment, c'est-à-dire à une filiation à une dynamique différentielle des sociétés dévoilée depuis ses premiers travaux qui sert d'appui pour repérer, dans les théories sociologiques du moment, des éléments renforçant la légitimité d'une connaissance des sociétés se faisant. Celle-ci s'effectue soit par une distanciation de l'évolutionnisme, du développementalisme, du structuralisme, d'une sociologie du conflit attentive au changement mais pas aux dynamiques, d'une sociologie marcusienne ou de celle des marxistes orthodoxes, soit par une affiliation franche, quand il s'agit des pensées de l'anthropologie dynamiste anglo-saxonne ou mesurée, quand les théories systémiques n'envisagent pas les éléments comme hiérarchiquement situés dans leurs interactions.

La pensée générative de Georges Balandier s'inclut ici dans une période de la fin des années 60 et des années 70 marquée par une distance au structuralisme mécaniste (à partir duquel Bourdieu constituera aussi une sociologie où le relationnel entre les structures est pris en compte dans la notion de « champ " et non de "système »), et par le développement de la pensée systémique orientée dans deux directions, celle des analyses stratégiques de Michel Crozier et d'Erhard Friedberg, celles des influences cybernétiques telles qu'elles se développent d'un point de vue anthropologique dans la pensée d'Edgar Morin ou dans les modélisations de Jean-Louis Le Moigne entre autres. L'épistémologie générative de Georges Balandier va aller s'amplifiant jusqu'à penser Le 
Grand Système en s'enrichissant de nouvelles théories comme la science du désordre ou la théorie du chaos qui prennent leur essor à partir des années 80 .

L'amplification de l'anthropo-sociologie générative aux sociétés de la modernité

(1980-2003)

Georges Balandier justifie le passage à une "anthropologie généralisée ", celle de nos propres univers sociaux et culturels, non par des raisons de confort devant des difficultés liées au terrain ou à une pratique ethnologique souvent critiquée, mais par un principe moral visant à établir un équilibre avec une "anthropologie des privilèges » caractérisée par des pouvoirs exorbitants liés à sa capacité de se substituer au regard et à la pensée de l'autre. L'anthropologie généralisée transfère à nous-mêmes la même démarche qui s'applique aux sociétés et aux cultures autres en les ouvrant à celles qui viennent des mondes de la « différence » (Balandier G., 1997b : 35). C'est ainsi que les grandes transformations des sociétés de la modernité et de la surmodernité vont s'éclairer par ce détour par les sociétés de tradition au moyen d'une démarche générative attentive à décrypter dans la modernité, la "théâtrocratie » en acte (Le Pouvoir sur scène, 1980), l'omniprésence du pouvoir (Le Détour, pouvoir et modernité, 1985) et celle du désordre (Le Désordre, éloge du mouvement, 1988) et, dans la surmodernité, le poids des transformateurs que sont la techno-science et l'économie ainsi que leurs effets sur la définition de l'homme (Le Dédale, pour en finir avec le XXe siècle, 1994; Le Grand Système, 2001). Ici vont s'amplifier les principes d'une société mobile, ouverte plus à la production qu'à la reproduction, régie par une instabilité entre l'excès d'ordre et le trop de chaos, principes renforcés par une épistémologie issue d'une science du désordre transférée aux sciences sociales.

L'éloge du mouvement dans la modernité (1980-1993)

Dans Anthropologie politique, Georges Balandier au moyen d'une démarche dynamique accordait moins d'importance aux structures qui signifient le pouvoir qu'aux fonctions et aux effets sociaux qu'il engendre. Il montrait comment ce pouvoir est un facteur d'ordre contre les formes de désordre obligées menaçant toutes les sociétés. Le pouvoir est en outre soumis à une précarité pouvant aller jusqu'à son élimination. Dans Le Pouvoir sur scènes (1980), la théorisation se construit sur le rapport indissociable entre l'ordre et le désordre, sur le principe « d'une thermodynamique sociale » qui exprime la fonction du désordre au sein de l'ordre. Sans qu'elle soit nommée comme précédemment, la démarche générative s'amplifie dans un sens qu'Edgar Morin lui donnera plus tard en illustrant le principe de l'order from noise, c'est-à-dire le principe de générativité consistant en la transformation du désordre en ordre, où, ce qui était bruit pour le système, se transmute en un élément constitutif de ce système, ce qui provoque l'auto-organisation du système, lequel se complexifie (Morin E., 1982 : 290).

La dynamique du pouvoir

Dans Le Pouvoir sur scènes, Georges Balandier n'effectue pas ce travail théorique sur le principe directeur de son analyse - ce qu'il fera ultérieurement dans Le Désordre (1988) - mais il entend bien dévoiler la mise en scène du pouvoir politique pour assurer sa conservation par la "théâtrocratie » et la dramatisation, discriminer le désordre en son sein produit par la dérision, les ruses ou les transgressions, montrer comment l'envers de l'ordre (le désordre) fait de l'ordre, souligner la rationalisation du pouvoir usant des technologies et de l'artifice des images dans les médias pour maintenir les dispositifs symboliques, insister enfin sur la contestation contre cet ordre, faite elle aussi, d'émotions, d'affects, voire de violences qui ne sont pas exclusivement 
symboliques. C'est bien l'amplification d'une démarche générative appliquée au politique qui se lit ici dans la mesure où Georges Balandier révèle les turbulences enfouies produisant les sociétés au-delà de leur apparence. Il part de l'hypothèse selon laquelle existe toujours présente, toujours gouvernante dans l'arrière-scène, une «théâtrocratie » de la société et de l'organisation des pouvoirs (Balandier G., 1980 : 11). En considérant le monde social comme une scène constituée autour d'un drame dont les acteurs seraient les pratiques collectives «tenants et aboutissants des pouvoirs et des actions sociales ", il postule que cette mise en scène montre "les jeux de la société qui la font et la défont » (ibid., : 12).

Georges Balandier révèle alors les processus sous-jacents de la théâtrocratie ordonnant l'efficacité pratique du pouvoir politique qui tient, non pas par le seul usage de la force ou d'une violence non domestiquée dangereuse pour son existence, mais par la « manipulation de symboles et leur organisation dans le cadre cérémoniel » (ibid., : 16). Cette théâtralité politique qui permet la subordination, se déploie dans la mise en scène des héros reconnus en raison de leur force dramatique, s'objective dans la spectacularisation orchestrée par les médias et la propagande ainsi qu'à l'occasion de fêtes manipulant les symboles (fêtes nazies, défilés où s'affiche l'idéologie dominante, commémoration ou exécution comme affirmation de la force) et se réfère soit à une rhétorique où les mots participent à la manipulation du réel, soit au silence.

Le retour aux formes de pouvoir des sociétés anthropologiques (Afrique, Amérique latine, Chine) ou des régimes traditionnels, permet de montrer le rapprochement de ces modèles avec ceux des sociétés de la modernité : «Tout se rapporte au souverain, se symbolise et se dramatise par lui: relations à l'univers, au monde extérieur, au territoire politique, au passé et donc à l'histoire, à la société, à ses œuvres. Il est au cœur de la représentation (...). Plus, il est lui-même, par son corps, lieu de représentation " (ibid., : 41). Ici, ce qui est montré, c'est bien l'impossible stabilité de l'unité dans une société ce qui amène les pouvoirs à produire «des effets ayant une forme de compensation » : « La société ne "tient" pas par le seul moyen de la coercition, des rapports de force légitimés, mais aussi par l'ensemble des transfigurations dont elle est à la fois, l'objet et le réalisateur. Son ordre reste vulnérable; il est porteur de perturbations et de désordre, eux-mêmes générateurs de ruses et de dramatisations montrant le pouvoir en négatif » (ibid., : 50-51).

Présents dans toutes les sociétés, les ruses et le désordre qui inversent symboliquement l'ordre, se décryptent dans les figures de l'ironie, de la rébellion et du mouvement. Ainsi, le ridicule est une arme du pouvoir pour préserver l'ordre chez les Esquimaux ou au Japon. Chez les Ashanti du Gana, la critique du pouvoir se fait par des astuces indirectement adressées au chef, rôle joué par les satiristes dans nos sociétés qui véhiculent le désordre en le désamorçant. L'analyse montre bien que « sans faire la part du mouvement, sans reconnaître et gérer le désordre qu'il ne peut pas ne pas engendrer, l'ordre réduirait la société à l'état d'astre froid» (ibid., : 48). L'ordre est vulnérable, et derrière les apparences se met en scène le désordre. Le bouffon dans les sociétés anthropologiques peut dire la vérité, mais sur le mode de la dérision qui la rend moins offensive. Le bouffon cérémoniel, chez les indiens américains, introduit le burlesque dans le sacré en faisant appel à la sexualité, à l'obscénité et, comme tel, il est à la fois « rupteur d'ordre et il en est le facteur » (ibid., : 66). Cette figure ambiguë a une fonction cathartique qui se maintient dans les cultures populaires, dans la caricature (politique ou anticléricale), dans les comédies burlesques affrontant le faible et le 
dominant. Dans les sociétés les plus développées, la culture et les pouvoirs technocratiques créent une culture conforme à leur image, faite de codes et de chiffres réduisant ainsi « l'espace réservé au mouvement libre », au désordre, aux contestations régénératrices et font alors abstraction des "profondeurs où travaillent les formes perturbantes, l'inattendu, l'expérience novatrice", autant de contre systèmes en œuvre dans le système qui répondent par la négation aux exclusions (ibid., : 92). La générativité du social s'exprime bien ici dans des mises en scène où se lit cette unité tensionnelle entre l'ordre et le désordre, entre des forces conservatrices et des dynamiques du changement ouvertes au nouveau et à l'inattendu.

Dans ce social produit par la dialectique de l'ordre et du désordre, il est une autre voie qu'explore Georges Balandier, celle qui consiste à montrer que tout désordre n'entraîne pas la destruction de l'ordre contesté : « L'inversion n'est pas son renversement, elle en est constitutive, elle peut être utilisée à son renversement. Elle fait de l'ordre avec le désordre, de même que le sacrifice fait de la vie avec la mort, de la "loi" avec de la violence apaisée » (ibid., : 95). Ainsi, chez les Lugbara d'Ouganda, la femme occupe une position inverse à celle de l'homme dominant, elle se situe du côté de la nature sauvage, elle fait le mal et toutes les caractéristiques du désordre lui sont associées. Mais il existe aussi une « inversion de l'inversion » dans des rites où la présence masculine s'efface et où la femme s'associe au souverain. De même la figure du sorcier est celle d'un agent du désordre et du mal, un "ennemi de l'intérieur » qui innocente le pouvoir des maux sociaux et renforce sa position. Cette figure trouve son équivalent dans la modernité, dans les « irréductibles » à travers lesquels la confrontation de l'ordre et du désordre se maintient : ces ennemis internes sont sacrifiés en cas de crise pour que le pouvoir ne soit pas accusé et la collectivité innocentée peut retrouver son équilibre (ibid., : 105). Le pouvoir souvent manipule à son profit le procès d'inversion dans une théâtralisation pour restaurer son autorité, et le désordre se convertit en légitimation de l'ordre, sans cependant que ce soit là une règle, car de nombreux exemples confirment que les inversions conduisent à des confrontations réelles. Le désordre devient un moyen de renverser l'ordre.

Enfin, Georges Balandier va montrer comment la théâtralisation persiste dans nos sociétés. Elle est présente dans la représentation du pouvoir qui se poursuit malgré la technicisation et la rationalisation des moyens qu'il utilise pour affirmer sa puissance ou sa compétence. Ceci se réalise par exemple à l'occasion de la mort d'un grand homme d'Etat par les pratiques ritualisées ou dans la dramatisation des débats politiques obligeant les acteurs à trouver "des coups" pour restaurer la vigilance défaillante du spectateur devant l'omniprésence de l'État-spectacle (ibid., : 153). La modernité politique n'efface pas la charge symbolique de la fonction souveraine malgré ses différences avec les sociétés exotiques, et les investissements mythiques demeurent. Georges Balandier souligne qu'existe aussi une dramatisation bien au-delà des frontières du politique, notamment dans le théâtre de la dérision où le comédien retraduit le bouffon rituel des cérémonies traditionnelles en opposant le désordre à la conformité. Cette charge se manifeste en outre dans des contestations spectaculaires (écologie, communautés rebelles), ou bien encore dans le recours aux nouvelles religiosités ou dans les fêtes, si elles conservent leur fonction transgressive malgré l'emprise de l'économie ignorant la fonction politique.

90 Par cette méthode comparative, Georges Balandier entend donc établir une meilleure connaissance de nos sociétés dans lesquelles la présence des mythes et des rites 
demeure constante dans la lutte de l'ordre contre le désordre tout en prenant d'autres formes: cette lutte "change de nature en s'universalisant et en disposant de technologies modernes de dramatisation; et comporte des enjeux dont le prix ne cesse de s'élever » (ibid., : 185).

Cette perspective générative du social à partir de ce que révèlent les sociétés autres, va se poursuivre dans Le Détour, pouvoir et modernité (1985). Georges Balandier fait ici le parallélisme entre le moment de chaos que traversent actuellement les sociétés de la modernité et la période de l'interrègne provoquée par la mort du chef, au sens où ce sont des périodes de mutation caractérisées par «ce moment où les formes s'effacent sans que d'autres aient pu encore les remplacer et imposer leur existence " (Balandier G., $1985: 8$ ). C'est du rapport entre le désordre et l'ordre dont il va de nouveau être question mais avec des angles originaux d'investigation à propos du pouvoir et de la modernité, deux notions qui renvoient l'une à l'autre car la modernité est "mobilité généralisée ", ouverture à de nouveaux possibles et opère des ruptures. S'agissant du pouvoir, Georges Balandier part de l'hypothèse « qu'il s'agit moins d'un effacement que d'un changement de régime (ou d'âge) quant à la nature des moyens et quant aux procédures génératrices d'effets d'ordre : il n'est pas accompli, il est en voie de se faire par l'accès aux nouvelles ressources en matière de technologie, de symbolique et d'imaginaires politiques» (ibid., : 13). Quant à la modernité définie comme étant «le mouvement plus l'incertitude", c'est à la clarification de cette définition et à l'incompréhension qui résulte de cette dynamique auxquelles va s'attacher Georges Balandier en retenant de ses premiers travaux africains que la modernité n'efface pas toute antériorité, ni la mémoire, ni la tradition qui cheminent en elle.

La question du pouvoir occupe la première partie de l'ouvrage et c'est sous l'angle des « anthropo-logiques» comme le sexe et son rapport avec le social qu'il est théorisé mais en accordant une place importance au corps dans la politique. Le corps apparaît comme une symbolisation du pouvoir du roi ou du chef, signifié tant par les marquages de l'apparence que par sa mort qui n'exprime pas la fin de la royauté car le corps physique du roi se double d'un corps mystique. L'importance du corps s'exprime aussi par la dérision ou la transgression comme remise en cause de l'ordre (dévergondages, homosexualités). Comme tel, le corps est le révélateur de l'ordre et du désordre. Dans les rapports entre les sexes, il exprime le désordre et en même temps le pouvoir d'une morale (adultère, inceste), ou signifie le rapport au pouvoir (la symbolique de la puissance, dont celle du sexe masculin) ou se situe aussi dans le hors sexe (comme la figure de l'eunuque associé au pouvoir).

Les signes de la dynamique du pouvoir se lisent dans la symbolique pour y accéder, pour asseoir son efficacité et son ordre par le consentement car il est menacé constamment, pour assurer une logique de manipulation par l'usage du discours. Le pouvoir sait aussi utiliser la ruse pour éviter les conflits, il se met au service de tous mais il est le gardien des inégalités et cherche ainsi à dire l'ordre sans le dévoiler. Ruse encore, mais cette fois contre lui pour le contester ou le subvertir et qu'il s'efforce de convertir en renforcement, en inversant sa finalité. C'est bien cette dynamique du pouvoir qui est révélée dans cette dialectique de l'ordre et du désordre et qui contribue à faire la société, dynamique qui est aussi approfondie à partir de la modernité.

Le mouvement dans la modernité

Dans ses travaux antérieurs, Georges Balandier utilisait déjà les notions de modernité ou de modernisation depuis les sociétés sous dépendance dans l'objectif d'édifier une 
sociologie générative. Ici, le même projet se développe mais par un approfondissement théorique des notions-clés permettant de comprendre le mouvement dans les sociétés de la modernité. Ainsi distingue-t-il dans Le Détour, le modernisme qui se modèle sur les mouvements de surface, de la modernité qui impose l'exploration de nouveaux possibles et ne se circonscrit pas à la quête d'un nouveau "nouveau » réduit aux apparences, mais elle révèle ce qui s'effectue en profondeur, le mouvement de fond, «le travail d'une société et d'une culture » (ibid., : 131-132). De même une différence est faite entre la modernité et la modernisation, la première étant ce vers quoi il faut aller, la seconde ce par quoi elle pourrait ou devrait être atteinte. Une autre différenciation existe entre la modernité et la postmodernité. La postmodernité désigne une manière de décrire les mutations des sociétés et des cultures et se veut être un mouvement de déconstruction de ce qui a été établi en paradigme ou en modèle, sans rupture avec ce qui précède. La modernité exaspère la rhétorique de la postmodernité (ibid., : 139-140). Mais c'est la modernité qui ici est l'objet essentiel de l'analyse. Elle est caractérisée par sa logique instrumentale et son efficacité ainsi que par une rhétorique lisible dans l'effacement du temps, la valorisation de l'éphémère, la conquête du présent et la recherche continue d'innovations fondée sur le changement pour le changement ou sur un changement empruntant au passé pour déconstruire et reconstruire ce qui est déjà là en empruntant à une culture extérieure (syncrétisme). Georges Balandier établit une revue de questions des critiques adressées à la modernité par Jürgen Habermas, Henri Lefebvre ou Jean Chesneaux, mais c'est une théorisation du changement social, des mutations ou des rapports à la tradition abordée dans ses travaux antérieurs, qu'il entreprend en filiation avec sa démarche générative. Déjà, les théories du changement social de type évolutionniste ou développementaliste avaient été l'objet de sa critique, car elles ne prenaient pas en compte la dynamique sociale et ne pouvaient alors pas conduire à faire surgir l'inattendu, l'aléatoire, les facteurs de ruptures, l'incertitude et les turbulences du devenir social (ibid., : 144). Il s'attache alors à préciser la notion de mutation - une notion difficile à identifier et à mettre à l'épreuve des faits - liée à l'idée de discontinuité et de rupture : "Elle ne surgit pas brusquement, à un moment donné, totalement apparente et immédiatement prise de conscience. Elle est masquée, cachée parmi les configurations latentes dont toute société est porteuse, destinées les unes à se réaliser, les autres, à avorter » (ibid., : 147). Le passage à une société inédite est difficile à définir par manque de recul. La question que pose alors Georges Balandier est de savoir comment les mutations sectorielles sont liées à la mutation globale. Ici encore, il s'agit bien de l'articulation entre les dynamiques différentielles d'un système dont les structures ne se modifient pas dans le même moment : « La modernité est l'expression de toutes ces tentatives » et elle se lit dans le partage des inerties et des mobilités (ibid., : 148).

Quant à la tradition, son opposition à la modernité est trompeuse. Elle poursuit son travail en interaction avec elle: "Tout ne change pas, et ce qui change ne se modifie pas en bloc " (ibid., : 168). Il existe bien une ruse du nouveau dans la mesure où la tradition peut paraître neuve et donner l'illusion de l'inédit. Ainsi, les mouvements de contre culture ou de contre modernité puisent dans le passé en créant une socialité communautariste ou tribale dans un pseudo traditionalisme recourant à des traditions refaites. L'anthropologie ne cesse de montrer le difficile effacement de la mémoire que les révolutions elles-mêmes ne peuvent dissoudre, et les échappées se font par des ruses avec la tradition, par un syncrétisme des croyances, par l'adhésion à de nouvelles 
religiosités, produisant une générativité du social par la création de formes sociales et culturelles nouvelles.

La théorisation de Georges Balandier sur la modernité vient renforcer ses idées premières issues des recherches sur les sociétés sous domination. Ici aussi l'approche générative plaide pour l'opacité née de la différenciation, de la complexité des transformations des sociétés pluralistes et rend illusoire le principe d'une unité au sein de la société ou l'idée d'une unidimensionnalité où toutes les sociétés seraient déterminées uniquement et en bloc par le pouvoir de la techno-science. Le détour anthropologique permet de comprendre le divorce entre la société et la culture qui deviennent étrangères l'une à l'autre. Il éclaire aussi les processus de dé-symbolisation de la raison instrumentale qui fabrique l'homme afin de ne pas « laisser notre avenir nous devenir étranger » et pour cela il fait apparaitre le rapport aux symboles, aux valeurs, aux croyances. Le détour dévoile aussi le travail de re-symbolisation en œuvre par l'essai de repersonnalisation du lien social, qu'il s'agisse de la création de cultures alternatives, de la revendication de valeurs libertaires, de la consolidation de réseaux de socialité, de la production de mouvements avant-gardistes, de la pluralité des religions ou encore de la production d'un imaginaire contre la rationalité économique. Autant de turbulences appelant à lire le désordre dans la société et les processus de la reprise de l'ordre.

C'est dans Le Désordre, éloge du mouvement (1988), que Georges Balandier va peaufiner sa démarche générative pour comprendre l'histoire réelle qu'écrivent les sociétés. Pour cela il s'appuie sur les débats théoriques des années 80 , notamment sur la situation de crise que connaissent la science et la culture liée à la régression des déterminismes et des stabilités et à l'accroissement des incertitudes (Le Pogam Y., 1994a, 1994b). Il établit des correspondances entre ses thèses et les débats scientifiques attentifs davantage au mouvement et aux fluctuations qu'aux structures, aux organisations et aux permanences. Il s'oriente vers la théorie du chaos qui conjoint ordre et désordre, ce dernier étant connoté d'une valeur heuristique dégagée de tout présupposé moral. En faisant une large part au désordre, à l'entropie, au doute, cette épistémologie des sciences relativise une théorie unifiante et plaide plutôt pour la complexité comme le montrent les travaux d'Edgar Morin $(1982,1985,1986)$. Cette épistémologie se renforce de la proximité avec la «biologie philosophante» et le développement de la notion d'auto-organisation (création d'un ordre par le système lui-même qui échappe à une maitrise) et du rapprochement avec les structures dissipatives d'Ilya Prigogine et Isabelle Stengers associant l'idée d'ordre et celle de gaspillage: «La dissipation d'énergie et de matière - généralement associée aux idées de perte de rendement et d'évolution vers le désordre - devient, loin de l'équilibre, source d'ordre » (Balandier G., 1988 : 54). Une création d'ordre se produit à partir du désordre, le chaos est devenu organisateur et fécond, et ce sont ces principes qui vont s'appliquer soit au vivant soit au social, en créant de nouveaux rapports interdisciplinaires. En transposant ces principes à la société, le postulat repose sur le fait que l'objet échappe à une maitrise totale et n'est contrôlé que partiellement. Dès lors sont récusées à la fois, une théorie substantialiste considérant un social comme un ordre global déjà là, et l'idée d'une société unifiée, conçue comme une totalité établie en permanence.

Cette approche de l'ordre et du désordre se renforce aussi de données philosophiques développées par Marcel Conche à partir des lectures de Platon et des stoïciens (1974) permettant d'approfondir la relation entre les deux termes: l'ordre représente une 
unité entre les éléments, dans le désordre les éléments d'un tout se comportent comme s'ils n'en faisaient pas partie, et dans ce cas il peut-être destructeur et créateur, car il engendre un gain d'ordre générateur d'un ordre nouveau.

Cette idée du social qui se construit l'amène à contester les théories sur la place du désordre de Raymond Boudon (1984) dans la mesure où l'individualisme méthodologique qu'il défend montre certes que la connaissance du social provient du jeu des acteurs et des interactions individuelles, mais «il ne pose ni la question du désordre dans le réel en commandant avec vigueur d'éviter le "piège du réalisme", ni celle du désordre en tant que catégorie ayant une fonction dans la logique explicative des fonctionnements (mode d'existence) et des transformations (mode de situation dans le temps) du social (...). L'individu absolu, par le primat accordé à l'individu sur le macro social, à l'élément sur l'ensemble, rend cependant mal compte des limites, des contraintes imposées à l'acteur et des désajustements qui en résultent. Il ne peut non plus expliquer un ordre de niveau supérieur (un méta-niveau) à partir de la seule agrégation des actions individuelles et du désordre partiel qui en est indissociable » (Balandier G., 1988 : 79).

101 Cette convergence épistémologique nouvelle, attentive au rôle organisateur du hasard, à l'ouverture des systèmes sur le dehors, aux interactions entre les éléments et les milieux, rencontre donc les fondements de la démarche générative de Georges Balandier et lui permet de revenir sur les sociétés de tradition soumises à l'épreuve des transformations et à celles de la modernité où prédominent le mouvement et l'incertitude. Toutes manifestent des configurations bouleversées, des réorganisations sous l'effet des interactions entre l'ordre et le désordre, des surgissements de l'inédit et de nouveaux engendrements dus au hasard et aux événements. Mais dans la tradition, le mythe et le rite participent de la construction et du maintien de l'ordre.

Ainsi les pratiques d'exorcisme visent à lutter contre les générateurs du désordre qui peuvent être des lieux suscitant la crainte comme les forêts, ou des personnages, comme la femme, objet de méfiance à cause de sa situation entre le monde socialisé et le monde sauvage à cause aussi de son pouvoir de fécondité et du sang menstruel lié à la vie et à l'impureté. Une autre figure est le cadet perturbant l'ordre de la séniorité qui fait naître du désordre entre les générations. Quant au sorcier, qui comme le souverain ou le décepteur (héros ou dieu dont les perturbations sont fécondes), il est détenteur d'un pouvoir destructeur qui le situe au dehors, mais il est aussi dedans car il réinstaure de l'ordre en transformant le négatif en positif (ibid., : 112). Le désordre dans les sociétés de tradition peut être mis en scène, par exemple dans la transgression rendant absurde l'idée du désordre. Ceci se réalise à l'occasion des récits ou des pratiques festives à fonction cathartique. Ici, le jeu accordant un espace au désordre est institué (par exemple dans le carnaval brésilien), il est contrôlé malgré la licence sexuelle et il renforce ainsi l'institution en renvoyant à l'ordre établi.

La pensée sociologique donne de la modernité l'image d'une désorientation liée à l'effacement des signes distinctifs et des classements sociaux devant les nouveaux modes de vie, une " ère du vide » où interfèrent des classes d'âge, des classes sexuelles et qui provoquerait la perte de cohérence des classes sociales, voire l'effacement des inégalités. Elle est décrite aussi par la montée de l'individualisme qui engendre la perte de l'idée d'une société comme ensemble construit où la modernité est définie par la postmodernité. Mais Georges Balandier va s'attacher à ouvrir sa thèse d'une modernité faite de mouvement et d'incertitude, et donc au sentiment du désordre qui devient un 
état, qui engendre une déperdition de sens par l'effacement des grands systèmes symboliques et explicatifs. La modernité conduit à la situation d'étranger dans sa propre société à cause du pouvoir de techno-science - notamment dans les sciences du vivant - qui affecte notre corps qui était programmable par les contraintes socio culturelles et qui devient fabricable par l'emprise des techniques. Ce désordre se repère aussi dans les événements économiques comme les krachs boursiers ou dans les maladies comme le Sida, dans l'expression de la violence, le vandalisme, le hooliganisme ou le terrorisme.

Mais Georges Balandier ne se circonscrit pas à ce seul aspect, et sa démarche dialectique l'engage à observer les réactions et les réponses au désordre dans trois directions. D'abord dans le totalitarisme, fondé sur l'utopie d'un ordre rétabli définitivement, négateur en cela de la créativité des hommes et des transformations de la société dont les pouvoirs peuvent être dissimulés par la techno-science. Ensuite dans des réponses de la personne, par le nomadisme ou par son image opposée, l'ancrage, fait de repli sur une culture ou un social imprégnés de passé et de tradition ou encore, dans le retour au sacré institué ou aux religiosités comme «exigence personnelle de sens» (ibid., : 221). Enfin une réponse pragmatique se manifeste contre le désordre, celle de l'ordre par le mouvement qui se lie dans la prise d'initiative, dans la prise de risque, dans la célébration de l'esprit entrepreunarial, dans l'esprit de profit et dans la valorisation de la performance.

Pour Georges Balandier, ordre et désordre sont étroitement liés et il n'est plus de partage entre les sociétés apolliniennes qui privilégient la mesure, l'ordre et l'harmonie et les sociétés dionysiennes marquées par l'excès et l'effervescence. Les certitudes n'existent plus dans les sciences de l'homme qui sont bousculées face à cette mobilité des sociétés et l'interpénétration entre les sciences est devenue nécessaire pour l'interpréter. Ce qui importe, c'est la prise en compte de la vitalité sociale, celle de la société civile et non celle des appareils, "autrement dit, faire l'éloge du mouvement, dissiper les craintes qu'il inspire, et, surtout, ne jamais consentir à exploiter la peur diffuse qu'il nourrit » (ibid., : 245).

Dans cette période marquée par la publication de trois ouvrages, Georges Balandier réaffirme en les approfondissant par une sensibilité à l'épistémologie du moment, les grands principes constitutifs de sa démarche générative appliquée à une anthropologie généralisée au moyen d'une méthode comparative entre les sociétés de la tradition et celles de la modernité. La dynamique des pouvoirs et de la modernité déjà analysées dans ses travaux antérieurs l'oblige, par une théorisation omniprésente de la relation ordre-désordre, à rechercher de nouvelles argumentations qui sont autant de preuves attestant de la production continue du social et de la culture. Mais le pouvoir dont il s'agit n'est plus seulement le pouvoir politique, et progressivement Georges Balandier déplace la question aux pouvoirs de la techno-science et à ses effets sur l'homme.

Les « grands transformateurs » dans la surmodernité (1994-2003)

107 Dans Le Dédale, pour en finir avec le $\mathrm{xx}^{e}$ siècle (1994), Georges Balandier va faire émerger deux notions, celle des sociétés de la « surmodernité » et celle de «nouveaux Nouveaux Mondes ", qui seront amplifiées dans Le Grand Système (2001). Son projet demeure identique : saisir le mouvement actuel des sociétés en identifiant les "générateurs de changement» qu'il va progressivement désigner comme des "grands transformateurs » (Balandier G., $2003: 239$ ).

Des constructions labyrinthiques 
Saisir le mouvement des sociétés, reconnaît Georges Balandier, n'est pas une tâche facile et il se sert de la métaphore du " chantier » pour indiquer le caractère inachevé de la société ainsi que la dé-construction et la reconstruction qui l'animent. Il utilise les figures mythologiques du Labyrinthe, de Dédale ou du Minautaure pour travailler à des interprétations successives plutôt que de donner des " raisons légitimes ». Ces figures contribuent à "une intelligence qui dénoue et permet d'échapper à l'enferment de l'inextricable » (Balandier G., 1994 : 10). Tel Thésée déjouant les pièges du labyrinthe en utilisant le fil d'Ariane pour vaincre l'obscur et en se fixant à un indice lumineux pour conduire sa progression, Georges Balandier utilise la raison critique pour fil et les intuitions guidant la compréhension pour indices. Le labyrinthe révèle ici l'illusoire, chaque issue est fausse. Actuellement, ce mythe parle encore et désigne l'avancée aveugle des pouvoirs en expansion, ceux de la techno-science et ceux de la technobureaucratie qui engendrent un monde où le désordre semble se dissoudre dans l'ordre. Les nouveaux Nouveaux Mondes sont des mondes complexes et inédits, où la puissance agit selon sa propre logique. Dès lors, le chaos devient une terre d'aventures car l'homme se trouve devant des territoires d'une nature nouvelle dont il n'a pas la maîtrise et dans lesquels sa progression est incertaine (ibid., : 224). La recherche de Georges Balandier vise à interpréter ce désordre afin de parvenir à se libérer du sentiment d'être enfermé dans ce labyrinthe - ceci malgré les incertitudes et les doutes - en orientant le parcours, en ordonnant ce qui est éprouvé et en étant attentif aux indices (ibid.,: 227). Dès lors, Georges Balandier va contribuer à dénouer cet écheveau complexe qu'est le mouvement des sociétés de la surmodernité généré par des transformateurs qui dessinent les voies du labyrinthe et ses bifurcations.

Pour cela, il revient sur sa définition de la modernité donnée antérieurement, en ne la circonscrivant plus seulement au temps du mouvement ou à celui de la conquête et de l'inédit, mais en y voyant aussi une période de renoncement marquée par l'obsolescence, l'oubli, le rejet, la désaffection, l'éphémère (ibid., : 13). En parlant des sociétés de la surmodernité, il entend montrer le flou des repères spatio-temporels qui les caractérise tenant non seulement au passé - car l'histoire ne montre plus ce qui est à venir - mais encore au futur, par son imprévisibilité et son désordre. Quant aux lieux définis par des fonctions, identitaire, relationnelle et historique, en référence aux travaux de Marc Augé (1992) sur les non-lieux, Georges Balandier note la prolifération du mot « espace » (espace-vert ; espace-loisir, espace aérien, etc.) instrumentalisant sa fonction au détriment de ce qui le constitue comme lieu. Il envisage la surmodernité dans son rapport avec l'espace sous trois aspects dont les effets sont les plus significatifs : la déqualification (espaces neutres que sont par exemple les agrégats de bureaux, d'administrations, de services, peu propices aux contacts entre eux), la déréalisation (l'univers des réseaux où la fonction de communication prévaut, la valeur marchande des déplacements se fait sur la durée et non sur la distance), enfin la virtualisation (brouillage entre le réel et le réel virtuel dans les images numériques). L'espace et le temps ne sont plus définis par des repères familiers, la surmodernité soumet à l'excès, à l'inédit et génère des bricolages individuels pour une réappropriation de l'espace par un attachement au privé ou aux groupes affinitaires.

Outre cette prolifération de non-lieux, Georges Balandier caractérise les sociétés de la surmodernité par l'hypertrophie de la raison technique qui colonise le social. La puissance fascinante des "révolutions » (informatique, électronique, cybernétique) fait reculer l'impossible et donne l'illusion d'une maitrise croissante faisant oublier la part 
d'inconnu. Cette colonisation multiplie les ruptures avec les configurations symboliques et provoque de nouvelles dépendances par les asservissements à la machinisation dans le cadre de la vie quotidienne. Cette colonisation se renforce par les bio-technologies pouvant devenir une «biocratie » (Balandier G., 1994: 92) qui affecte le corps dans les rapports nature/culture, dans la mesure où la vie et la mort deviennent des enjeux qui n'échappent pas à l'économie, générant ainsi des incertitudes et un nouvel imaginaire. Techno-science et économie deviennent les générateurs des changements dont les pouvoirs sur le corps provoquent de nouvelles acculturations. Le "Grand Système technique scientifique programmé » engendre le social programmé (ibid., : 84) ainsi qu'un «techno-imaginaire », celui du monde de la raison renforcé par la communication qui donne toute sa puissance à l'oralité, à l'image, brouillant ainsi la distinction entre la connaissance vraie et la connaissance superficielle. Ce "pouvoir médiacratique » affecte aussi le sport: "La célébration sportive à laquelle il [le téléspectateur] assiste, par l'intermédiaire de son écran, est l'équivalent de la messe télévisée à laquelle le fidèle participe en acceptant de prendre ainsi la part du mystère liturgique » (ibid., : 137). Ceci ouvre aussi à la reconnaissance d'un sacré non institué comme réappropriation individuelle ou collective de ce que la surmodernité défait.

111 La surmodernité réduit le sacré sans le détruire et il demeure sous la forme d'une sécularisation de la culture, c'est-à-dire sous une forme non instituée, diffuse, dans des formes faites de syncrétisme empruntant à des croyances disparates. Cette perte des références à la transcendance et l'appropriation individuelle de formes de religiosités se lisent aussi dans la spectacularisation des émotions, des dramaturgies et des paroxysmes comme dans les spectacles musicaux ou sportifs, ou dans des tribus où la socialité chaude se substitue aux groupes dans lesquels le lien social est distendu, mais sans que se retrouve l'univers singulier de la tribu, "il s'agit surtout d'un communautarisme tribal métaphorique » (ibid., : 162). Le sacré peut aussi être détourné par des mouvements sectaires régis par un quasi totalitarisme ou par des fondamentalismes désignant une seule voie, celle de la tradition parmi les multiples voies de la surmodernité.

Cet univers de chaos et ses voies labyrinthiques sont éclairés par une dimension chère à Georges Balandier, celle de l'anthropologie politique dans les sociétés de la surmodernité, ici l'accès à la démocratie dont les chemins sont inextricables. Pour argumenter, il développe l'exemple de démocraties dont le régime s'instaure sur la déconstruction des totalitarismes comme les puissances communistes, et il montre comment l'économie de marché remplace l'économie planifiée par l'Etat et comment la conquête de la démocratie est délicate. Tous les secteurs ne bougent pas au même moment, et ceux qui se transforment ne le font pas en même temps. Des permanences se maintiennent et «l'homme soviétique » n'est pas effacé. Il s'agit bien d'une phase de transition ou de mutation, dont l'analyse a toujours passionné Georges Balandier, car s'y décrypte l'image d'un passé nostalgique (le nationalisme) à la recherche de nouvelles substitutions. La construction démocratique est décrétée, sorte de "démocratisme ", mais son accomplissement parait différé. Les démocraties occidentales sont animées de mouvements et sont dynamisées par la concurrence entraînant une instabilité moins identifiable où l'inédit surgit en de multiples endroits. Les démocraties de l'Est ont des difficultés à être, celles de l'Ouest des difficultés à se maintenir. Et puis Georges Balandier ne peut passer sous silence ni la théâtrocratie qu'il avait mise en évidence dans Le Pouvoir sur scènes, c'est-à-dire la spectacularisation 
de la démocratie par des images et sa dramatisation, ni sa place dans le rapport mondialisation-fragmentation. La démocratie est écartelée entre deux dimensions : la première dans sa logique économico-politique estompe les identités, renforce les contraintes extérieures et révèle des volontés démocratiques inégales, la seconde concourt à la dispersion, rend les individus socialement moins liés par le pluralisme, les forces créatives et la multiplication des initiatives locales (ibid., : 214).

C'est bien à la lumière de cette nouvelle alliance entre le pouvoir médiatique et le pouvoir technique que se décryptent les sociétés de la surmodernité dans lesquelles s'affirment la puissance des générateurs des transformations que sont la technoscience et l'économie. C'est à leur connaissance que s'attache la sociologie générative de Georges Balandier qui explore les nouveaux territoires qu'ils produisent en éclairant ces chemins qui déplacent nos repères parce qu'ils sont tracés par des forces obscures dont il va de nouveau approfondir le sens dans Le Grand Système.

Des mondes inédits

114 Dans Le Grand Sytème (2001), la notion de modernité s'efface devant celle de surmodernité et une amplification est donnée aux « nouveaux Nouveaux Mondes » qui engendrent des pouvoirs inconnus et des dominations inédites. Bien que Georges Balandier définisse la surmodernité par le fait «d'épouser le mouvement et vivre cependant avec l'incertitude »- ce qui rappelle les caractéristiques de la modernité - il note une différence entre les deux notions, en ce sens que le mouvement de la modernité antérieure n'est plus perçu comme un progrès qui s'accomplit nécessairement par étapes, mais «comme une addition de progrès, souvent inouïs, réalisés dans la dispersion à mesure que ces possibles deviennent exploitables » (Balandier G., : 57). Les progrès ne s'inscrivent plus dans une vision d'ensemble permettant de préciser vers quel univers humain ils conduisent, sauf à le décréter meilleur et capable d'accomplissements alors inatteignables (ibid., : 57). Par rapport à la postmodernité pensée en terme de ruptures et de recompositions effectuées dans l'espace des cultures, la surmodernité actuelle emportée par les progrès de la technoscience, est saisie en terme d'accomplissement. Sous l'effet de la techno-science et de l'économie, la surmodernité mondialisante engendre des univers inconnus, des territoires de l'inédit à la conquête du vivant, de l'information, de la communication, $\mathrm{du}$ virtuel (et le techno-imaginaire), que Georges Balandier appelle les «nouveaux Nouveaux Mondes ». Ceux-ci contribuent à édifier un nouvel ordre générateur de pouvoir ainsi que des nouvelles formes de domination et de colonisation.

Cette imposition d'une vision instrumentale universelle devient une référence dont la mondialisation est la dynamique permettant son accomplissement. Sous la puissance des transformations, cette généralisation d'une vision instrumentale engendre une perte du symbolique que l'anthropologie a pour tâche de signifier en montrant l'alliance en toute société du savoir-faire (agir sur le monde) et du pouvoir symbolique (ibid., : 16-18) : « Elle [la surmodernité] a la puissance acquise pour moteur, la technique et le marché pour énergie, le capitalisme libéral pour orientation de ses flux » (ibid., : 18-19). Elle se fonde aussi sur la rhétorique de la perte (de croyance, de la volonté de changer les sociétés, de l'attachement aux valeurs, etc). Le projet instrumental vise à organiser toutes les sociétés en un réseau planétaire à la recherche d'une unification sous l'impulsion des forces économiques et technologiques débarrassées d'une vision mythique, il rétablit des inégalités à partir de la seule considération des concurrences et des performances, sans source symbolique originelle fondatrice. Et pour Georges 
Balandier, l'énergie du Grand Système est donnée par ces trois facteurs du global: techno-scientifique, économique et réticulaire qui constituent la dynamique d'expansion d'une "culture globale». Ce sont les effets de ces "transformateurs" qu'éclaire Georges Balandier, car même s'ils génèrent une vision du monde centrée sur la puissance et qu'ils subordonnent le social qui doit s'ajuster, ils sont soumis au doute en raison de leur imprévisibilité.

Cette exaltation du nouveau apparaissant dans des formules comme "les nouvelles technologies », «la nouvelle économie » ou "la nouvelle croissance » procèdent au " réenchantement » de nos sociétés, mais l'incertitude persiste et la constitution d'un techno-imaginaire se nourrit de la rationalité scientifique et de la logique instrumentale comme l'atteste le développement des espaces immatériels et virtuels du cybermonde. C'est là une "première embûche " que souligne Georges Balandier: la fonction imaginante est asservie à ce qui l'équipe et son pouvoir de se distancier de cette contrainte s'anémie, la seconde tient à la confrontation entre les effets de la mondialisation et ce qu'accomplit le Grand Système, et l'individu démuni exploitant les possibilités à sa portée (ibid., : 200-201). L'économie devient l'agent du Grand Système et unifie le mondial par son emprise.

117 Il est une autre voie explorée de nouveau, celle du lien entre la surmodernité et le politique. La surmodernité ne prend pas forme par les seules ruptures provenant des nouvelles techno-sciences, mais il faut y ajouter aussi le dépérissement des idées révolutionnaires - qu'elles soient restauratrices ou progressistes - qui ne subsistent que sous la forme de protestations épisodiques (ibid., : 125-127). De même le pouvoir politique se technicise par le poids accordé aux experts, et Georges Balandier donne raison aux idées de Marx: "Les forces productives, la techno-science et la nouvelle économie sont encore plus les déterminants qui prévalent contre tout autre -, mais en étant détachée de toute visée historique à relativement long terme » (ibid., : 129). Seule la performance compte, il s'agit d'une sorte de «techno-messianisme».

Mais la perspicacité de Georges Balandier ne se circonscrit pas à la seule définition de la surmodernité caractérisée par le pouvoir des transformateurs conférant un nouvel ordre mondial, et s'attache aussi, d'un point de vue anthropologique, à saisir les effets sur l'homme dus à l'engendrement d'univers inconnus, de territoires de l'inédit, de ces nouveaux Nouveaux Mondes qui procèdent du Grand Système. Cette exploration est rendue nécessaire pour en dévoiler les orientations qui déstabilisent l'homme, ceci dans l'objectif d'avoir une prise sur ce Grand Système en sachant ce que nous devenons dans ce désordre dont les savoirs deviennent aveugles. Le Grand Système fonctionne dans le paradoxe : il est le moteur de progrès inouïs, de changements continus et il contribue en même temps à une « définition de l'homme qui lui reste inconnue » (ibid., : 52). Dans ce sens, Georges Balandier analyse les territoires défaits par la mondialisation, ces non-lieux, ces « espèces d'espaces » comme le disait Georges Perec, investis par la spécialisation, par l'utilité et la rationalisation et qui s'opposent aux lieux marqués par un passé, par une existence où l'identité personnelle s'exprime et se réalise par un investissement symbolique et imaginaire (ibid., : 64). Ce sont, selon la formule de Marc Augé des " lieux anthropologiques »: « Ils font de l'homme en ce qu'il est, comme il les a faits en ce qu'ils sont " (Balandier G., : 64). Dans les non-lieux, l'économique et le marché dominent le social, le régionalisme comme la nature (mer, soleil) deviennent des valeurs rentabilisant les désirs. De même Georges Balandier consacre un long développement à l'emprise du Grand Système sur le corps, car la 
techno-science introduit une rupture symbolique par la rationalisation dont il devient l'objet et engendre des incertitudes quant à l'idée de nature.

119 Mais Georges Balandier montre encore la présence de réactions dans la surmodernité qui se lisent dans la vulnérabilité du sentiment de puissance provoqué par la nature systémique de la globalisation, notamment dans la dynamique concurrentielle qui contrarie la régulation et le met en état de crise périodique (cf. les sommets alternatifs). De même suggère-t-il de s'interroger sur la fin du sujet face au monde de réseau qui défait le lien social, une vision qui conduit à une société sans hommes, car pour lui la virtualisation du monde ne rend pas le sujet entièrement dépendant, comme l'attestent les mouvements alternatifs et déviants ou subversifs d'Internet. Des réactions s'affirment encore dans les contre cultures et dans les contestations de la surmodernité ou contre les «maîtres du monde ».

C'est là un nouveau défi pour les sciences sociales où la dynamique du mondial est indissociable de la dynamique du local et qui pose des questions à ce qu'est la mondialisation, comme mouvement colonisateur, comme importation d'une civilisation universelle, comme mort d'une civilisation.

Dans cette période de près de vingt autres années, Georges Balandier n'a de cesse de parfaire son anthropo-sociologie générative critique. Certes, peu à peu, la distance avec les sociétés de tradition se crée - du moins comme objet de recherche - mais les grands traits de sa démarche demeurent présents. Il les fait "travailler» dans les contextes des modernités. La nature systémique des relations entre les colonisateurs et les colonisés se retrouve dans les pouvoirs des grands transformateurs technoscientifiques et économiques qui affectent les anciens pays colonisateurs dont il montre qu'ils sont eux-mêmes colonisés. C'est un curieux renversement de l'histoire que nous livre ici Georges Balandier dans une démarche qui, fidèle à ses principes, ne dit pas l'histoire qu'il faut écrire, mais qui éclaire la complexité de la nébuleuse des turbulences et des nouvelles formes de domination mondialisées et des réactions différentielles qu'elles génèrent, tant à l'échelle individuelle que collective. C'est bien ce caractère inachevé des sociétés et des cultures, depuis les tragédies du Tiers-Monde jusqu'aux nouveaux Nouveaux Mondes et le procès de la mondialisation qui guide les interrogations de Georges Balandier, celles qui concernent le sort des sociétés devenues toutes sous dépendance et traversées par la présence du corps et des métissages qui deviennent des analyseurs des bouleversements.

Corps, métissages, générativité du social et de la culture

Depuis ses premiers travaux, Georges Balandier n'a cessé de maximiser les dimensions " anthropo-logiques ", entendues comme des données premières créatrices de tensions et de désordres à cause des différences instaurées dans un ordre social inégalitaire, que celles-ci se rapportent au domaine du masculin/féminin, au rapport entre le sexe et le social ou à la relation entre le pouvoir et le social dans sa forme politique ou non. Toutes ces questions sont progressivement approfondies dans le temps, au contact des sciences sociales qui doivent elles-mêmes opérer une "révolution épistémologique " pour pouvoir décrypter les mutations et les crises engendrées par ces tensions.

Il est possible de revenir ici sur les notions de «corps » et de «métissages » dont la présence dans son travail est constante, contrairement à l'impression selon laquelle la réflexion sur les métissages culturels appartiendrait à ses recherches africaines et au temps des colonies, et celle relative au corps se rapporterait au contexte des modernités. Certes, des critères objectifs peuvent donner raison à cette idée puisque 
Georges Balandier consacre une grande attention au corps dans ses derniers ouvrages. Mais une lecture plus profonde accrédite la thèse d'une transversalité et d'une permanence de ces deux thèmes qui sont «l'essence " de ses recherches, dans la mesure où les problématiques de l'acculturation ne concernent pas exclusivement le rapport colonisateur/colonisé, puisqu'il a été vu que les modernités s'ouvraient ellesmêmes à des syncrétismes, qu'elle étaient acculturées. De même la question du corps, dans sa relation au pouvoir par exemple, ne concerne pas exclusivement l'effet sur lui des grands transformateurs que sont les sciences et les techniques dans la surmodernité, mais se rapporte aussi à la théâtrocratie qui affecte autant le pouvoir des royautés ou des chefs dans les sociétés traditionnelles que celui des hommes politiques de notre temps. Alors, le parti pris organisateur de ce dernier point consiste à déconstruire l'organisation diachronique des parties précédentes qui montraient la genèse de la démarche générative de Georges Balandier, pour mieux l'approfondir à partir de ces deux indicateurs que sont le corps et les métissages. Ces indicateurs sont déclinés en quatre repères dialectiques que sont les rapports tradition/modernité, dominants/dominés, ordre/désordre et nature/culture, repères qui s'interpénètrent plus qu'ils ne se superposent et qui sont choisis en raison de leur permanence dans le questionnement sur la générativité du social et de la culture.

Les métissages : la dialectique tradition/modernité

L'anthropo-sociologie générative se construit dès le début sur les analyses de la "situation coloniale " par l'attention qu'elle porte aux contacts entre les cultures, et elle contribue à une définition des métissages renvoyant à une dynamique des acculturations et des processus de transformation des cultures en présence. Dans cette perspective, les métissages culturels apparaissent comme une synthèse nouvelle révélant des traits culturels inédits. La culture dans ce sens est un ensemble dynamique qui se transforme au moyen des métissages. Cette conception ne naît pas d'une théorie du social posée a priori, mais émerge des données du terrain que sont les populations colonisées soumises aux transformations générées par la colonisation qui rencontrent leur histoire singulière : l'intérêt étant alors d'analyser les processus tensionnels entre des formes de cultures qui se modifient du fait de leurs interactions réciproques et qui les conduisent à des combinaisons inédites et à des recompositions. Si parfois Georges Balandier utilise la notion de "syncrétisme" dans un sens proche de celui de «métissage » pour souligner les mélanges culturels entre les sociétés de la tradition et les sociétés de la modernité, ce n'est pas au sens d'une juxtaposition d'éléments sans liens entre eux, mais bien pour désigner l'engendrement d'une réalité nouvelle. Une telle conception qui émerge dans les années 50 est novatrice, car l'ethnologie du moment valorisait surtout l'idée de "pureté » des populations comme objet de recherches et Georges Balandier, comme Roger Bastide, ouvre à une prise en compte des transformations des groupes sociaux du fait de leurs contacts, engendrant par là une instabilité et des bouleversements identitaires. En choisissant en 1946 des pêcheurs proches de Dakar comme terrain de recherche, il rompt avec une tradition ethnologique à la recherche de peuples les plus distanciées de l'histoire africaine et des rapports avec le système colonial, pour s'intéresser aux effets de la domination et aux métissages culturels. Une anthropologie du "pur", des "cultures premières " est contestée car ces mots n'osent pas dire "primitifs», "sauvages » ou " archaïques » (Balandier G., 2003 : 112).

Dès ses premières recherches, il montre que la genèse du métissage est complexe car elle se lie à des influences internes et externes qui permettent de comprendre la force 
et la vitalité créatrice des Afriques : «Les métissages, les mélanges, les syncrétismes se sont effectués par développement interne et aussi par de très anciennes relations avec les mondes berbère, arabe, occidental, et non pas seulement par les effets des dominations coloniales modernes" (ibid., : 113). Ainsi, les peuples africains, par les migrations, les brassages et le poids de leur histoire singulière, connaissent de multiples métissages comme en témoignent les pêcheurs Lébou dont le peuple est constitué à partir de différentes composantes, parmi lesquelles le oualof reçu de l'Islam pour leur religion, ou encore le sérère pour leur système social fondé sur l'ordre de la parenté et de la filiation ou pour les cultes de la possession, tandis que le cabotinage est associé à la petite agriculture et à l'élevage développés par les voisins (ibid., :112-113).

Leur culture ne cesse par ailleurs de se transformer sous l'effet d'une appropriation externe, celle de la colonisation, sans pour autant effacer certains savoirs traditionnels comme en témoignent la cohabitation des écoles coraniques avec l'adoption des écoles laïques de la République coloniale (Balandier G., 1997a : 236-237). Ceci s'affirme encore dans le culte du Bwiti des Fang gabonais qui reconstruit un univers religieux alliant leurs origines indigènes au christianisme. Ces recherches remettent en cause la question de «l'authenticité des cultures » ou de «l'identité ethnique » qui contiennent l'idée d'une stabilité, contradictoire avec la création d'une culture inédite faite du maintien de traits traditionnels articulés en une synthèse avec les traits importés. La culture formée au contact de la dépendance est faite d'innovations, de recompositions nouvelles et de permanences comme le montrent les transes permettant de résister à la modernisation en réduisant l'angoisse née du contact avec une culture autre.

Ce que dévoilent ces recherches c'est bien la fécondité des métissages faits de conjugaisons d'influences, c'est-à-dire l'envers d'une pureté qui devient «mythique et fictive " (ibid., : 238). De là, Georges Balandier tire trois enseignements : «Première affirmation : l'authentique, le pur, le primitif aussi, au sens premier, relèvent plus de l'idéologie que de la nature des choses. Deuxième affirmation : le métissage, le mélange, l'acculturation ne produisent pas une médiocre juxtaposition de composantes hétérogènes, ce n'est pas du bricolage hétéroclite. Ils transforment, ils allient, ils inventent, ils ajoutent. Dans le mouvement historique, ils manifestent la vitalité culturelle, alors que l'économique et le politique expriment des rapports de force. Enfin, dernière affirmation: toute modernité, l'actuelle plus que les précédentes, par son intensité et son expansion mondiale, ouvre une nouvelle ère des métissages et des acculturations, des incertitudes, des rejets et des risques qui les accompagnent " (Balandier G., 2003 : 114-115).

Ces recherches indirectement touchent au politique, car en dévoilant les dynamismes culturels sous la forme des métissages, Georges Balandier réagit contre une anthropologie qui réduirait l'histoire de la culture à la seule histoire coloniale et qui occulterait de la sorte la dynamique de l'entrecroisement. Il démontre au contraire que la tradition ne se réduit pas à une répétition mais que s'effectue un travail continuel d'ajustement et de réponses aux conjonctures (ibid., : 154). Dans ses recherches sur les Brazzavilles noires, il montre ainsi que le milieu urbain africain conçu comme «centre du pouvoir colonial» permet de prendre conscience de ce que "la scène coloniale déporte dans l'ombre ", c'est-à-dire les reprises d'initiatives culturelles et politiques. L'acculturation et les métissages peuvent, certes, se réaliser dans une passivité des peuples dominés, mais génèrent aussi des réactions organisées, nées de la prise de conscience conduisant au désir de renversement de la domination à cause d'une 
situation créatrice d'écarts différentiels fondés sur une logique inégalitaire. Inévitablement, les métissages sont féconds, mais ils sont aussi porteurs de désordre, de tensions et de crises qui se manifestent par des phénomènes de contre acculturation, préservant une tradition et une histoire dont les travaux de Georges Balandier montrent toute la complexité et la diversité, non seulement dans les sociétés sous dépendance, mais encore dans les sociétés de la modernité.

Les sociétés de la surmodernité en effet, génératrices de la mondialisation, s'ouvrent aux apports extérieurs et activent les métissages dont le corps devient l'analyseur. La porosité des frontières favorise de nouvelles acculturations venues de l'Amérique du Nord ou des pays étrangers, comme ceux du Tiers Monde ou de l'Orient. Ces métissages se lisent dans le corps et dans le sport dans deux directions, dans des pratiques et dans l'imaginaire. Ainsi se multiplient des syncrétismes culturels qui empruntent de nouveaux territoires, une nouvelle histoire ou de nouveaux espaces de civilisations saisissables dans le yoga, le zen, le karaté (Balandier G., 1991: 9) ou dans des danses comme la salsa, la bossa-nova ou la capoiera (cf. l'article de ce numéro). Ce recours aux traditions venues d'ailleurs témoigne de la conjugaison de plusieurs temps dans la modernité et appelle à une critique de ces recours aux civilisations autres pour restaurer du sens dans nos sociétés, car il peut s'agir de pseudo traditionalismes recomposés qui s'appuient sur un imaginaire recourant au mythe de communautés perdues. Ceci s'illustre par les tribalisations multiples fondées sur le désir d'établir des socialités affectuelles ou par les nouvelles formes de religiosités, qu'il s'agisse du sport ou des religions fondées sur un syncrétisme de croyances distanciées des religions instituées.

Si l'appel aux traditions dans la modernité ne contribue pas à l'élaboration d'une contre modernité, il en est d'autres qui, ouvertement, s'appuient sur le refus des métissages mélangeant le pur et l'impur et qui résistent à une acculturation générée par la surmodernité, par exemple dans l'affirmation des cultures ou d'intégrismes religieux. La puissance des "Grands Tranformateurs" de l'Occident et leur désir d'universalisation peuvent provoquer ce que Georges Balandier appelle «une insurrection des différences ", car si les autres nations veulent se moderniser, ce n'est pas dans le sens d'une occidentalisation (Balandier G., 2003: 374). Ce divorce modernisation/occidentalisation exprime bien la vulnérabilité de l'emprise mondialisante des pouvoirs de la techno-science et de l'économie libérale qui se traduit en impuissance. L'histoire actuelle est faite de ces autres tensions produites par les inégalités grandissantes avec les mondes « sous modernisés » qui veulent entrer dans le procès de la modernité sans rompre avec des traditions. Georges Balandier avait bien montré le pluralisme au sein de sociétés composées de "sociétés ». Ici, il complexifie la problématique pour montrer les différentialismes au niveau d'un monde composé de civilisations dont certaines sont peu enclines à suivre aveuglément les voies fixées par un ordre unitaire. La dialectique de la tradition/modernité depuis les pêcheurs Lebou s'est élargie aux sociétés et aux cultures mondialisées.

Le corps opérateur social et politique : la dialectique ordre/désordre

Le corps est un autre champ d'exploration de la générativité du social et de la culture qui, tout en participant de la dialectique tradition/modernité, relève aussi du registre de l'ordre et du désordre. Ici il ne s'agit pas de parler du corps de l'anthropologue, même si Georges Balandier souligne qu'il est pour lui un vecteur de compréhension des cultures corporelles autres, soit par les émotions ressenties au contact d'autres modes 
de vie, soit par le sentiment d'étrangeté qui le frappe dans des situations comme les rituels africains, ce qui montre que les expressions corporelles sont des constructions symboliques propres à chaque société. Il s'agit plutôt de considérer le corps comme un "opérateur social et politique " rendant compte de la dialectique ordre/désordre, dialectique ouvrant à une approche générative du social.

Un des apports de l'anthropologie politique de Georges Balandier est de montrer, à partir de l'analyse du souverain dans les royautés de tradition, comment le corps est partie « constituante et signifiante » de tout pouvoir (Balandier G., 1974, 1985:12), et qu'il est un signifiant de l'ordre. Le corps devient un support symbolique et imaginaire de la fonction du roi lors de la dramatisation et de la mise en scène des rituels d'investiture du pouvoir. Cette sacralisation marque une distance du corps des sujets qui rend possible la domination (Balandier G., 2003 : 188). Le corps porte des signes marquant son rang, des parures changeantes selon les circonstances qui deviennent des signifiants symboliques du pouvoir. Ces rites d'institution, ou « d'intronisation » selon sa formule, confère au roi une puissance qui l'associe à l'Etalon, au Taureau, au Lion ou au Bélier et chez les Moundang du Tchad, le premier acte du roi neuf est l'appropriation de nouvelles épouses choisies parmi les femmes jeunes du défunt: l'accession à la charge suprême s'affirme dans une continuité du pouvoir transmise par le corps des femmes et la fécondité qu'il recèle (Balandier G. 1985: 62). Ces rituels "font» le roi jusqu'à sa mort où le corps est devenu un corps "nul» (chez les Moundang, la tête du roi défunt est transformée en autel et son corps est abandonné à la nature sauvage). Cette séparation d'avec le commun s'accompagne d'une transgression du tabou de l'inceste (réel ou symbolique avec sa sœur), autorisé alors à une personne unique, le roi, dont la sacralité renforce la domination légitime de l'ordre qu'il représente. Chez les Mosi du Burkina Faso, le passage à l'état de roi se fait par une incorporation des territoires sur lesquels il exerce sa fonction, le roi parcourt le territoire et son corps devient alors le foyer des forces d'ordre et de fécondité (Balandier G., 2003 : 190). Chez les Suku du Zaïre, le roi est capturé avant le rituel pour lui faire subir une purge, car son corps doit être exempt de tout désordre, de toute impureté car il représente aussi l'ordre du monde. Georges Balandier voit dans l'accession à cette souveraineté une forme suprême de l'initiation : « Le roi neuf naît en cette qualité après avoir été "tué" dans les aspects de sa condition antérieure. Dans cette métamorphose le corps entre nécessairement en jeu, il est l'objet et le moyen de l'opération symbolique » (Balandier G., 2003: 191).

133 Ceci atteste des thèses d'Ernst Kantorowicz sur les deux corps du roi (1989). Le corps physique (mortel car naturel) est relativisé par rapport au corps politique (mystique et non assujetti à la maladie ou à la mort) (Balandier G., 1985 : 32). Les rituels servent aussi à piéger le temps en donnant « l'illusion d'un pouvoir capable d'échapper à l'usure et à la dégradation, à l'incapacité », ce qui permet la continuité de l'ordre car le rituel valorise symboliquement la permanence intemporelle contre le corps appelé à disparaître (Balandier G., 2003 : 188). À la mort du roi, existent des rituels permettant de régénérer l'ordre suite au désordre causé, comme chez les Suku où le roi est remplacé par un mannequin dans les périodes d'interrègne contribuant à l'effacement du corps du roi pendant ce moment de chaos (Balandier G., 1985 : 35-39).

134 Dans les sociétés de la surmodernité, le corps et les rituels continuent de signifier la symbolique du pouvoir, même si les signes changent. La théâtrocratie, la dramatisation des mises en scène et la manipulation des symboles dans le cadre cérémoniel, confèrent 
une sacralité par la distance établie vis-à-vis du commun. L'ordre continue de s'affirmer, renforcé par le pouvoir des images, soit de manière ouverte dans les pays totalitaires, soit de façon plus discrète par les défilés ou les commémorations ailleurs. Les Grands Transformateurs n'ont rien ôté à la permanence de la symbolique des pratiques rituelles malgré leur instrumentalité et leur rationalisation : le renforcement du pouvoir de l'ordre se construit sur de nouveaux mythes (les Etats modernes, la Nation). Au-delà de ces ressemblances avec les royautés africaines existent des différences qui tiennent à une généralisation de la puissance par l'organisation des appareils politiques et par le pouvoir des médias. L'objectif demeure identique, l'affirmation de l'ordre: «Les moyens dont dispose le pouvoir afin de provoquer la conformité sont multiples. Ils comportent la Loi, comprise dans son acceptation la plus extensive (ensemble de normes, interdits, codes), ainsi que les dispositifs réprimant la déviance. Ils comprennent, bien que leur action et leurs effets soient plus insidieux, les dispositifs cognitifs, symboliques et rituels qui entrainent l'adhésion de l'individu; ils ne sont pas les moins efficaces. C'est par eux que l'ordre social est mis en analogie avec celui de la nature, donnant à croire qu'il existe une "nature sociale" à laquelle on ne commande qu'en lui obéissant » (Balandier G., 1985 : 11).

Mais si le corps comme opérateur politique produit l'ordre, il est simultanément soumis aux figures du désordre qui usent du corps et du sexe comme moyens de transgression ou de contestation. Corps et sexes participent certes de la construction de l'ordre, mais représentent aussi une menace pour lui en le déconstruisant. Ceci s'affirme dans les déviances sexuelles ostentatoires, dans l'errance sexuelle généralement reconnue comme acte contraire à la vie sociale, ou encore dans l'homosexualité qui sont autant de provocations remettant en cause l'ordre sexuel dominant et auxquelles les pouvoirs répondent par des exclusions. Ici, le corps est destructeur de la Loi, des conventions et des normes, et il menace la société de chaos. Georges Balandier fait bien apparaître les expressions du politique dans son rapport avec le social, soit dans des lieux spécifiquement dédiés aux institutions affirmant sa légitimité, soit dans les mécanismes sociaux où s'affirment des tensions et où se dessinent des contre pouvoirs à l'égard de l'ordre. C'est ce jeu dialectique entre l'institué et les capacités créatrices instituantes qui fait la générativité du social et rend les sociétés instables. Les ruses existent de la part de l'ordre pour transformer le désordre en ordre, qu'il s'agisse des fêtes ou de carnavals où le chaos est orchestré, institué, tout en montrant ce que serait une société sans règles. En cela, la fête libère les tensions par le désordre, mais recrée de l'ordre : l'inversion de l'ordre conduit alors à son renforcement.

Masculin-féminin : la dialectique dominants/dominés

Le rapport masculin-féminin est un autre axe d'investigation de la générativité du social, car ces deux "classes sexuelles", selon le mot de Georges Balandier, sont socialement construites sur une hiérarchie engendrant des inégalités du fait de la domination masculine. Dès les années 60 , alors que la sociologie est plus attentive aux problématiques des classes sociales, Georges Balandier, toujours sensible aux problèmes sociaux du moment, accorde une attention soutenue à cette dimension qu'est la sexualité, à son partage inégalitaire et à l'engendrement des pratiques, des imaginaires et des symboles produits par cette division. En se situant dans la période militante des mouvements de libération des femmes émergeant dans ce contexte, il veut mettre l'anthropologie au service de la connaissance de cette dualité, afin de réduire "les justifications de la domination masculine, les formes culturelles qui conduisent à occulter la moitié féminine de la société - la moitié dangereuse» 
(Balandier G., 1967, 1975: 18). Sans faire de militantisme, il souhaite donner une interprétation anthropologique aux mécanismes de domination pensés dans les relations hommes/femmes, une "opposition complémentaire", en considérant la sexualité comme « un phénomène social total » (Balandier G., 1985 : 57).

Ainsi, les mythologies africaines accordent une place importance à cette dualité masculin-féminin, que ce soit dans les récits expliquant la création, dans les systèmes d'interprétation qui par liaison révèlent le recours au symbolisme sexualisé pour rendre compte de l'ordre du monde, ou dans la reconnaissance du caractère problématique de toute formation sociale dans laquelle la relation est simultanément ordre et désordre. Par exemple, chez les Bambara du Mali, ce dualisme sexualisé devient un système d'interprétation du social et de la culture dont les éléments sont marqués par les relations entre les signes de la masculinité et ceux de la féminité (Balandier G., 1974 : 33-35). Cette union du masculin et du féminin n'est jamais parfaite, c'est une " union tensionnelle » menacée, car l'échec de la complémentarité, c'est-àdire le désordre, peut se manifester à tout moment. De même, les récits des Bambara connotent-ils la femme d'une façon négative: elle évoque la nuit, l'image de la rébellion et du désordre. Ce sont là des indicateurs d'un "sexisme dépréciatif de la féminité ». Les Lugbara de l'Ouganda et du Zaïre maintiennent les femmes dans des limites étroites : elles ne participent pas à la discussion des affaires lignagères, se situent en marge des activités rituelles et sont réduites à une fonction instrumentale en assurant les tâches de production et d'entretien des hommes, alors que les hommes instaurent des relations fondées sur les structures de la domination. Il s'agit d'une " société virile, qui se présente comme toute la société, met la femme à son service en la considérant individuellement; une société féminine faible, à influence restreinte, se situe à la périphérie » (ibid., : 41). La dualité sexuelle s'exprime socialement par des pratiques symboliquement liées à la position inférieure de la femme Lugbara, située du côté de la nature sauvage et non du paysage humanisé, du temps et de l'espace d'avant les hommes, des « choses » et non des " personnes» (ibid., : 42). Les éléments féminins sont l'inverse de ceux qui constituent la dimension masculine et désignent ce qui est mauvais et qui affaiblit l'ordre, d'où les systèmes d'opposition entre d'un côté les signes du masculin - bien, normal, moral, social - et de l'autre, les caractéristiques du féminin, mal, anormal, amoral, immoral, a-social, anti-social (ibid., : 43).

Cette coupure, génératrice de conflits, est encore plus nette chez les Ndèmbu de Zambie étudiés par Turner, car les inégalités se manifestent dans la répartition des activités : ainsi s'opposent l'instabilité des activités des hommes (la chasse) à la stabilité de celles des femmes (mariage, fécondité), la discontinuité des tâches des hommes à la continuité répétitive de celles des femmes, la participation sociale entière des hommes à la marginalité des femmes. Cette tension masculin/féminin s'opère à l'occasion des rituels où la masculinité est exaltée au moment de la circoncision, et la fécondité des femmes lors des cérémonies de la puberté, signes de l'opposition structurelle et d'une opposition symbolique entre les deux « classes sexuelles » (ibid., : 46). D'autre exemples pris chez les Béti du Cameroun ou les Fang gabonais convergent pour montrer que système symbolique et théorie du social recourent à un dualisme sexualisé hiérarchisé dans lequel les femmes sont traitées comme des objets et assimilées aux choses. Excepté quand elle est mère, tous ces exemples convergent pour démontrer la marginalité ou l'infériorité de la femme, sa situation d'altérité et son assimilation à une « contre société » (ibid., : 48). 

pratiques sociales, font qu'est privilégié un type de rapport à la sexualité qui exclut l'inceste parce que l'union entre deux éléments parents ou semblables n'est pas socialement féconde. Il s'agit, précise Georges Balandier d'une situation «homorelationnelle " qui alors déconstruit les relations établies sur la conjugaison des différences et qui génère des réactions à l'égard de l'homosexualité «l'union du semblable apparaît comme état zéro des relations sociales, non-relation et en quelque sorte, l'inverse de l'union des différences qui montre la fécondité dans ce caractère exemplaire, ou mieux paradigmatique, attribué au rapport masculin/féminin » (ibid., : $56)$.

Mais fidèle à une lecture du social faite d'ambivalence, Georges Balandier repère une complexité dans les rapports d'inégalités de certaines sociétés due au croisement avec des hiérarchies qui ne sont pas sexuelles. Chez les femmes, des différences existent entre elles comme le montre l'exemple des femmes Bamiléké du Cameroun occidental. Elles sont certes marquées par des inégalités lisibles dans la répartition des activités économiques dont certaines leur sont interdites, mais des auteurs notent, qu'à la différence des femmes d'autres peuples qui sont marginalisées, elles assument des fonctions collectives, par exemple rituelles et politiques. Le statut de "mère-chef " permet à ces femmes de participer effectivement et symboliquement au système du pouvoir : elles sont associées au chef et instituent une sorte "d'aristocratie féminine", elles ont presque le statut d'un homme et se comportent comme tel (ibid., : $64 \mathrm{sq}$ ). Les femmes Bamiléké combinent donc en elles les signes de la masculinité et ceux de la féminité, les signes de l'infériorité et ceux de l'équivalence avec l'homme, voire même sont capables de révolte à l'égard de la domination masculine par la destruction de plantations par exemple comme signes du refus de céder de nouveaux espaces de culture, comme l'a montré Gabriel Gosselin (ibid., : 71). De même, existent chez les Zoulou des cérémonies permettant d'inverser l'ordre masculin, au cours desquelles les femmes s'affrontent aux hommes afin de libérer les tensions produites par ces inégalités. À l'occasion de ces rituels religieux associés aux activités agricoles et à une divinité féminine qui permet la fertilité, les filles inversent les interdits, deviennent des hommes et s'attribuent les signes et les symboles de la masculinité, subvertissent les règles de pudeur imposées en se dénudant et en chantant des obscénités, tandis que les hommes sont dévolus aux tâches domestiques marginalisées. Ainsi s'opposent-elles à l'ordre masculin dominant la cité et présentent-elles une image ambivalente de la sexualité : à la fois symbolisant l'ordre par leur fonction d'épouse, mais génératrices de désordre aussi par l'image de la séduction érotique et la possibilité potentielle de la transgression. Mais la reprise de l'ordre s'effectue malgré la présence des conflits qu'expriment ces cérémonies. Comme Georges Balandier l'a montré par ailleurs, le renversement de l'ordre n'est pas rupture, il n'est pas le désordre, car cette catharsis restaure la symbolique du pouvoir masculin et son ordre (ibid., : $76 \mathrm{sq}$ ).

Georges Balandier note bien comment ces observations témoignent d'une approche générative critique: le décalage entre ce qu'une société rend visible et les figures souterraines qui œuvrent masquées, ici, les statuts «officiels » de la femme et les moyens dont elle dispose pour inverser les contraintes de la domination masculine. Les inégalités produisent des contestations visant à remettre en cause la subordination qu'elles créent. Georges Balandier mentionne comment une action collective peut être conservatrice si elle se conforme aux codes culturels traditionnels, mais aussi force de

Corps et culture, Numéro 6/7 | 2004 
changement quand elle participe aux processus de modernisation et aux transformations politiques. Cependant, il existe pour lui une « autonomie relative » des rapports sociaux établis entre les sexes qui se lit dans la permanence de la subordination à l'ordre masculin que la subversion féministe tente de renverser en reprenant les thèmes soulevés par l'anthropologie: un statut d'infériorité, une dépréciation du travail, l'enfermement domestique, l'assimilation à une minorité et l'exploitation sociale liée à cette dépréciation (ibid., : 83). En cela les revendications féministes dans leur radicalité, ne cherchent pas à résoudre la question de la différence et de l'altérité, mais la maintiennent pour faire surgir la « société cachée » (ibid., : 84), en insistant sur la volonté subversive de ce mouvement social visant à les délivrer du machisme et de la virilité qui colonisent et instrumentalisent le corps féminin pour faire surgir une identité et une égalité.

Georges Balandier note que ces objectifs ne sont pas atteints. La décolonisation n'est pas effective et les identités féminines et masculines sont retravaillées : «Le dominant se définit mal et le masculin devient un genre flou " (Balandier G., 1994: 19). De nouveaux rapports de force surgissent alors, signes du travail incessant de redéfinition des identités de genre soumises à des décompositions/recompositions permanentes. Ce sont les situations qui entraînent les transformations liant indissociablement le masculin et le féminin. Les analyses anthropologiques montrent certes le statut d'infériorité accordée aux femmes, mais appellent aussi à lire une complexification de ce dualisme en tenant compte des différences entre les sociétés. Dès lors, le rapport dominant/dominé, comme le dualisme colonisateur/colonisé, peut provoquer une « insurrection des différences» qui intègre l'histoire propre à chaque société et les constructions symboliques singulières qui les caractérisent, témoignant encore de turbulences sociales et de nouvelles colonisations qui s'écrivent dans un jeu social inachevé.

Corps et techno-sciences : la dialectique nature/culture

Georges Balandier analyse une autre forme de pouvoir, de domination et de colonisation dont le corps est partie prenante, qui est celle exercée par la technoscience dans les sociétés de la surmodernité. C'est ce processus de " culturalisation » de la biologie et de l'humain bouleversant l'idée de nature que l'anthropologue dévoile, en montrant une autre forme de colonisation du vivant qui engendre des transformations relativement à la sexualité, à la vie et la mort. Ici, les «révolutions» des biotechnologies du vivant rendent caduques l'opposition nature-culture et conduisent à ces « nouveaux Nouveaux Mondes » inédits et incertains. La générativité se lit ici dans les nouveaux engendrements opérés par ces générateurs qui façonnent le corps en le dé-naturant : " Toute société a une théorie de la nature qui ne s'exprime pas seulement dans des configurations intellectuelles, mais aussi dans des agencements symboliques, des instruments et des pratiques»(Balandier G., 1967, 1985: 16). L'anthropologie a alors pour tâche de montrer la subversion du rapport nature-culture instaurée par les transformations que la modernité produit, notamment sous l'effet de la raison technique et de la rupture symbolique qu'elle opère.

Ainsi, dans les sociétés de tradition, non déterminées par le pouvoir de la technique, c'est l'ordre symbolique qui prédomine dans lequel le rapport entre le corps et le social est étroitement mêlé à la nature et aux figures mythiques: "L'image du corps, lorsqu'elle est révélée par les significations et les pratiques ritualisées, devient irréductible à celle du « corps-objet » (Balandier G., 2001 : 102). Comme il a été vu, dans 
ces sociétés, les marquages corporels et la sexualité sont imposés et sont des opérateurs sociaux, c'est-à-dire des opérations symboliques par lesquels sont signifiés et validés un ordre et des pouvoirs (Balandier G., 1985: 179). Mais pour Georges Balandier, la surmodernité «fait du corps, bien plus fortement que les périodes antérieures, son révélateur " (ibid., : 102) et les modernités ont inventé un autre corps où sa relation avec la nature sous la forme d'une identité biologique est rationalisée. Les technologies du vivant, l'ingénierie médicale conduisent à une objectivation du corps qui désagrège les interprétations métaphysiques, symboliques et sociologiques et engendrent le risque de la «disparition de la fonction symbolisante, exercée jusqu'alors par la médiation du corps, au profit d'une instrumentalisation de plus en plus poussée, qui aboutirait à faire de l'homme un système complexe connectable à des systèmes instrumentaux » (Balandier G., 2001 : 108). Cette alliance du vital et du machinique conduit à un «techno-vitalisme » à un «techno-messianisme » liés à un «technoimaginaire».

La puissance se manifeste encore par l'économie dont la rationalité diffuse aussi une économie corporelle semblable à celles des choses et des services. Ceci se perçoit dans la banalisation de la nudité et sa trivialisation, ôtant tout pouvoir de transgression contre les normes et l'ordre social, et elle devient alors « un moyen de stratégies de conduites sur le marché du désir et des émotions » (ibid., : 105). La gestion du corps et de la sexualité par la diffusion de l'hygiène, les pratiques médicales, les interventions et les informations sexologiques, traduit une rupture qui affecte en profondeur la nature humaine et nécessite le recours à une bio-éthique soucieuse de respecter la nature en établissant des bornes qui deviennent de plus en plus poreuses sous l'effet des pressions des scientifiques et des demandes sociales. C'est cette perte de significations unifiantes et le désordre né des mutations symboliques opérées par la surmodernité qui retiennent l'attention de Georges Balandier d'un point de vue anthropologique, car l'homme est désemparé face aux grandes transformations qui engendrent des risques et des incertitudes sur les questions relatives à la vie.

Ainsi, il montre comment l'homme est "fabriqué » corporellement, socialement et culturellement, sous l'effet des modes, de la vulgarisation des techniques d'entretien et des contrôles corporels que développent par exemple les salles de mise en forme. Le sport entretient le mythe du recul de l'âge biologique, de la maîtrise du corps et de la performance par le dépassement des limites du risque. L'objectif vise à faire du corps « une composante majeure de l'identité et de l'image personnelle » (Balandier G., 1985 : 249-250). Ce sentiment de maîtrise se réalise aussi sous l'effet de la médicalisation et de ses dispositifs techniques complexes où le corps est placé sous haute surveillance, ce qui se substitue à une connaissance intuitive antérieure. L'image mécaniste et instrumentale du corps se renforce par la multiplication des transplantations, les manipulations, l'usage des prothèses, la maîtrise de la sexualité (contraception, IVG), l'assistance chimique pour l'obtention du plaisir ou encore par les explorations internes et les cartographies du corps. Le travail sur les apparences corporelles résulte lui aussi d'une culture dépendante de techniques chirurgicales que renforce le pouvoir de la médiatisation de l'image du corps qui rend cette exigence plus astreignante et plus changeante (ibid., : 103). Georges Balandier livre ici de nouveaux engendrements, et son approche générative demeure résolument critique.

147 Cette «biocratie » qui s'enracine aussi dans l'économie conduit à des paradoxes : «Le corps devient davantage que le médiateur reliant au réel : il est le réel immédiat et la 
possession la moins incertaine. Il vaut par lui-même, et toutes les jouissances qu'il peut procurer en sont d'autant exaltées" (ibid.,: 167). Mais les contradictions sont maintenues car il impose toujours sa faiblesse et ses défaillances, ce qui relève de sa nature même, sans que la techno-science médicale n'en ait la maîtrise totale. C'est dans cette ambivalence que se lit le pouvoir des techniques qui apportent certes des bienfaits mais dont les dérives sont toujours présentes quand il s'agit de la nature. Cela concerne le clonage qui pose la question de la relation de l'homme avec son corps et avec sa mort, la commande d'enfants avec des caractéristiques sur mesure, la destinée des embryons surnuméraires détruits ou vendus comme marchandises, la procréation liée à la sexualité puisqu'à terme elle pourrait être dissociée du corps (utérus artificiel) ou encore la fabrication d'un "techno-métissage ", contribuant à un obscurcissement de la nature humaine devenue imprécise car métissée dans les xénoplantations avec des tissus et des cellules d'organes prélevés chez des animaux dont le patrimoine génétique a été modifié pour être humanisé afin de les transférer à l'homme (Balandier G., 2001 : 119). Ces dérives impliquent aussi l'économie, comme ce fut le cas soulevé par Bernard Edelman (1999) de l'homme aux cellules d'or dont le procès fait au monde médical rendra réparation au plaignant en raison de la propriété de ses tissus corporels prélevés et vendus à son insu par des médecins à des instituts de génétique car ils avaient des propriétés très rares (ibid., : 116). C'est bien de la dialectique nature/culture dont il est question dans le Grand Système qui pousse l'homme «à se produire comme marchandise " selon la formule qu'emprunte Georges Balandier à Bernard Edelman. Georges Balandier indique bien que c'est par le corps que le Grand Système manifeste son emprise en générant des risques: "L'inquiète incertitude, puis les angoisses des rencontres inédites resteront longtemps les compagnes de l'espérance » (ibid., : 123).

La dialectique nature/culture, dominants/dominés, ordre/désordre, tradition/ modernité traduisent le mouvement dans le contexte des modernités qui atteint les racines et l'identité de l'individu soumis à de perpétuelles désymbolisationsresymbolisations, décompositions-recompositions signes de la production d'un social se faisant en défaisant les repères anciens. L'anthropologie de Georges Balandier conduit à montrer que les chemins empruntés ne conduisent pas à la maîtrise des situations engendrées. Le corps devient l'analyseur de ces méandres qui suivent l'affrontement entre le pouvoir de la techno-science et de l'économie libérale qui prescrivent les devenirs, et les contre pouvoirs, les réactions différentielles qui s'écrivent et qui les rendent vulnérables. Dialectique, ambivalence, ambiguïté ressortent de l'exploration de Georges Balandier qui aide au déchiffrement de ces labyrinthes avec le désir de faire des sujets « éclairés, vigilants et critiques » plutôt que fascinés et apeurés (Balandier G., 1994 : 96).

149 Les logiques de domination œuvrant dans toutes les sociétés demeurent un champ exploratoire qui traverse toutes les recherches de Georges Balandier. Cette question est constante aussi dans les projets de bon nombre de sociologues, notamment dans les approches de Pierre Bourdieu. Cependant, si des points sont communs aux deux épistémologies et que Georges Balandier adhère au choix de Pierre Bourdieu, celui "d'une sociologie "réellement génétique", ou générative, d'une pratique de recherche qui entretient la posture critique en transformant le regard porté sur le social qui révèle les effets de la domination exercée par les moyens symboliques ", il ne considère pas pour autant la sociologie comme un «métier » au sens où la scientificité serait un idéal auquel doivent souscrire toutes les sciences de l'homme (Balandier G., 2003a: 321). C'est une autre voie qu'il choisit en voulant mesurer le prix à payer pour parvenir 
à l'état de sociologie scientifique car «la place concédée au désir, aux passions, aux apparences, aux défaillances de la rationalité, ne peut qu'être que chichement mesurée" (ibid., : 321). L'anthropologie est pour lui plus un art qu'un métier, au sens médiéval du terme, «c'est-à-dire une connaissance et une pratique personnalisée. Je ne crois que l'on puisse être anthropologue sans feeling, le contact, la curiosité passionnelle de ce qui est autre » (Balandier G., 2003b). L'anthropologie qu'il défend est résolument en phase avec son propre temps, celui des colonisations incessantes, depuis les pays dominants, jusqu'à l'imposition de l'ordre masculin, des pouvoirs politiques ou de la puissance des techno-sciences et de l'économie, traversant toutes les époques en bouleversant les rapports sociaux. Il n'a de cesse d'observer « des peuples qui étaient faits, défaits, refaits, des pouvoirs aux assises et aux formes changeantes, des société et des cultures jamais pleinement constituées » (Balandier G., 1997a : 255).

Cette anthropologie générative prend en considération la place de l'événement, le surgissement des inattendus, qui font douter de l'hégémonie des déterminations et de la norme pour reconnaitre le rôle des aléas dans les conduites humaines et les mutations sociales. Ceci l'amène à développer une pensée politique à propos des événements mondialisés (l'Iran, l'Irak, le Moyen Orient, le chaos du 11 septembre 2001, les changements de régimes politiques) en soulignant les bouleversements engendrés, l'exaltation des renouveaux et les désenchantements. Cette exploration vise aussi à civiliser les nouveaux Nouveaux Mondes dont certaines formes de non-civilisation peuvent apparaître dont le corps est l'analyseur. Dans ces turbulences et ces inédits, la culture devient pour lui un enjeu politique majeur et le développement « des sciences sociales et de la culture » une nécessité pour comprendre le présent dans son mouvement et l'avenir dans ses incertitudes ${ }^{6}$.

\section{BIBLIOGRAPHIE}

Afrique plurielle, Afrique actuelle. Hommage à Georges Balandier (1986) Paris, Katharla.

Ansart P. (1979) « Toute connaissance du social est-elle idéologique? », in Duvignaud J. (textes réunis par) Sociologie de la connaissance, Paris, Payot, 33-48.

Ansart P. (1990) Les Sociologies contemporaines, Paris, Seuil, Points, 211.

Autour de Georges Balandier (1981), Fondation d'Hauvillers pour le dialogue des cultures Paris.

Augé M. (1992) Non-lieux. Introduction à une anthropologie de la surmodernité, Paris, Le Seuil.

Balandier G. en collaboration avec Mercier P. (1943) Lettres sur la poésie, Paris, Les Cahiers Littéraires.

Balandier G (1947), Tous comptes faits, Paris, Ed. du Pavois.

Balandier G. (1951) «La situation coloniale : approche théorique », Cahiers internationaux de Sociologie, vol XI, 44-79.

Corps et culture, Numéro 6/7 | 2004 
Balandier G., Mercier P. (1952) Les Pêcheurs Lébou au Sénégal : particularisme et évolution, Etudes sénégalaises, 3, Saint-Louis, Centre IFAN.

Balandier G. en collaboration avec Pauvert J.- Cl. (1952a) Les Villages gabonais : aspects démographiques, économiques, sociologiques. Projets de modernisation, Montpellier, Imprimerie de la Charité.

Balandier G. (1952b) «Contribution à une Sociologie de la Dépendance », Cahiers internationaux de Sociologie, XII, 47-69 ; ou Sociologie de la dépendance (version révisée) in Balandier G. (1971) Sens et Puissance, les dynamiques sociales, Paris, PUF., 151-168.

Balandier G. (1954) « Sociologie de la colonisation et relations entre sociétés globales », Cahiers internationaux de Sociologie, XVII, 17-31; ou Sociologie de la colonisation (version corrigée), in Balandier G. (1971) Sens et Puissance, les dynamiques sociales, Paris, PUF, 169-184.

Balandier G. (1955a) Sociologie actuelle de l'Afrique noire, dynamique sociale en Afrique centrale, Paris, PUF (1971).

Balandier G. (1955b) Sociologie des Brazzavilles noires, Paris, A. Colin (nouvelle édition augmentée, Presses de la Fondation nationale des sciences politiques, 1985).

Balandier G. (1956a) (sous la direction de) Le Tiers Monde : sous développement et développement, Paris, PUF.

Balandier G. (1956b) « Le Tiers Monde, sous développement et développement », in Balandier G. (sous la direction de) Le Tiers Monde : sous développement et développement, Paris, PUF ; ou Sousdéveloppement et mise en rapport de sociétés " différentes ", extrait révisé in Balandier G. (1971) Sens et Puissance, les dynamiques sociales, Paris, PUF., 185-201.

Balandier G. (1957) Afrique ambiguë, Paris, Plon, (Paris Terre humaine/Poche, Pocket 1998).

Balandier G. (1959) « Anthropologie et étude du changement », in Balandier G. (dir.) Les Implications sociales du progrès techniques, Paris, PUF ou texte révisé in Balandier G. (1971), Sens et Puissance, les dynamiques sociales, Paris, PUF, 128-147.

Balandier G. (1967a) La vie quotidienne au royaume de Kongo du XVI au XVIII siècle, Paris, Hachette (nouvelle édition, 1992).

Balandier G. (1967b) Anthropologie politique, Paris, PUF.

Balandier G. (1967c) « Années 60, le moment structuraliste du Xx $\mathrm{e}^{\mathrm{e}}$ siècle », Le Nouvel Observateur, 22 février, reproduit in Balandier G. Civilisés, dit-on, Paris, PUF, 1993, 67-73.

Balandier G. (1968a) « Préface », in Balandier G., Bastide R., Berque J., George P., Perspectives de la sociologie contemporaine. Hommage à Georges Gurvitch, Paris, PUF, VII-XII.

Balandier G. (1968b) « Tradition et continuité », Cahiers internationaux de Sociologie, XLIV, republié in Balandier G. (1971) Sens et Puissance, les dynamiques sociales, Paris, PUF, 1986, 99-110.

Balandier G. (1969) « Les sociologies en question », La Quinzaine littéraire, 72, 1-15 mai,19-20.

Balandier G. (1970) « Sociologie des mutations », in Balandier G. (sous la direction de), Sociologie des mutations, Actes du VIIème Colloque de l'Association Internationale des Sociologues de Langue Française, Paris, Anthropos, 13-37, republié in Sens et Puissance, les dynamiques sociales, Paris, PUF, 74-110.

Balandier G. (1971) Sens et Puissance, les dynamiques sociales, Paris, PUF, (1986).

Balandier G. (1972) Georges Gurvitch, sa vie, son œuvre, Paris, PUF. 
Balandier G. (1974) Anthropo-logiques, Paris, PUF (nouvelle édition augmentée, Livre de Poche, Biblio-Essais, 1985).

Balandier G. (1975) «Communautés chaudes et communautés froides », in Solitude et communication, XXVème Rencontres Internationales de Genève, Boudry-Neuchâtel (Suisse), Les Editions de La Braconnière, 11-19.

Balandier G. (1977) Histoire d'Autres, Paris, Stock.

Balandier G. (1979) « Imaginaire, religion et politique dans les cultures africaines », in Duvignaud J. (textes réunis par), Sociologie de la connaissance, Paris, Payot, 251-259.

Balandier G. (1980) Le Pouvoir sur scènes, Paris, Balland.

Balandier G. (1981) « La sociologie aujourd'hui », Cahiers internationaux de Sociologie, LXXI, 197-204.

Balandier G. (1983) « Le pluriel », Recherches sociologiques, XIII, 5-7.

Balandier G. (1985) Le Détour, pouvoir et modernité, Paris, Fayard.

Balandier G. (1986) Au-delà de l'anthropologie, in L'Etat des sciences sociales en France, Paris, La Découverte, 11-15.

Balandier G. (1987) « Les années 66-86 », Magazine Littéraire (« Idéologies : le grand chambardement »), 239-240, 25-27.

Balandier G. (1988a) Le Désordre, éloge du mouvement, Paris, Fayard.

Balandier G. (1988b) « Postface, où il est question de modernité », Les Nouveaux enjeux de l'anthropologie. Autour de Georges Balandier (1988), Revue de l'Institut de Sociologie, 3-4, 295-302.

Balandier G. (1989a) « Le lien social en question », Cahiers internationaux de Sociologie, LXXXVI, 5-13.

Balandier G. (1989b) « Anthropologie de la modernité », Conférence, Université Paul Valéry Montpellier III, 20 mars.

Balandier G. (1990) « Le regain sociologique », Le Monde, 29 septembre.

Balandier G. (1991a) « Regard anthropologique sur la modernité et la post-modernité », in Martin J.-B. (textes réunis par), Laplantine F. (textes présentés par), Corps, religion, société, C.R.E.A. (Centre de Recherches et d'Etudes Anthropologiques), Lyon, PUL, 115-123.

Balandier G. (1991b) « Le corps sous les effets de la modernité », in Actes du colloque «Performance et santé », Nice, Co-Edition AFRAPS-LANTAPS, 7-11.

Balandier G. (1992) « Pour une anthropologie dynamiste, rencontre avec Georges Balandier », Sciences Humaines, 20, 22-25.

Balandier G. (1994) Le Dédale, pour en finir avec le $\mathrm{XX}^{e}$ siècle, Paris, Fayard.

Balandier G. (1997a) Conjugaisons, Paris, Fayard.

Balandier G. (1997b) « Comment peut-on être socio-anthropologue ? Libre propos », in Comment peut-on être socio-anthropologue? (« Autour de Georges Balandier »), Utinam, Paris, Ed.

L'Harmattan, 21-40.

Balandier G. (1997c) « Les espaces de la surmodernité, » Sciences Humaines, 73, 28-29.

Balandier G. (2001) Le Grand Système, Paris, Fayard.

Balandier G. (2003a) Civilisés, dit-on, Paris, PUF. 
Balandier G. (2003b) Entretien, Télérama, 2791, 12 juillet.

Balandier G., Bastide R., Berque J., George P. (1968) Perspectives de la sociologie contemporaine. Hommage à Georges Gurvich, Paris, PUF.

Bastide R. (1968) «La connaissance de l'événement », in Balandier G., Bastide R., Berque J., George P., Perspectives de la sociologie contemporaine. Hommage à Georges Gurvich, Paris, PUF, 159-168.

Berthelot J.-M. (2000) La Sociologie française contemporaine, Paris, PUF.

Boudon R. (1984) La Place du désordre, critique des thèses du changement social, Paris, PUF.

Bourdieu P. (1972) Esquisse d'une théorie de la pratique, Genève, Droz.

Cahiers internationaux de Sociologie (2001) « Georges Balandier. Lecture relecture », vol CX

Conche M. (1974) Orientation philosophique, Villers-sur-mer, Ed. du Megare.

Copans J. (1896) « Les mystères des Brazzavilles noires », in Afrique plurielle, Afrique actuelle. Hommage à Georges Balandier (1986), Paris, Katharla, 255-263.

Copans J. (2001), La « situation coloniale » de Georges Balandier : notion conjoncturelle ou modèle sociologique et historique?, Cahiers internationaux de Sociologie (« Georges Balandier. Lecture relecture $»)$, vol CX, 31-52.

Edelman B. (1999) La Personne en danger, Paris, PUF.

Farrugia F. (1997) «Phénomène social total » contre « structure sociale ». Balandier-Gurvitch: une dynamique commune, in Comment peut-on être socio-anthropologue? (« Autour de Georges Balandier »), Utinam, Paris, Ed. L'Harmattan, 43-71.

Gosselin G. (1993) (sous la direction de) Les Nouveaux enjeux de l'anthropologie. Autour de Georges Balandier (Reprise des articles de la Revue de l'Institut de Sociologie, 3-4, 1988).

Gurvich G. (1962) Dialectique et sociologie, Paris, Flammarion.

Janne H. (1988) Ethnologie et sociologie de Georges Balandier, in Les Nouveaux enjeux de l'anthropologie. Autour de Georges Balandier, Revue de l'Institut de Sociologie, 3-4, 39-47.

Kantorowicz E. (1957) Les Deux corps du roi, essai sur la théologie politique du Moyen Âge, Trad. française, Paris, Gallimard (1989).

Le Pogam Y. (1994a) « Sociologie générative et nouvel esprit du temps », in Guth S. (sous la direction de), Une sociologie des identités est-elle possible ?, Paris, L'Harmattan, 227-238.

Le Pogam Y. (1994b) «L'Education Physique et le chaos. Entropie et ordre institutionnel », in Baillette F., Brohm J.-M. (sous la direction de), Traité critique d'Education Physique et Sportive, Editions Quel Corps ? 53-67.

Le Pogam Y. (1999) «Rites du sport et générativité du social », Corps et Culture, « Corps, sports et rites », 4, 147-175.

Les Défis de la complexité: vers un nouveau paradigme? Autour d'Edgar Morin, Georges Balandier (1994), Paris, L'Harmattan.

Maffesoli M., Rivière C. (1985) Une anthropologie des turbulences. Hommage à Georges Balandier, Berg International Editeurs.

Morin E. (1982) Science avec conscience, Paris, Fayard.

Morin E. (1985) « Sociologie de la sociologie », Cahiers internationaux de Sociologie, vol LXXVIII, 39-58. 
Morin E. (1986) «Sur la définition de la complexité », in Science et pratique de la complexité, Actes du Colloque de Montpellier (1984), 79-85.

Morin E. (1991) Introduction à la pensée complexe, Paris, E.S.F.

Péquignot B. (1997) «Un jeu croisé de regards », in Comment peut-on être socio-anthropologue? (« Autour de Georges Balandier »), Utinam, Paris, Ed. L'Harmattan, 13-20.

Poirier J. (1985) « Sociétés africaines et hétéroculture », in Maffesoli M., Rivière C. (sous la direction de) Une anthropologie des turbulences. Hommage à Georges Balandier, Berg International Editeurs, 75-87.

Poirier J. (1988) « Tradition et novation, de la "situation coloniale" à la situation hétéroculturelle ", in Les Nouveaux enjeux de l'anthropologie. Autour de Georges Balandier, Revue de l'Institut de Sociologie, 3-4, 69-80.

Revue de l'Institut de Sociologie (1988) Les Nouveaux enjeux de l'anthropologie. Autour de Georges Balandier, 3-4.

Recherches sociologiques (2002) («L'anthropologue à l'épreuve du temps »), Actes de la journée d'hommage à Georges Balandier 13/10/2000, 2.

Rey P.-P (1986), «L'anthropologie dynamique et critique de 1960 à aujourd'hui », in Afrique plurielle, Afrique actuelle. Hommage à Georges Balandier, Paris, Katharla, 103-114.

Rivière C. (1978) L'Analyse dynamique en sociologie, Paris, PUF.

Rivière C. (1985) « Cap sur les turbulences » in Maffesoli M., Rivière C. (sous la direction de) Une anthropologie des turbulences. Hommage à Georges Balandier, Berg International Editeurs, 9-25.

Rivière C. (2000) « La socio-anthropologie de la modernité » in Berthelot J.-M. (sous la direction de ) La Sociologie française contemporaine, Paris, PUF (2003), 89-97.

Saada E. (2001) « La « situation coloniale » vue d'ailleurs : regards croisés transatlantiques », in Cahiers internationaux de Sociologie « Georges Balandier. Lecture relecture », vol CX, 5-7.

Stengers I. (1987) « La propagation des concepts », in Stengers I. (sous la direction de) D'une science à l'autre, des concepts nomades, Paris, Ed. du Seuil.

Utinam (1997) Comment peut-on être socio-anthropologue? (« Autour de Georges Balandier »), Paris, Ed. L'Harmattan

\section{NOTES}

1. Dans la préface de Sens et puissance (1971) qui fait référence nommément à cette approche, Georges Balandier mentionne que les remarques de son texte sont une actualisation d'un article intitulé « Les sociologies en question » déjà publié en 1969 dans La Quinzaine littéraire (72, 1-15 mai). Dans ce dernier texte, la sociologie est vue comme " fille de l'événement ", les sociétés comme « des agencements approximatifs et instables » qui imposent aux sociologues des obstacles redoutables et des problèmes à une science sociologique débattant avec les dynamismes sociaux et historiques qui bouleversent les configurations sociales. Même si Georges Balandier avance que des questions s'imposent au sociologue - celles des mutations sociales, de la confrontation généralisée de sociétés et de cultures différentes ou encore celles des contraintes résultant du développement technique et économique - le terme «science sociale générative » n'apparaitt pas dans ce développement. De ce fait, il semble émerger en 
1971, bien que le terme " générateur " apparaisse dès 1967 dans Anthropologie politique. Il semble bien que les guillemets utilisés en 1971 pour encadrer l'usage de la notion dans les sciences sociales, dont il se libérera ensuite dans ce même texte et après dans Anthropo-logiques en 1974, témoignent de ses proximités avec d'autres champs comme celui de la linguistique ou des « sciences dures ». Dans le domaine de la linguistique, Noam Chomsky, dès 1955, construit une grammaire générative qui est définie académiquement comme une théorie linguistique selon laquelle la syntaxe est conçue comme un système de règles grammaticales et de principes permettant de générer, en interaction avec d'autres parties de la grammaire toutes les phrases acceptées par la langue. Ce mot-clé " générative » figure dans une centaine de thèses ayant pour objet la langue et la grammaire, mais renvoie aussi au traitement d'images, à une « sémiologie générative » du film ou à une " phonologie générative ». Dans une autre orientation, Edgar Morin associe cette notion aux transformations de la physique au début du XXè siècle quand elle perd son caractère déterministe et gagne en complexité par l'autoorganisation grâce à la thermodynamique, et qu'elle introduit alors des principes d'imprécision et d'incertitude, d'ambiguïté et de contradiction. Edgar Morin mentionne en outre comment la logique probabiliste de Von Neuman « est non dégénérative, voire potentiellement générative (de par ses potentialités combinatoires) (...). Il nous faut une nouvelle logique générative qui non seulement intègre tous ces traits, mais qui les dépasse en faisant leur part à l'aléa, au désordre, au bruit » (Morin E., 1982 : 277-290). Mais selon Edgar Morin, c'est à Gottard Gunther que l'on doit un principe de générativité au sens mutationnel et créationnel, à partir du " order from noise ». Cette double origine du terme, comme il sera montré ici, peut donner deux orientations théoriques contrastées à l'anthropologie : l'une structurale, issue du primat de la linguistique, l'autre dynamique, privilégiant l'aspect novateur, créatif, l'engendrement du nouveau, une orientation qui prend sens dans l'anthropo-sociologie de Georges Balandier qui n'exclut pas l'aspect linguistique transposé à l'analyse anthropologique pour penser les structures sociales, si celui-ci est considéré dans son aspect cinétique et tensionnel.

Dans cette dernière acception dynamique, il existe aussi une sociologie urbaine générative attachée au département Economie et Sciences Sociales du Centre Scientifique et Technique du Bâtiment (CSTB) dont l'activité de recherche et d'intervention se polarise sur la requalification des questions urbaines, notamment, la programmation des opérations de restructuration des questions urbaines et paysagères, l'analyse des modes d'habiter et les dynamiques différentielles (www.cstb.fr). Des thèses en sociologie politique sont également orientées dans cette voie dynamique comme en témoigne celle de Pierre-Gerlier Forest à l'Université de Laval au Québec : «Pour une approche générative des partis politiques » soutenue en 1984. Cette orientation est également développée en géopolitique dans l'ouvrage de Jean-Paul Charnay, Stratégie générative, de l'anthropologie à la géopolitique où l'auteur montre comment « la stratégie reflète ou plus exactement incarne la nécessité de l'action qu'engendre l'insatisfaction, l'anxiété, l'angoisse humaines. Si celles-ci sont trop fortes, elles débouchent sur l'atarexie ; le plus souvent elles éveillent le désir de stratégie (...), cette démarche stratégique engendre l'invention et la saisie des techniques et des tactiques qui insèrent dans l'histoire ces stratégies, lesquelles investissent toute la société et tout l'espace et formalisent en idéologies justificatrices des volontés de puissance ou d'apaisement, et des devenirs des entités stratégiques (individus, groupes organisés, classes, nations, sociétés...) en présence » (Paris, PUF, 
1992 : 6-7). Cette stratégie générative est bien liée à l'action et aux systèmes de légitimation de cette action.

Ces approches diversifiées dans les objets ont en commun de lier l'approche générative à celle de dynamique et se distinguent en cela de l'épistémologie d'Eric Gans qui utilise en 1985 la notion d'anthropologie générative dans The end of the culture. Toward a generative anthropology, Berkeley, University of California Press, amplifiée en 1993 dans Originary thinking. Elements of generative anthropology, Stanford, Californie, Stanford University Press. Eric Gans dirige la revue Anthropoetics. A journal of generative anthropology. Son approche théorique, ultérieure à celle de Georges Balandier, repose essentiellement sur sa rencontre avec René Girard en 1978 et sur la lecture de son œuvre dont il retient les hypothèses sur le désir mimétique, la crise sacrificielle, la victime émissaire et veut appliquer l'hypothèse de la pensée originaire à toutes les sciences humaines et sociales, art, sacré, économie, politique, etc. (cf. www.anthropoethics.ucla.edu).

Dans toutes ces publications, la dénomination " générative » ou " generative » en langue anglaise, est libérée de l'enfermement des guillemets.

2. Cette facilité n'est en fait qu'apparente. Georges Balandier a en effet publié plusieurs ouvrages en partie autobiographiques qui font le point sur son parcours intellectuel et scientifique (Afrique ambiguë en 1957 ; Histoire d'Autres en 1977 ; Conjugaisons en 2000 ; Civilisés, dit-on en 2003) dans lesquels il revient sur ses premiers travaux scientifiques et la période africaine, mais avec une conceptualisation qui s'est armée d'idées et de lectures ultérieures à cette période. Certains de ses ouvrages, comme Sens et Puissance (1971), contiennent des articles écrits en 1952. Restituer alors la genèse de ses idées suppose que cette dimension temporelle soit prise en considération en tentant de ne pas attribuer à un moment, des éléments théoriques formulés ultérieurement dans le champ scientifique.

3. Francis Farrugia montre bien comment le conflit émerge dès 1950, au moment où Georges Gurvitch demande à Claude Levi-Strauss de préfacer l'ouvrage de Marcel Mauss Sociologie et anthropologie et qu'il écrit en post scriptum, que Levi-Strauss donne de l'œuvre de Mauss « une interprétation très personnelle ». Chacun va vouloir alors s'approprier la pensée de Mauss, le premier parce que la notion de phénomène social total participe d'une vue dynamogène du social, le second parce qu'il voit des éléments de construction de la structure. A partir de là vont s'enchaîner colloques et productions permettant à chacun d'affirmer ses positions ( $c f$. Georges Gurvitch, Le concept de structure sociale dans Les Cahiers internationaux de Sociologie en 1955 ; suivi d'une réponse de Claude Lévi-Strauss dans Anthropologie structurale écrit en 1956 et publié en 1958 d'après Farrugia F., 1997).

Ce débat se poursuit en s'amplifiant dans les années 60 par la production en $1966 \mathrm{du}$ numéro 243 des Temps modernes, «Problèmes du structuralisme » dont Georges Balandier fera le commentaire en 1967 (publié dans Civilisés, dit-on, 2003 : 67-73), de même construira-t-il Anthropologie politique en 1967 en relativisant l'idée de structure et en privilégiant une perspective dynamique. Si ces critiques anthropologiques contre le structuralisme mécaniste de Claude Levi-Strauss continuent d'animer une réflexion sur les paradigmes en sciences sociales dans les années 70 ( $c f$. Jean Duvignaud, 1979), elles servent aussi de construction à une théorie de la pratique pour Pierre Bourdieu. Il montre ainsi les limites du formalisme linguistique de Saussure à propos de la langue et de la parole : « La linguistique saussurienne privilégie la structure des signes, c'est-àdire des rapports entretenus entre eux, au détriment de leurs fonctions pratiques qui 
ne se réduisent jamais à des fonctions de communication ou de connaissance (...) [celles-ci] étant toujours orientées aussi, de façon plus ou moins ouverte, vers des fonctions économiques et politiques ", principes qui, dans le structuralisme ethnologique de Claude Lévi-Strauss tel qu'il paraît dans Anthropologie structurale (les systèmes de parenté comme les systèmes phonologiques sont élaborés par l'esprit à l'étage de la pensée inconsciente), évacuent les normes culturelles (Bourdieu P., 1972 : 168-172). Ici aussi, comme pour Georges Balandier, c'est bien une critique de la méthode qui est avancée. L'anthropologie structurale ne peut prétendre révéler qu'une vérité autorisée par ses schèmes théoriques, excluant de la sorte toute autre possibilité d'accès à cette vérité ( Bourdieu P., ibid., : 172-173).

4. Cela est lié à la notion d'hétéroculture développée ensuite par Jean Poirier et qu'il définit comme " la situation dans laquelle se trouve une société qui s'alimente à deux matrices culturelles considérées comme essentielles (et même probablement vitales) et antagonistes : la tradition et la modernité - autrement dit la continuité et la novation » (Poirier J., $1988:$ 75).

5. L'attention se portera ici sur la première partie, " "Sociétés" dans la société », et sur le chapitre VI « Anthropologie et critique de la modernité » de la seconde partie intitulée, «Continuité et ruptures dans la société ». Les autres chapitres de cette partie approfondissent la dynamique en œuvre dans les sociétés de tradition contre la vision a-historique et structuraliste.

6. Je remercie vivement Sylvain Ferez pour sa générosité bibliographique qui a été d'une aide précieuse à la rédaction de cette note ainsi que Gilles Bui-Xuân et Philippe Liotard pour la qualité de leur relecture et la pertinence de leurs remarques.

\section{RÉSUMÉS}

L'œuvre de Georges Balandier dans les sciences sociales est considérable, non seulement par le nombre de publications, mais plus encore par les avancées originales qu'elle produit dans les connaissances anthropo-sociologiques du social et de la culture au moyen d'une approche générative. C'est la genèse de cette épistémologie générative qui est ici construite en fragmentant sa vie intellectuelle en périodes. Ceci permet de comprendre comment la production d'une approche singulière, naît du croisement de données personnelles, de découvertes de terrain et de débats intellectuels qui traversent une vie. Puis il est possible de lire son travail à travers les notions de " corps » et de " métissages ", transversales à sa pensée, dans la mesure où elles rendent compte de la dynamique du social et de la culture, née de la tension entre tradition/modernité, ordre/désordre, dominants/dominés, nature/culture.

The work of George Balandier in social sciences is considerable, not only by the number of his publications, but more by the original progresses in the anthropo-sociological knowledge of social and culture, thanks to a generative approach. The genesis of this generative epistemology is presented here by splitting up his intellectual life in periods. This process makes possible to understand how the production of this singular approach comes from his all life crossing of personal data, work discoveries and intellectual debates. It is then possible to reread his work through the key concepts of «body» and «interbreedings» that evoke the dynamics of social 
and culture, born from the tensions between tradition and modernity, order and disorder, dominant and dominated, nature and culture.

INDEX

Mots-clés : corps, modernité, anthropologie, métissages culturels

Keywords : body, modernity, tradition, anthropology, cultural half-interbreedings

\section{AUTEUR}

YVES LE POGAM

Equipe « Corps et Culture », Faculté des Sciences du Sport, Université Montpellier 1 